Glycosylation patterns of human immunoglobulin $\mathbf{G}$ - recombinant IgG, vaccineinduced IgG and allo-immune specific IgG

Anne Cathrine Vestrheim

University of Oslo

2013

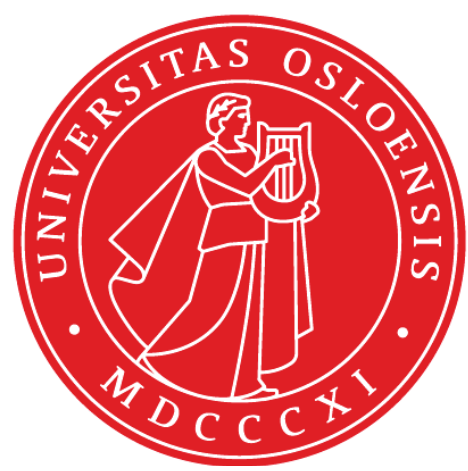


(C) Anne Cathrine Vestrheim, 2013

Series of dissertations submitted to the

Faculty of Mathematics and Natural Sciences, University of Oslo No. 1357

ISSN 1501-7710

All rights reserved. No part of this publication may be

reproduced or transmitted, in any form or by any means, without permission.

Cover: Inger Sandved Anfinsen.

Printed in Norway: AIT Oslo AS.

Produced in co-operation with Akademika Publishing.

The thesis is produced by Akademika publishing merely in connection with the thesis defence. Kindly direct all inquiries regarding the thesis to the copyright holder or the unit which grants the doctorate. 
'Letting your mind play is the best way to solve problems'

Bill Watterson, Calvin and Hobbes 


\section{ACKNOWLEDGEMENTS}

The present work was carried out at the School of Pharmacy, University of Oslo and the Norwegian Institute of Public Health from 2008 to 2013. The work has been funded by Glyconor, School of Pharmacy at University of Oslo and the Norwegian Institute of Public Health, for which I am very grateful.

My supervisor has been Professor Terje E. Michaelsen, who I want to thank immensely. I was given the opportunity to be his final $\mathrm{PhD}$ student before his retirement after many years in research. He has introduced me to the exiting, although somewhat daunting, world of immunology. He has been a continuous pillar of support and guidance through these years with his genuine interest and knowledge in the field. I would not have reached the finishing line without him, and I am deeply indebted for all his help.

I would like to thank my co-supervisors Wolfgang Egge-Jacobsen and Berit Smestad Paulsen. Wolfgang has introduced me to the exiting world of mass spectrometry and with his vast experience and knowledge in the field has taught me some of the wonders achievable with these techniques. Berit is, like anyone in the pharmacy world would know, a never ending source of support, ideas and solutions to whatever obstacle arises. Your support and vast knowledge has been much appreciated.

A huge thank you to Anders Moen in the mass spectrometry lab, for never tiring (at least not showing signs of it) of answering questions, explaining things for the umpteenth time and generally being enthusiastic about whatever idea I could come up with.

Diane Bryant Bratlie has been my roomie in various offices in various buildings over the time course of my PhD, and has been a superb roomie! Thank you for being so supportive, turning up at work at $6 \mathrm{AM}$ to help with experiments and generally making life in the lab fun. She has been a huge support and I have learnt so much from working with her. Her love for computers should never be underestimated and my vocabulary in terms of computer-related-affectionwords has been vastly expanded. On her trips to the US she has brought home fine American delicatessen, such as Ding Dongs and Ho Ho's, which has worked a treat whenever a (rather artificial) sugar rush has been required through the course of the work days. 
Gro, Merete and Beathe - thank you! Great friends, great colleagues and generally just great fun! I couldn't have done it without you.

To the rest of the IM-L8 gang - the lab would never have been the same without you! I've learned so much from you all, and what fun we have had in the lab - where would we have been without the monkey dance and the grim reaper?

To everybody that donated their blood - thank you! And to all those who collected the blood - thank you as well! (one of the donators also decided to become a member of the collectors, but she just had to, hadn't she? A challenge? Bring it on!)

To all the people at School of pharmacy and especially Ingvild and Kari, it has been a ball! Ingvild - it has been great teaching with you, and I'm confident we have taught those students many things, but we mustn't forget that we've learned something as well, for instance the correct translation of a rather small mammal. Kari - my second roomie and my great hiking pall - thanks for inspiration, help and friendship!

To everyone else at the Norwegian Institute of Public Health - thank you for making my work days both fun and interesting, and supporting me all the way to the end.

A great thank you to all the people in Holland, both at Sanquin and in Leiden, I really enjoyed my time working in the lab with you!

To all my family I own a huge thank you for encouragement, motivation and just being there. I'm not quite sure if you quite know what I have been doing all these years, but I do hope to have educated you enough to know that the carbohydrates I work with are unrelated to both pasta and bread.

To all my friends - none mentioned but none forgotten - thank you for listening to rants, frustrations and what must have sounded like gibberish to you, but fortunately also joy and excitement when things have worked out. Also here I'm not sure if half of you know what I've actually been doing, but I do hope words such as vaccines, antibodies and the immune system now make slightly more sense than it did before I started this.

Anne Cathrine Vestrheim

May 2013 


\section{LIST OF ABBREVIATIONS}

ADCC

ADCML

ALA

ARG

ASN

ASP

AUC

BSA

CFU

CID

ELISA

ER

ESI

Fab

$F A B$

$\mathrm{Fc}$

FcR

FcpR

FNAIT

FUT8

Gal

GlcNAc

HCD

HEK cells

HexNAc

HIS

HLA

Ig

ITAM

ITIM

ITP

IVIG

LC

Leu antibody-dependent cell-mediated cytotoxicity

antibody dependent complement-mediated cytotoxicity

Alanine

Arginine

Asparagine

aspartic acid

area under the curve

bovine serum albumin

Colony forming units

collision induced dissociation

enzyme -linked immunosorbent assay

endoplasmic reticulum

electrospray ionization

antigen-binding fragment

fast atom bormbardment

crystallizable fragment

Fc receptor

Fc receptor for IgG

Fetal and neonatal alloimmune thrombocytopenia

$\alpha-1,6$-fucosyltransferase

Galactose

Acetylglucosamine

higher energy C-cell dissociation

human embryonic kidney cells

Acetylhexosamine

Histidine

human leukocyte antigen

Immunoglobulin

Immunoreceptor tyrosine activation motif

Immunoreceptor tyrosine inhibitory motif

idiopathic thrombocytopenic purpura

intravenous immunoglobulin

liquid chromatography

Leucine 
LLO

MAIPA

MALDI

Man

MHC

MS

NIP

NK

OMV

OPA

PRO

RB

RIP

SBA

SGE

TGE

WT lipid linked oligosaccharide

Monoclonal Antibody-specific Immobilization of Platelet Antigens

Matrix-assisted laser desorption/ionization

Mannose

major histocompatibility complex

mass spectrometry

5-iodo-4-hydroxy-3-nitro-phenacetyl

natural killer

outer membrane vesicle

opsonophagocytosis

Proline

respiratory burst

radioimmunoprecipitation

serum bacterical activity

stable gene expression

transient gene expression

wild type 


\section{LIST OF PAPERS}

I

Different glycosylation pattern of human IgG1 and IgG3 antibodies isolated from transiently as well as permanently transfected cell lines

Anne Cathrine Vestrheim, Anders Moen, Wolfgang Egge-Jacobsen, Diane Bryant Bratlie, Terje Einar Michaelsen

(submitted)

Differences in glycosylation pattern of IgG subclasses induced by pneumococcal, meningococcal and two types of influenza vaccines Anne Cathrine Vestrheim, Anders Moen, Wolfgang Egge-Jacobsen, Leon Reubsaet, Trine Grønhaug Halvorsen, Diane Bryant Bratlie, Berit Smestad Paulsen, Terje Einar Michaelsen (submitted)

A prominent lack of IgG1 Fc-fucosylation of platelet-alloantibodies in pregnancy

Rick Kapur, Anne Vestrheim, Carolien AM Koeleman, Leendert Porcelijn, Dave Jackson, Belinda Kumpel, André M Deelder, Dennis Blank, Björn Skogen, Mette Kjaer Killie, Terje E. Michaelsen, Masja de Haas, C. Ellen van der Schoot, Manfred Wuhrer and Gestur Vidarsson

(submitted) 


\section{TABLE OF CONTENTS}

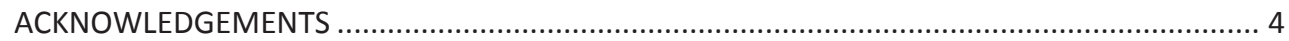

LIST OF PAPERS

TABLE OF CONTENTS

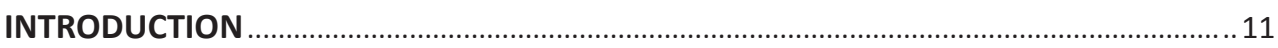

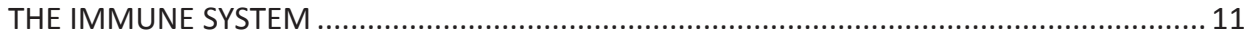

HUMORAL IMMUNITY ……………………………… 12

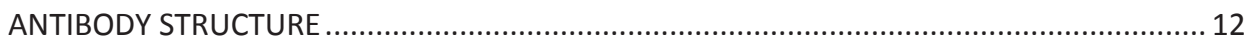

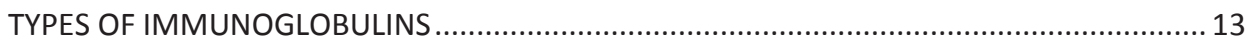

$\lg$.

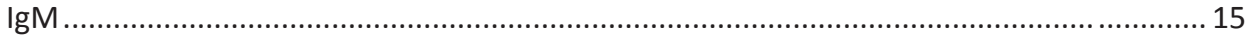

IgD

IgA

IgE

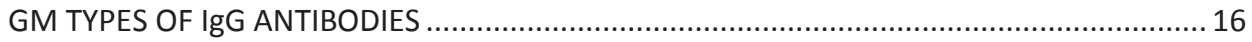

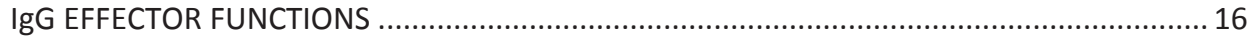

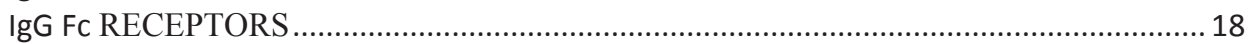

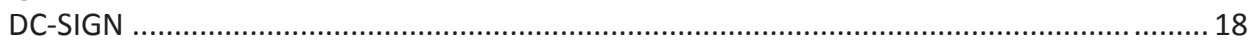

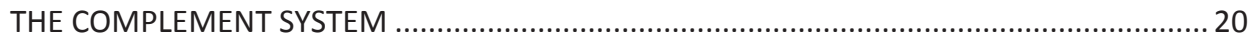

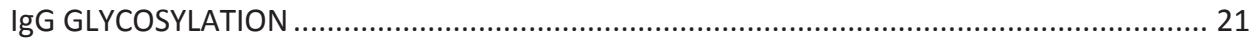

GALACTOSE .

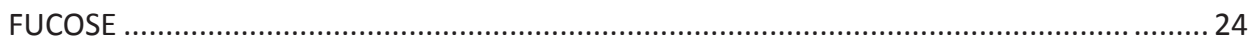

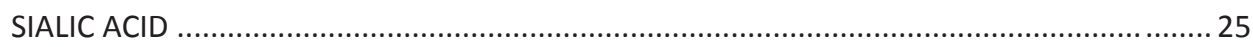

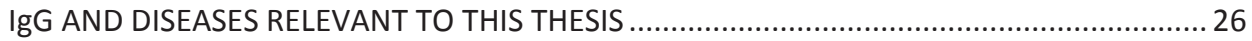

FETAL AND NEONATAL ALLOIMMUNE THROMBOCYTOPENIA ……………………….......26

INFECTION PREVENTED BY VACCINES USED IN THIS THESIS ............................................. 28

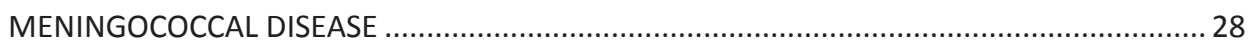

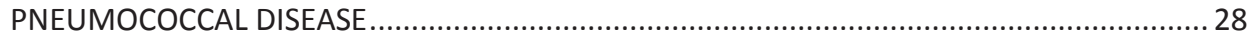

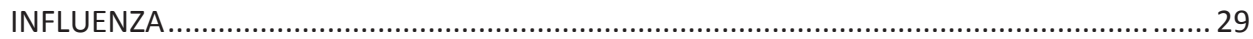

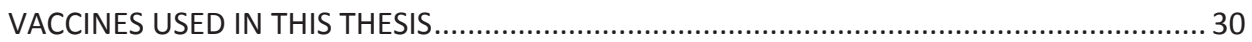

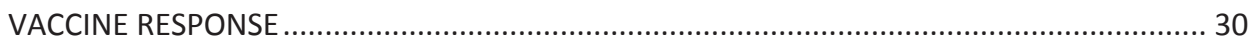

IgG MUTANTS RELEVANT TO EFFECTOR FUNCTIONS.................................................. 31

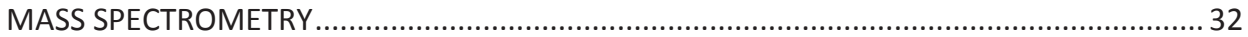

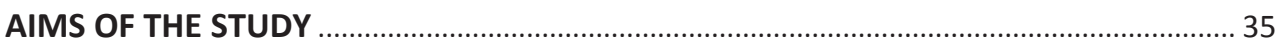

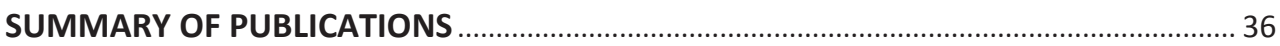

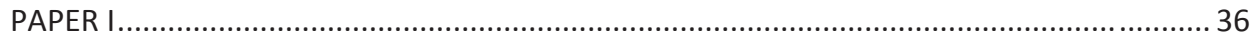

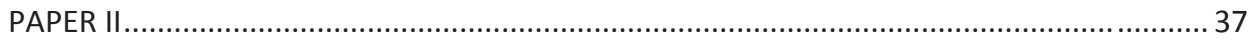

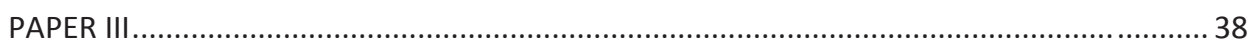

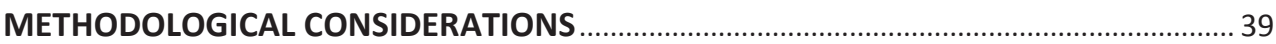

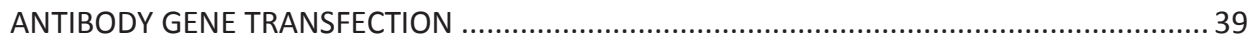

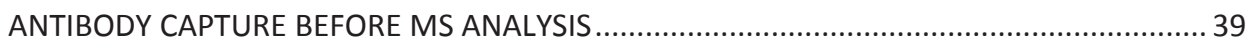

IN WELL TRYPSIN DIGESTION BEFORE MS ANALYSIS ........................................................ 40

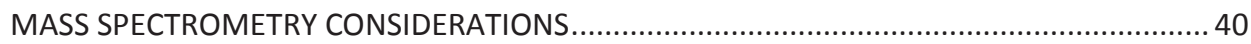

MEASUREMENT OF EFFECTOR FUNCTIONS ………............................................... 42

HUMAN SERUM COLLECTED FOLLOWING IMMUNIZATION ……………........................ 42

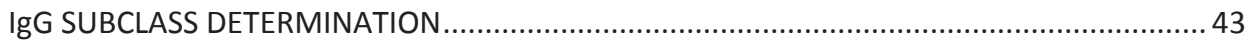


PROTEIN A AND PROTEIN G COLUMNS WERE USED TO ISOLATE TOTAL BACKGROUND IgG

PATIENT SAMPLING FOR FETAL AND NEONATAL ALLOIMMUNE THROMBOCYTOPENIA

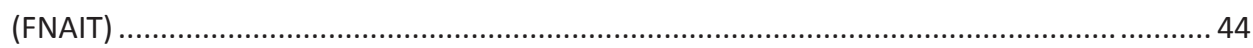

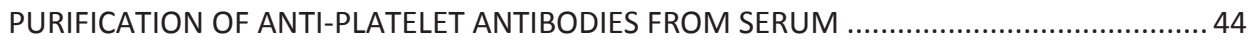

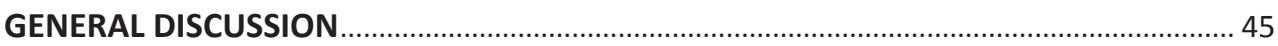

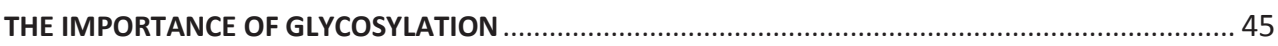

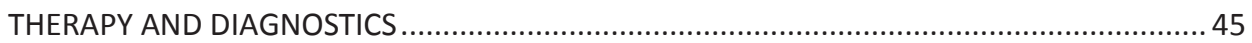

ARE THERE COMPREHENSIVE DIFFERENCES IN ANTIBODY GLYCOSYLATION BETWEEN DISEASES,

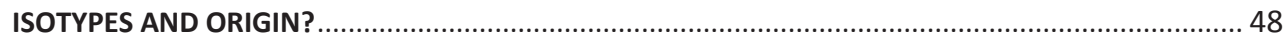

DIFFERENCES IN GLYCOSYLATION BETWEEN IMMUNOGLOBULIN ISOTYPES.................... 48

DIFFERENCES IN GLYCOSYLATION OF RECOMBINANT IgG1 AND IgG3 COMPARED TO

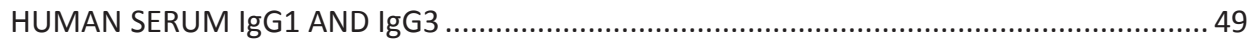

GLYCOSYLATION INDUCED AFTER IMMUNIZATION - HUMANS VS. MICE …...................... 51

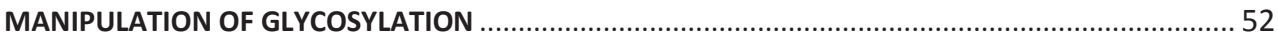

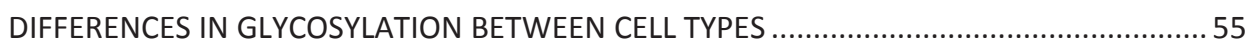

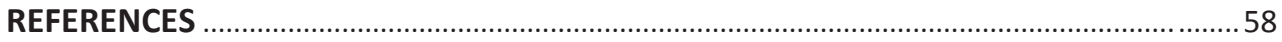




\section{INTRODUCTION}

\section{THE IMMUNE SYSTEM}

The human immune system is an intricate system that serves to protect the body from invading organisms, prevent them from replicating or spreading and to remove them. There are physical barriers in place that is the first line of defence that physically prevent the organisms from entering, and these are the skin and the mucous membranes. If these barriers are breached, for instance through cuts or wounds in the skin or particles are inhaled and enter through mucosal surfaces in the nose or the mouth, the body has other methods to deal with this - the two-parted immune system, the innate and the adaptive immune system.

The innate immune system is the first to respond as it will locate and recognize foreign particles and effector mechanisms will continue the procedure by killing and eliminating them. The effector mechanisms constitute effector cells that kill infected cells and engulf bacteria with the added support by a whole colony of serum proteins, named complement. These actions are the body's natural response, and they attack foreign particles without specificity. This means when the particle has been labelled as foreign and dangerous, it is attacked.

The next level of protection is from the adaptive immune system. As the name implies, this system is adaptive, taking in to consideration what it has encountered on previous occasions and using this knowledge to create memory. A very important group of cells from the adaptive immune system are lymphocytes, B lymphocytes and $\mathrm{T}$ lymphocytes. Blymphocytes express immunoglobulins on their surface and they can recognize and bind to foreign antigens. After binding to its antigens, several differentiation and maturation steps follow, usually involving $\mathrm{T}$ cells ( $\mathrm{T}$ helper cells). This results in the B-cells giving rise to plasma cells that will secrete these immunoglobulins; termed antibodies. The next time the body is attacked by the same pathogen, the body remembers this, and the production of that specific antibody will start more rapidly. The sole purpose of B-cells is to induce the production of antibodies, while T-cells have different roles; all involving interaction with other cells. T-cell antigen receptors, or T-cell receptors as they are often called, recognize antigens that are presented to them through the help of antigen presenting glycoproteins known as Major Histocompatibility Complex, MHC, molecules. 
If the innate immune system can not handle a foreign particle, it will try its best to fight it until the elements of the adaptive immune response starts working, and the white blood cells come in to action.

\section{HUMORAL IMMUNITY}

An immune response that is caused by antibodies and their actions is termed a humoral immune response. A B-cell that has not yet encountered an antigen it is called a mature B-cell and it produces membrane-bound immunoglobulins that act as a receptor for antigens. Development of B-cells includes several phases where different constituents of B-cell receptor are assembled. After assembly, each B-cell will express only one type of B-cell receptor, but which type will vary between cells. As an antigen binds to this receptor, the Bcell differentiates in to a plasma cell, and begins to secrete antibodies. These antibodies are of the same specificity as that of the membrane-bound immunoglobulin. Production of antibodies is the only effector function B-cells have in the immune system and antibodies with a variety of different specificities can be produced. There are five classes of antibodies produced; IgA, IgD, IgE, IgG and IgM, which each will be discussed in more detail.

\section{ANTIBODY STRUCTURE}

Immunoglobulins are comprised of 4 polypeptide chains, two identical heavy chains and two identical light chains, and these are assembled as a Y (See figure 1). The heavy chains of an IgG molecule each weigh around 50 kilodalton and exist in five isotypes, $\gamma, \mu, \alpha, \varepsilon$ and $\delta^{1}$. The light chain weighs around $25 \mathrm{kDa}$ and exists in two isoforms, $\lambda$ and $\kappa$, hence a total weight of around $150 \mathrm{kDa}$ is the norm for a whole immunoglobulin. Each arm of the Y consists of a heavy and a light chain, while the stem of the Y consists of two heavy chains, and they are all linked through disulphide bonds. In order to create diversity between antibodies, the polypeptide chains have different amino acid sequences. These differences are found at the top of each of the $\mathrm{Y}$ arms, in the variable region. The variable region is also where the antigen binding sites are found, hence where the antibody will bind to the antigen, the Fab portion. The antigen binding site on one arm of the $\mathrm{Y}$ is identical to the other arm of the Y. The rest of the polypeptide chains - the lower half of the light chains and all of the heavy chains are known as the constant regions, as a low level of variation in amino acid sequences are found here. The protease papain will cleave an immunoglobulin in to different fragments; two fragments of $\mathrm{Fab}$ and one fragment crystalline $(\mathrm{Fc})$ (see figure 1). The $\mathrm{Fv}$ portion is the 
smallest fragment that can still bind an antigen. The Fc portion will bind to different Fc receptors for $\mathrm{IgG}$, known as Fc $\gamma$ receptors, $\mathrm{Fc} \gamma \mathrm{R}^{2-8}$.

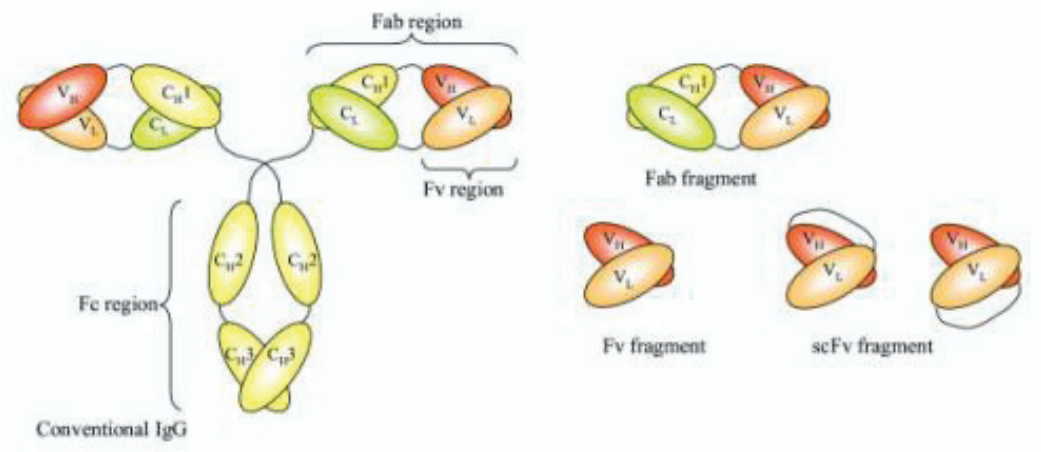

Figure 1: The protease papain will cleave an immunoglobulin in to different fragments; two fragment antigen binding (Fab) portions and one fragment crystalline (Fc). The Fab fragment can further be cleaved to Fv, the smallest fragments that can still bind to an antigen. Fv made by expression of relevant gene fragments are termed recombinant single-chain $\mathrm{Fv}, \mathrm{scFv}^{9}$.

\section{TYPES OF IMMUNOGLOBULINS}

Immunoglobulins, Ig, are divided in to 5 different isotypes, $\operatorname{IgA}, \operatorname{IgD}, \operatorname{IgE}, \operatorname{IgG}$ and $\operatorname{IgM}$, and they have different functions and are found in different areas of the body. Immunoglobins have carbohydrate moieties attached at different amino acids, found as conserved sites at both the Fc and the Fab portion. IgG only have its glycosylation site at asparagine 297 on the Fc part, whilst other types have several sights at different amino acids, located on both the Fc and the Fab portion. For three of the immunoglobulins, the Fab and Fc parts are linked by a flexible hinge region, these being $\operatorname{IgA}$, $\operatorname{IgD}$ and $\operatorname{IgG}$. $\operatorname{IgE}$ and $\operatorname{IgM}$ have a rigid $\operatorname{Ig}$ domain instead of the flexible hinge region ${ }^{1}$. Emphasis will be put on $\operatorname{IgG}$, as this is the antibody that has been studied in this thesis, but the other isotypes will be described briefly.

$\operatorname{IgG}$

IgG is the most abundant antibody in lymph and blood, where it will circulate just like IgM. It can be divided in to four subclasses, IgG1, IgG2, IgG3 and IgG4. It is a smaller molecule than $\operatorname{IgM}$, and can therefore enter extracellular spaces and reach tissues more easily than IgM. The four polypeptide chains are linked by disulphide bonds, and the hinge region connecting the 
two heavy chains have various numbers of disulphide bonds, 2 for IgG1 and IgG4, 4 for IgG2 and 11 for IgG3. This makes the hinge region of $\operatorname{IgG} 3$ exceptionally long (see figure 2$)^{10}$. When IgG binds to an antigen, it can either activate the complement system as well as triggering phagocytes to eat the antigen-antibody complex ${ }^{11}$ or it can cross the placenta and provide a foetus with immune protection while that of the foetus' is still insufficient ${ }^{12}$.

There are four subclasses of IgG, IgG1, IgG2, IgG3 and IgG4 (see figure 2). IgG1 (9 mg/ml) and $\operatorname{IgG} 2(3 \mathrm{mg} / \mathrm{ml})$ are most abundant in serum, followed by $\operatorname{IgG} 3(1 \mathrm{mg} / \mathrm{ml})$ and $\operatorname{IgG} 4(0,5$ $\mathrm{mg} / \mathrm{ml})$. IgG1 and IgG3 are the two subclasses mainly involved in Fc-receptor interactions and capability of complement activation. IgG1 is the subclass with the strongest ability to opsonise particles, followed by IgG3, while IgG3 is the main activator of the complement system, followed by IgG1. Both IgG1 and IgG3 can sensitize cells for elimination by NK cells. All four subclasses can neutralize particles to the same degree. IgG3 has a half-life of only 1 week, whilst the other subclasses have a half-life of 3 weeks ${ }^{13}$. In the mutant IgG3$\mathrm{R}_{435} \mathrm{H}$, where arginine at position 435 is exchanged with histidine, an increased half-life is seen, comparable to $\operatorname{IgG} 1^{14}$.
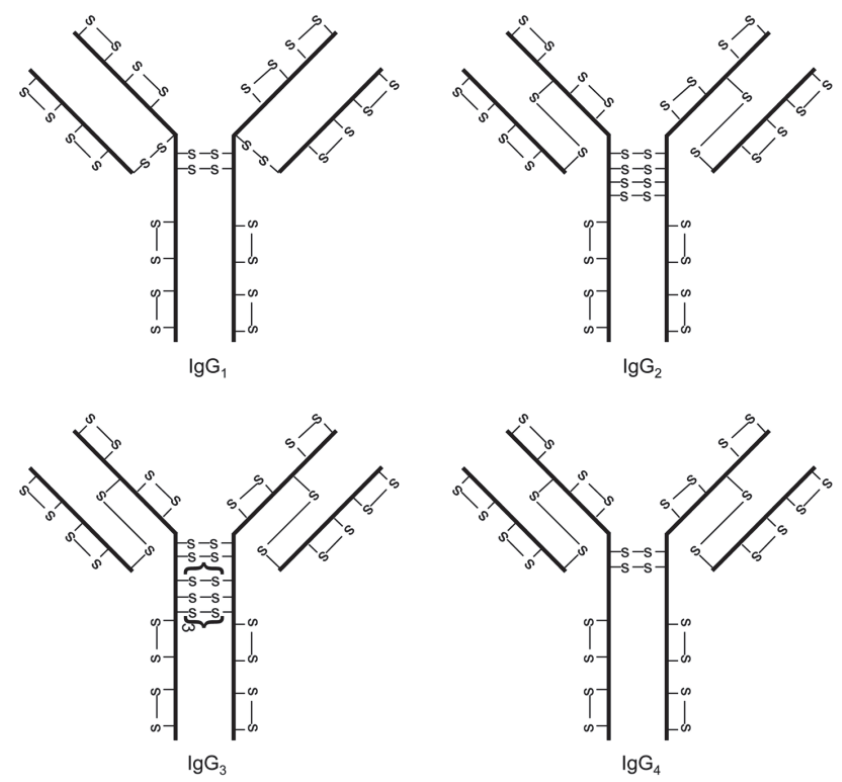

Figure 2: A schematic model of the four IgG subclasses. The molecules are composed of four polypeptide chains, two identical heavy chains and two identical light chains connected with disulphide bonds ${ }^{10}$. 
$\operatorname{IgM}$

After an antigen encounter, IgM is the first antibody that is produced during an immune response. Following secretion from B-cells, IgM antibodies are mainly found in blood and $\operatorname{lymph}^{15}$. IgM has a low affinity for all sorts of pathogens, including bacteria, virus and selfantigens, which is crucial in the onset of an early immune response ${ }^{16,17}$. The immune response of IgM is not very strong; hence multiple binding sites for the antigens are necessary for an effective response. IgM can group together as pentamers, i.e. 5 IgM molecules bound together, and can therefore bind to 10 antigenic determinants at the same time ${ }^{15}$. IgM is also a potent activator of the complement system.

\section{$\operatorname{IgD}$}

$\operatorname{IgD}$ is expressed together with IgM on the surface of B-cells before antigen stimulation, where it acts as a trans-membrane antigen receptor ${ }^{18}$. IgD can also be secreted and seems to have some effect on mucosal secretion and on the cell surface of basophils and other innate effector cells, but its exact role is not well understood ${ }^{19,20}$.

\section{$\operatorname{IgA}$}

IgA is the most abundant antibody isotype and most of it is exported across mucous membranes. While IgG dominates the systemic immune system, IgA dominates the humoral mucosal immunity ${ }^{21}$. IgA is synthesised and secreted on mucosal surfaces over the entire body, though the gastrointestinal tract is the most important site because of its area. This is a sensible location as the majority of antigens that are swallowed or inhaled will end up in the gastrointestinal tract. IgA can exist in two forms, monomeric IgA is mainly found in the bloodstream and dimeric IgA is transported across the epithelial border and found on mucosal surfaces, in the gut and in saliva, tears and other secretions ${ }^{22}$. IgA can therefore have different functional properties depending on location and molecular form ${ }^{23}$. Intestinal IgA antibodies can activate immune responses by high-affinity binding as well as low-affinity binding, giving an effective protection ${ }^{24}$. IgA seems to lack an ability to activate complement ${ }^{21}$.

$\operatorname{IgE}$

IgE and IgG are antibody isotypes found exclusively in mammals and are located mainly in tissue, unlike the other immunoglobulin isotypes ${ }^{13}$. $\operatorname{IgE}$ is the main antibody involved in type I hypersensitivity reactions, manifesting itself as allergic reactions in the lower or upper 
respiratory tract, gut, skin or eyes, or as anaphylactic shock - a life-threatening immune reaction $^{25}$. In this type of reaction, allergens crosslink to IgE molecules, which again bind to the IgE receptor FceRI. This receptor is a high affinity receptor situated on basophils and mast cells surfaces, and this interaction results in release of histamine and other local mediators, causing a strong inflammatory response $\mathrm{e}^{26}$. Mast cells are found in all connective tissues, and even though the concentration of IgE in serum is very low and the half life is short (around 2.5 days), the affinity of the receptors on mast cells is so high that a strong response is still seen $^{25}$.

\section{GM TYPES OF IgG ANTIBODIES}

Immunoglobulin allotypes are antigenic determinants that are recognized by specific antibodies. In a given isotype, the polymorphism of the chain is determined by the amino acids and the composition of these will determine the allotype ${ }^{27}$. Allotypes are named based on the heavy or light chains on which they were found. For IgG, the allotypes expressed on the constant region of the heavy chain are named Gm (genetic marker), followed by the number of the subclass, together with the allotype number or letter; for instance G1m1 or $\mathrm{G} 3 \mathrm{~m} 5^{28}$. Gm allotypes are not found in IgG4, but are found in the other three IgG1 subclasses, and vary between different races ${ }^{29,30}$.

\section{IgG EFFECTOR FUNCTIONS}

\section{ADCC}

Antibody dependent cellular cytotoxicity is a process where antibodies cover the antigen by binding to it with their Fab portion while the Fc portion binds to FcyR's, causing a lytic attack $^{31}$. ADCC is usually mediated by Natural Killer (NK) cells, but may also be mediated by neutrophils and eosinophils.

NK cells are a subgroup of white blood cells and are classified as large granular lymphocytes. They are usually considered a part of the innate immune defence due to a lack of antigenspecific cell surface receptors and their absence of sensitization requirements before expression $^{32-34}$. NK cells play a major part in ADCC and they possess several receptors, both inhibitory and activating, that all binds to MHC class I molecules, MHC class I-like molecules and molecules unrelated to $\mathrm{MHC}^{35}$. When ADCC is initiated by NK cells, the low affinity Fc $\gamma$ RIIIa receptor (CD16) on NK cells bind to the Fc portion of antibodies bound to 
the target cells. Upon this antibody-NK cell binding, NK cells release cytotoxic granules and cytokines like interferon $\gamma($ IFN- $\gamma)$. These granules contain granzymes and perforin, and they enter through the target cell wall and cause apoptosis, cell death ${ }^{36}$. The activity of NK cells can be increased up to 10 -fold by treatment with interleukin-2 (IL-2), a cytokine signalling molecule ${ }^{37}$.

\section{ADCML}

Antibody dependent complement-mediated lysis (ADCML) is a process where IgM or two or more IgG antibodies bind to the surface of target cells. This will activate complement through the binding of IgG to $\mathrm{Clq}$, the first step in the complement cascade and eventually lead to lysis of the target cell. The ability to cause ADCML can be measured using NIP specific antibodies, sheep red blood cells (SRBC) that are labeled with radioactive chromium, ${ }^{51} \mathrm{Cr}$. The SRBC's act as target cells and react with rabbit anti-SRBC Fab fragments that are conjugated with NIP. Complement serum is added and the degree of lysis is determined by the level of radioactivity emitted, measured in a gamma counter ${ }^{38}$. Changes in the Fc region of IgG affects ADCC and ADCML, as modifications in the IgG3 hinge region gave different results between the two routes ${ }^{39}$. An IgG3 molecule with a modified hinge region, reduced from 62 amino acids in the wild type to 15 amino acids caused a 10-times increase in ADCML activity ${ }^{40}$.

\section{OPSONOPHAGOCYTOSIS AND SERUM BACTERICIDAL ACTIVITY}

When IgG binds to a pathogen with the Fab portion, and the Fc portion binds to an FcR on a phagocyte, then the phagocyte engulfs the pathogen by phagocytosis. The antibody that binds to the pathogen in order to induce phagocytosis is termed opsonin; hence the whole process is termed opsonophagocytosis. Opsonophagocytic activity can be measured by using respiratory burst, RB, that takes place in the effector cell; the phagocyte, and is measured by a flowcytometer and termed $\mathrm{OPA}^{41,42}$. OPA has been used to measure effectiveness of vaccines by immunization with an outer membrane vesicle vaccine against Neisseria meningitidis ${ }^{43}$.

Serum bactericidal activity (SBA) is measured by an SBA assay where antibodies and bacteria are mixed, and a complement source is added to agar plates. After over-night growth, colony forming units (CFU) are counted and the results showed as percentage $\mathrm{CFU}$ surviving ${ }^{41,44,45}$. 


\section{IgG Fc RECEPTORS}

Fc-receptors - FcR - are found on several cell types of the immune system. When antibodies bind to antigens in one end, and to an FcR in the other, powerful effector functions are activated. Fc-receptors that bind to $\operatorname{IgG}$ are termed $\mathrm{Fc} \gamma \mathrm{R}$, and six isotypes of FcR are found in

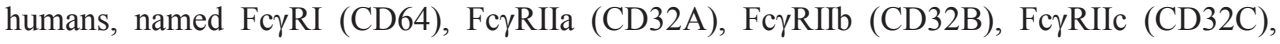
Fc $\gamma$ RIIIa (CD16A) and Fc $\gamma$ RIIIb (CD16B) ${ }^{46}$.

There are two main types of receptors, inhibitory and activating. The activating receptor contains immunoreceptor tyrosine based activation motifs (ITAM), while the inhibitory receptor contains immunoreceptor tyrosine based inhibitory motif (ITIM). These motifs are necessary to recruit proteins involved in triggering activating (ITAM) or inhibitory (ITIM) signalling proteins ${ }^{47}$. Both activating and inhibitory receptors can be found on the same cell, causing a regulation of the immune response. NK cells only express Fc $\gamma$ RIIIa- an activating receptor, while B cells only express FcyRIIb - an inhibitory receptor. As some receptors have a higher affinity for some antibody isotypes than others, this will further tighten the regulation of the immune response ${ }^{48}$. The only inhibitory Fc $\gamma \mathrm{R}$ is Fc $\gamma \mathrm{RIIb}$, the rest are activating.

Fc $\gamma R I$ is a high affinity receptor, while the rest are all of low to medium affinity. Fc $\gamma$ RI binds $\operatorname{IgG} 1$ and $\operatorname{IgG} 3$ in humans at an affinity of $10^{8}-10^{9} \mathrm{M}^{-1}$. The low affinity of most of the Fc $\gamma \mathrm{R}$ is necessary, as a high affinity would cause a high degree of non-specific activation of the immune system ${ }^{47}$. The neonatal Fc receptor, FcRn, is an Fc receptor first thought to be predominantly involved in the transportation of IgG across the placenta ${ }^{49}$. It has since become clear that this is just one of a number of functions this receptor has. In addition to mediating passive transfer of IgG from mother to offspring, FcRn also regulates IgG and albumin concentrations, MHC class II presentation and movement of IgG from one compartment to the next ${ }^{50}$. The binding of albumin and $\operatorname{IgG}$ to $\mathrm{FcRn}$ is $\mathrm{pH}$ dependent and binding occurs at acidic $\mathrm{pH}$, ideally at $\mathrm{pH} 5$, and then the proteins dissociate at $\mathrm{pH} 7.4$. IgG can therefore be transported from the gut to the bloodstream ${ }^{51}$. This relationship between FcRn and IgG and albumin can possibly be used therapeutically to change half-life of administered therapeutics or antigens or to ease transport of therapeutics through the mucosa $a^{49,52}$.

\section{DC-SIGN}

SIGN-R1 is a C-type lectin receptor found on splenic macrophages in mice that among other roles binds to sialylated IgG and mediates the anti-inflammatory effect. DC-SIGN is the human orthologue and found on human dendritic cells ${ }^{53}$. IgG that has $\alpha-2,6$ sialylation can 
bind to DC-SIGN, cause an anti-inflammatory effect and reduce the affinity to $F c \gamma \mathrm{R}^{54}$. When the sialylation was $\alpha-2,3$-sialylated, this IgG binding to DC-SIGN did not occur, making $\alpha-2,6$ sialylation essential for anti-inflammatory activity ${ }^{55}$. The interaction between sialylated Fc and DC-SIGN is thought to lead to an innate Th2 response by activation of IL-33 from the spleen, causing an anti-inflammatory response ${ }^{56}$. When the body is in a state of inflammation the level of sialylation should therefore be reduced, meaning that the body makes adjustments in order to obtain homeostasis, by up-regulating and down-regulating anti-inflammatory and pro-inflammatory antibodies. This again would indicate that IgG that cause ADCC and trigger inflammation should be without fucose and sialic acid, whilst anti-inflammatory IgG ideally should be sialic acid- and fucose-rich ${ }^{57}$. 


\section{THE COMPLEMENT SYSTEM}

The complement system is a complex, but highly important part of the innate immune response that eliminates microbes and participate in process including clearance of immune complexes, synapse maturation, tissue regeneration and lipid metabolism ${ }^{58}$. It is a cascade of events including more than 30 different serum proteins that are present in blood at all times; it can be activated in three different ways but will congregate at the same step; the cleavage of $\mathrm{C} 3$ in to fragments $\mathrm{C} 3 \mathrm{a}$ and $\mathrm{C} 3 \mathrm{~b}$, and the binding of $\mathrm{C} 3 \mathrm{~b}$ to the surface of the pathogen. The three different pathways are the classical pathway, the alternative pathway and the lectin pathway (see figure 3).

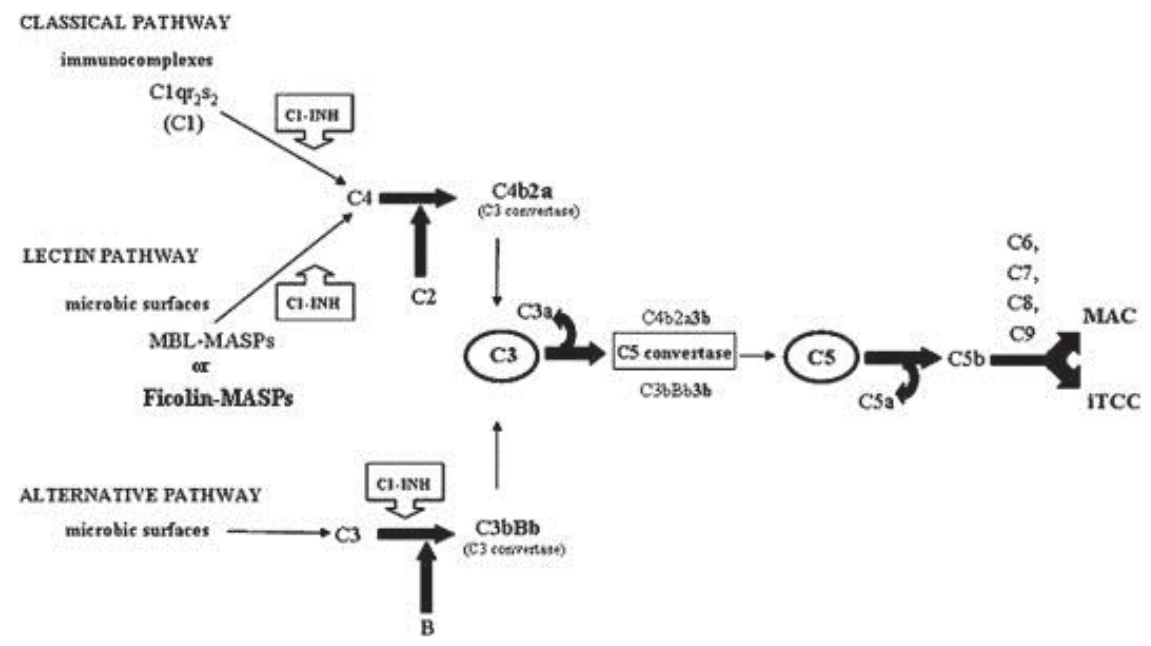

Figure 3: The complement system with the three different pathways, classical, lectin and alternative $^{59}$

The classical pathway was the first to be discovered, and is sometimes termed the antibodydependent as it is initiated by the Fc portion of $\operatorname{IgM}$ or IgG. The first step in the classical complement pathway is triggered by an immune complex, formed by the binding of IgG or $\operatorname{IgM}$ to the surface of an antigen. This further binds to the complement component $\mathrm{C} 1$, consisting of one active protein, $\mathrm{Clq}$, that binds to the immune complex, and two inactive proteins, $\mathrm{C} 1 \mathrm{r}$ and $\mathrm{C} 1 \mathrm{~s}$. The binding of the immune complex to $\mathrm{C} 1 \mathrm{q}$ sets of a chain of events, with cleavage of $\mathrm{C} 2$ and $\mathrm{C} 4$, and the generation of $\mathrm{C} 3$ convertase $\mathrm{C} 4 \mathrm{~b} 2 \mathrm{a}$ that cleaves $\mathrm{C} 3$. This sets of the rest of the cascade with proteins labelled up to C9 and in most cases eventually leads to the death of the pathogen ${ }^{59}$. The lectin pathway is triggered by mannose-binding 
lectins (MBL) and ficolins that are situated on the surface of microorganisms, and activate MBL-associated serine proteases that cleave $\mathrm{C} 4$ and $\mathrm{C} 2$, leading to formation of $\mathrm{C} 3$ convertase $\mathrm{C} 4 \mathrm{~b} 2 \mathrm{a}$ and follows the same path as the classical pathway from there ${ }^{60}$. The alternative pathway is activated by hydrolysis of $\mathrm{C} 3$ in plasma, and the hydrolysed product will bind to factor $\mathrm{D}$, creating the $\mathrm{C} 3$ convertase, $\mathrm{C} 3 \mathrm{bBb}$, and from this point on joining the same path the rest of the cascade as the two other pathways ${ }^{61}$.

\section{IgG GLYCOSYLATION}

Glycan is a term for complex carbohydrates and can be attached to for instance proteins or lipids. In humans these are found in two versions, N-glycosylated or O-glycosylated. In Nglycosylation, the glycans are attached to a nitrogen molecule situated on the amino acid asparagine, originating from a lipid-linked oligosaccharide precursor; LLO, synthesised in the endoplasmic reticulum, $\mathrm{ER}^{62}$. Then follows a number of assembling and processing steps, mainly taking place in the Golgi apparatus ${ }^{63}$. O-glycosylation is attached to one of two amino acids, threonine or serine and shows a greater diversity than $\mathrm{N}$-glycosylation, but is only assembled, not processed ${ }^{63}$. Human IgG contain a single $\mathrm{N}$-glycosylation site at asparagine 297 on their heavy chains, located in the Fc-part of the IgG molecule; hence N-glycosylation will be described in more detail (see figure 4$)^{64}$.

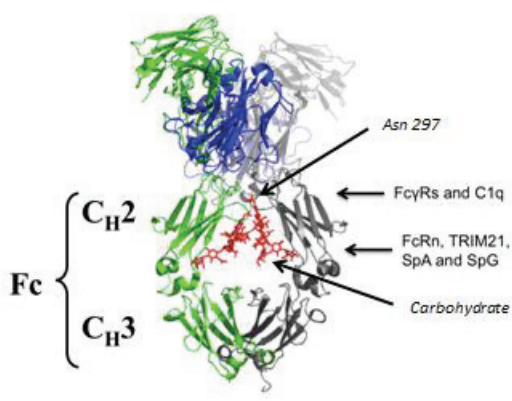

Figure 4: Crystallisable image of $\operatorname{IgG}$ showing the carbohydrate moiety (in red colour) attached to asparagine 297 in the Fc region ${ }^{65}$

Other immunoglobulins have other and occasionally several glycosylation sites for carbohydrate moieties. Normal polyclonal IgG molecules display 15-20 \% N-linked 
glycosylation in the variable regions where the majority of glycoforms have 2 galactoses $^{66,67}$. There are three principal classes of N-glycans, oligomannose, hybrid and complex (See figure $5)^{68}$. The oligomannose variant only has mannose residues attached to the core, while the complex type has to arms that start with $\mathrm{N}$-acetylglycosamine attached to the core. The final variant is the hybrid where one arm only has mannose and there are one or two antennae on the other $\operatorname{arm}^{69}$.

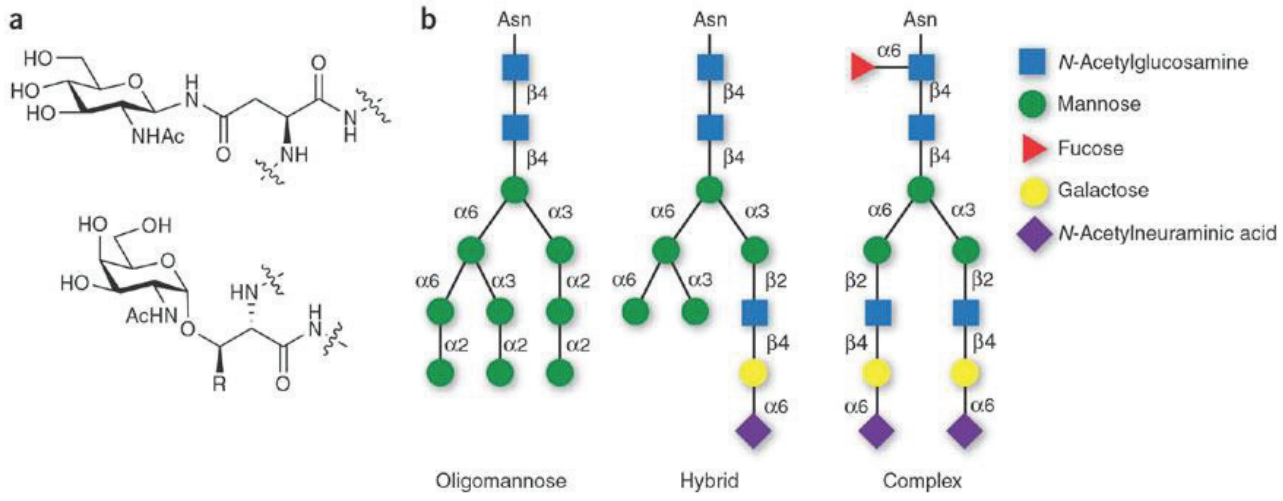

Figure 5: The three types of N-glycans, oligomannose, hybrid and complex ${ }^{68}$

N-linked glycosylation occurs at the sequence Asn-X-Ser/Thr, with the glycan attaching to asparagine and where $\mathrm{X}$ can be any amino acid apart from proline. The first step in the assembly of $\mathrm{N}$-glycosylation starts in the rough endoplasmic reticulum, involving the acceptor dolichol monophosphate and the sugar nucleotide donor uridine diphospho- $N$ acetylglucosamine (UDP-GlcNAc). The main product of this first reaction is dolichol pyrophosphoryl-GlcNAc, serving as the precursor for the assembly of the lipid-linked oligosaccharide, LLO. A number of assembly steps follow that result in the LLO $\mathrm{Glc}_{3} \mathrm{Man}_{9} \mathrm{GlcNAc}_{2}-\mathrm{P}-\mathrm{P}-\mathrm{dolichol}$. This LLO has 14 sugar residues and is the precursor for the biosynthesis of all eukaryotic N-glycans. $\mathrm{Glc}_{3} \mathrm{Man}_{9} \mathrm{GlcNAc}_{2}-\mathrm{P}-\mathrm{P}$-dolichol is transported to an asparagine residue in an emerging protein, catalysed by an oligosaccharyltransferase (OST) and a cascade of trimmings take place, starting with the removal of three glucose units by the enzymes glucosidase I and II in the lumen of the ER, steps that are associated with protein folding ${ }^{70}$. Following this, one mannose is removed by the enzyme $\alpha$-mannosidase I, and the glycoprotein is transferred to the cis-Golgi apparatus, now comprising the formula

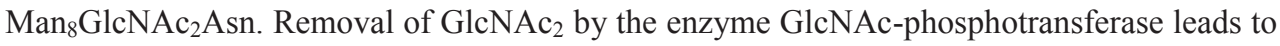
Man-6- $\mathrm{P}^{70}$. High mannose N-glycans can be converted to hybrid- or complex type N-glycans 
in the Golgi, mannosidases in the Golgi remove mannose, and the resulting Man ${ }_{5} \mathrm{GlcNAc}_{2} \mathrm{Asn}$ is a substrate for a glycosyltransferase in the next steps of the biosynthesis of either hybrid- or complex type $\mathrm{N}$-glycans, formed by $\mathrm{N}$-acetylglucosaminyltransferase I and II (GlcNAc-T-1 and GlcNAc-T-2) activity ${ }^{63}$. Further steps include removal of all but three mannoses, followed by the addition of combinations of GlcNAc, galactose and sialic acid. The addition of corefucose attached to the GlcNAc closest to asparagine 297 also occurs in some cases ${ }^{63}$.

Carbohydrates can influence functional properties of immunoglobulins and the different carbohydrates may be combined to form several different glycoforms (see figure 6). Aglycosylated immunoglobulins have a shorter half-life, binds less well to Fc $\gamma$ R's and activate complement less effectively than their carbohydrate containing counterparts ${ }^{71}$. The sugar moiety is attached to asparagine 297 and always comprises a back-bone consisting of two N-acetylglucosamines. This is followed by three mannoses which are bi-antennary and each of the mannoses has a second $\mathrm{N}$-acetylglucosamine attached. The rest of the sugar moiety includes fucose, sialic acid and galactose in different combinations. Terminal sugars, such as core-fucose and sialic acid affect the binding to Fc $\gamma$ RIII, which again will have an effect on antibody dependent cellular cytotoxicity (ADCC). The absence of specific terminal sugars may also affect the interactions between the amino acids and the sugar residues on the Fc part of an IgG, both hydrophobic and hydrophilic, which again can have a large impact on the effector functions of the antibody ${ }^{72}$.
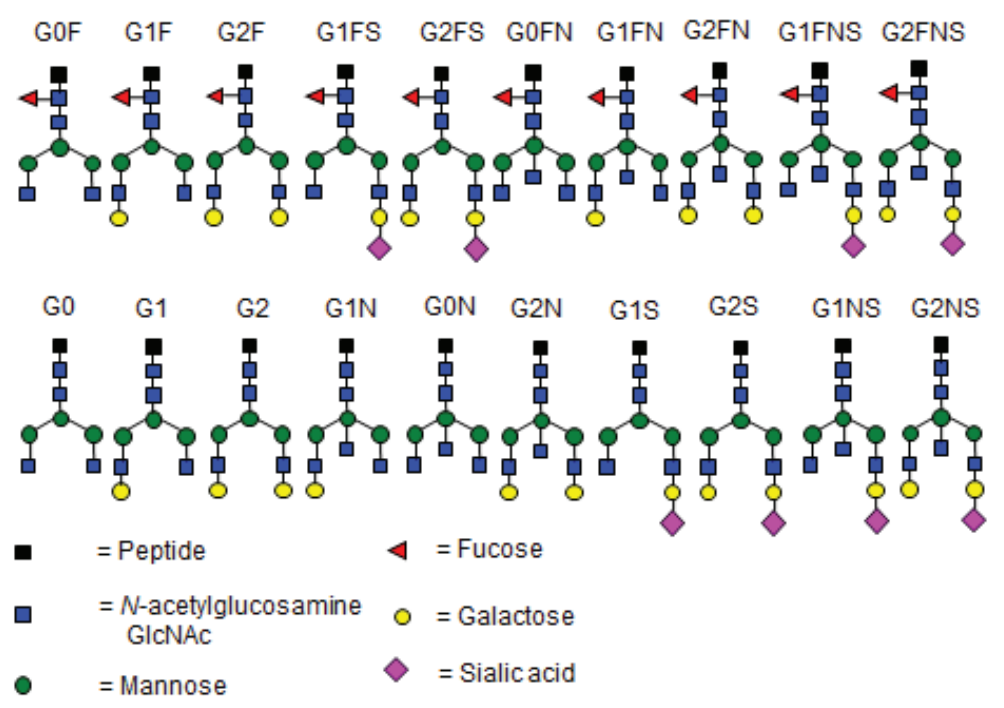
Figure 6: 20 glycoforms situated at asparagine 297 on the Fc portion of IgG antibodies. Others have been observed, but these are the primary glycoforms, and the varities analyzed in this thesis.

\section{GALACTOSE}

Galactose is the first sugar added after the mannose and GlcNAc backbone, and is attached to the biantennary N-acetylglucosamine (GlcNAc) on IgG (See figure 6). The glycans can hence be split in three subsets, depending on the presence of galactose or not, and also how many galactoses are present, IgG-G0 (no galactose), IgG-G1 (1 galactose on one of the biantennary GlcNAc's) or IgG-G2 (1 galactose on each of the biantennary GlcNAc's) ${ }^{1}$. IgG-G0 is present in around $16 \%$ of total human IgG glycan pools, IgG-G1 and IgG-G2 both in around $35 \%$. That leaves $14 \%$ of the pool, which is made up of IgG-G1 and IgG-G2 that also contain sialic $\operatorname{acid}^{73}$. A lack of galactosylated $\operatorname{IgG}$ is often seen in patients with rheumatoid arthritis ${ }^{74,75}$. Pregnancy in rheumatoid arthritis sufferers can result in an increase in antibodies with galactose combined with a decrease in symptoms ${ }^{64,76}$. A lack of fucose gives an increased ADCC, but galactose was previously not thought to affect ADCC, as no change in ADCC was seen upon removal of galactose in monoclonal human $\mathrm{IgG1}$ or in $\mathrm{CHO}$-produced $\operatorname{IgG} 1^{31,77}$. A slightly increased ADCC have been seen in highly galactosylated human IgG monoclonal $\alpha$ $\mathrm{D}$, but this effect was only minor ${ }^{78}$. Interestingly, mouse IgG1 with high content of galactose has recently been shown to hold anti-inflammatory activity by engaging the inhibitory Fc $\gamma$ RIIb, further elucidating the glycan importance for IgG function ${ }^{79}$.

\section{FUCOSE}

Fucose is a sugar attached to the first N-acetylglucosamine (GlcNAc) of the sugar moiety attached to asparagine 297 on $\operatorname{IgG}$ and is hence called core-fucose (See figure 6$)^{74}$. Around 70 $\%$ of total human serum IgG contains core-fucose ${ }^{73}$. The presence or absence of fucose has been shown to be of vital importance to ADCC, as a lack of core-fucose causes an up to 50fold increase in the binding to FcyRIII, and this will further lead to an increase in ADCC ${ }^{31,80}$. When the immunomodulator swainsonine was added to mouse IgG2a antibodies, the ASN297 glycan moiety was removed, resulting in a decline in effector functions and FcR binding. The effector functions required to activate ADCC mediated by mouse spleen cells were however not affected ${ }^{81}$. This is however not the case for all cells, as when swainsonine was used on monoclonal $\operatorname{IgG}$ from hybridoma clones, this resulted in a marked reduction in 
ADCC mediated by interferon- $\gamma$ activated human polymorphonuclear leukocytes ${ }^{82}$. When adding $\beta-1,4-\mathrm{N}$-acetylglucosaminyltransferase III to human embryonic kidney-EBV nuclear antigen cells, this led to an increased production of a hybrid type IgG1 antibodies without fucose, termed Glyco-1. These antibodies caused the expected increase in ADCC, 10-fold in this case, by increased binding to Fc $\gamma$ RIIIa ${ }^{83}$. Producing antibodies without fucose by using $\alpha$ 1,6-fucosyltransferase (FUT8), but with three different oligosaccharides at ASN-297, a hybrid, a complex type and a high-mannose variant, gave different ADCC responses. The complex type bound strongest to FcyRIIIa and hence mediated the strongest human PBMC-mediated ADCC. Then followed the high-mannose antibodies, and lastly the hybrid non-fucosylated IgG1 with the weakest FcyRIIIa binding and the weakest $\mathrm{ADCC}^{84}$. NMR analysis of IgG produced in $\mathrm{CHO}$ (Chinese Hamster Ovary) cells with and without fucose showed similar structures, while crystal structure analysis did not. By using X-ray crystallography, a structural difference was found between fucosylated and a-fucosylated IgG around tyrosine 296; and this difference was a water molecule. Fucosylated IgG1 had two water molecules, whilst a-fucosylated IgG had only one water molecule, and this seemed to cause a difference in the environment surrounding tyrosine 296, and this alteration could possibly influence the $\mathrm{ADCC}^{85}$. To determine how non-fucosylated antibodies exhibit their high ADCC activity in human whole blood, two types of $\alpha$-CD20 IgG1, one fucosylated and one non-fucosylated, were tested for their ability to bind to antigens on target cells and to FcR on effector cells. The two types of IgG competed for binding to target cell antigens, and binding of fucosylated IgG1 blocked the increase in ADCC otherwise seen by non-fucosylated IgG. On the effector side, the non-fucosylated IgG1 bound so strongly to FcyRIIIa that plasma IgG could not compete for this binding. Plasma IgG could however almost entirely stop fucosylated IgG1 from binding to Fc $\gamma$ IIIa. The non-fucosylated IgG used in therapy therefore causes higher ADCC by preventing plasma IgG from binding to Fc $\gamma$ RIIIa and also by avoiding antigen binding competition with fucosylated $\operatorname{IgG}^{86}$. A lack of fucose is seen in leukocyte adhesion deficiency, LAD II, where bloodgroup $\mathrm{H}$ and Lewis antigens have a lack of fucose. This causes recurrent infections, as well as growth and psychomotor retardation ${ }^{87}$. Lack of fucosylation showed an increase in ADCC and Fc $\gamma$ RIIIa binding for all IgG subclasses compared to their fucosylated variants ${ }^{88}$.

\section{SIALIC ACID}

Sialic acid is a sugar moiety attached to galactose, hence without the presence of galactose there can be no sialic acid (See figure 6). Intravenous immunoglobulin (IVIG) is often used as 
a treatment for autoimmune diseases, such as immune thrombocytopenia (ITP) and Kawasaki's Disease. The doses needed are very high, usually 1-2 gram/kg bodyweight once a day, meaning extremely large quantities must be administered ${ }^{89}$. The presence of sialic acid causes a reduced affinity for subclass restricted Fc $\gamma$ R's, and hence a decrease in cytotoxicity is seen ${ }^{74}$. Sialic acid is required as it causes an up-regulation of the inhibitory Fc $\gamma$ RIIb, which will lead to a higher level of Fc $\gamma$ RIII needed for inflammation caused by auto-antibodies ${ }^{90}$. If sialic acid is responsible for the anti-inflammatory effect, that could explain the large doses needed, as less than $10 \%$ of total $\mathrm{IgG}$ is sialic acid rich-IgG ${ }^{74,91}$. The human C-type lectin receptor DC-SIGN is found on human dendritic cells that when bound to $\alpha-2,6$-sialylated IgG elicit an anti-inflammatory effect and reduce affinity for Fc $\gamma \mathrm{R}$. This effect was not observed when using $\alpha-2,3$-sialylated $\operatorname{IgG}$, making $\alpha-2,6$ sialylation essential for anti-inflammatory activity $^{53,54}$. This anti-inflammatory effect seen after interaction between sialylated $\mathrm{Fc}$ and DC-SIGN is thought to lead to an innate Th2 response by activation of IL-33 from the spleen $^{56}$. This up or down-regulation of anti- and pro-inflammatory antibodies could therefore be the body's way of obtaining homeostasis ${ }^{57}$.

IgG AND DISEASES RELEVANT TO THIS THESIS

\section{FETAL AND NEONATAL ALLOIMMUNE THROMBOCYTOPENIA}

Fetal and neonatal alloimmune thrombocytopenia (FNAIT) is a condition where pregnant women develop antibodies against the fetus' platelet antigens. These antigens are termed human platelet alloantigens (HPA). 6 bi-allelic forms exist, with 1A being the most common, followed by $1 \mathrm{~B}^{92}$. Whether the allelic form $1 \mathrm{~A}$ or $1 \mathrm{~B}$ is generated depends on the gene encoding integrin $\beta 3$, as Leu33 generates $1 \mathrm{~A}$ and Pro33 generates $1 \mathrm{~B}^{93,94}$. In Caucasians, it is caused by passage of maternal anti-HPA $1 \mathrm{~A}$ antibodies through the placenta $85 \%$ of the cases, as the HPA 1A negative mothers become immunized during the pregnancy ${ }^{94}$. In most cases this does not lead to clinically significant bleeding, but it can also lead to minor bleedings such as petechial and in the worst cases to intracranial haemorrhage and subsequently death can occur ${ }^{95}$. FNAIT occurs in about 1 in 1000 of all live births and should be considered for any neonate suffering from unexplained thrombocytopenia ${ }^{92}$. Expression of 
fetal glycoproteins on platelets takes place from 16 weeks gestation ${ }^{96}$. A HPA 1B mother only produces HPA 1A antibodies to a HPA 1A fetus in $10 \%$ of the cases, with an increased risk if she carries the HLA-DRB3*0101 allele, occurring in $30 \%$ of the population ${ }^{97}$. It may occur at the first pregnancy, but in many cases, the women have been pregnant before ${ }^{98}$.

To diagnose FNAIT, blood samples from the parents are analysed using either MAIPA or RIP assays. Monoclonal Antibody-specific Immobilization of Platelet Antigens (MAIPA) is an enzyme immunoassay where monoclonal antibodies are used to identify the maternal alloantibodies with glycoprotein specificity, excluding all other antibodies ${ }^{99,100}$. Radioimmunoprecipitation (RIP) is an assay that uses radioisotopes to tag the glycoproteins and platelet targets, capturing the maternal alloantibodies on a solid phase, making it more complex and more expensive than MAIPA. By using these methods the maternal alloantibodies can be tested for incompatibility to the fetus and be somewhat quantitated ${ }^{99}$. Maternal and paternal phenotyping is done by $\mathrm{PCR}^{101}$. Screening for HPA $1 \mathrm{~A}$ negative women is not routinely carried out, but in a study were 100000 pregnant women were screened and interventions carried out where suitable, the number of severe cases were reduced to 3 out of 57 compared to 10 out of 51 in prospective studies. The 100000 women had their blood analysed for anti-HPA 1a antibodies every four weeks and the women who were positive for these antibodies received HPA 1A negative platelets one or two days before delivery, which was carried out by caesarean section 2-4 weeks before term ${ }^{102}$. It is also important to measure anti-Human Leukocyte Antigens (HLA) antibodies, as these might interfere with diagnosis and management. Even without blood transfusion, anti-HLA antibodies may still develop in 20-30\% of pregnancies. Platelets express HLA class I antigens and this can cause FNAIT induced by anti-HLA antibodies ${ }^{103,104}$.

Treatment of FNAIT includes administration of IVIG, (beginning at 24 weeks' gestation if a previous infant was affected), corticosteroid treatment, fetal blood sampling and intrauterine platelet transfusion, and early delivery in some cases ${ }^{99,105}$. Post-natal management includes administration of IVIG to the infant, as well as HPA -1A negative donor platelet concentrates if available ${ }^{105}$.

Correlations between the degree of symptoms and the level of anti-HPA 1A antibodies have been seen in several studies ${ }^{106-108}$. Anti-HPA 1A levels have been significantly higher in women giving birth to children with severe thrombocytopenia (platelet count of $<50 \times 10^{9} / \mathrm{L}$ ) compared to women giving birth to children who were moderately thrombolytic (platelet count between $50 \times 10^{9} / \mathrm{L}$ and $149 \times 10^{9} / \mathrm{L}$ ) or normal platelet count (between $150 \times 10^{9} / \mathrm{L}$ and $\left.450 \times 10^{9} / \mathrm{L}\right)^{109}$. The effect of glycosylation on these antibodies was considered for the first 
time by mass spectrometry analysis of sera from 9 women who all developed IgG1 alloantibodies against the fetus' HPA. The specific IgG1 antibodies showed decreased fucosylation and increased galactosylation and sialylation compared to total background IgG1 antibodies. As decreased fucosylation is known to increase ADCC activity, glycosylation could affect the severity of the disease ${ }^{110}$.

\section{INFECTION PREVENTED BY VACCINES USED IN THIS THESIS}

\section{MENINGOCOCCAL DISEASE}

Neisseria meningitidis is Gram-Negative diplococci that can be either encapsulated or uncapsulated and can cause meningitis and sepsis ${ }^{111}$. Several serogroups have been determined based on their capsular polysaccharide and three serogroups account for at least $90 \%$ of all meningococcal disease, serogroup A, B and $\mathrm{C}^{112,113}$. The area where the disease is most widespread is in Africa, in what is termed the meningitis belt. This extends from Ethiopia to Senegal and the main serogroup seen in this area is A, followed by W-135, C and $\mathrm{X}{ }^{114}$. N.meningitidis can cause meningitis of both epidemic and sporadic nature, and the clinical presentation is in most cases bacterial meningitis, where haemorrhagical skin lesions, stiffness in the neck, sensitivity to light and fever is seen. Pneumonia and conjunctivitis are other symptoms that may be present ${ }^{111}$. Signs of sepsis; hypotension and organ failure may also be presenting symptoms. It is treated with antibiotics and a rapid onset of treatment is vital to decrease morbidity and mortality ${ }^{114}$.

Different vaccines exist against the different serogroups, some with higher success rates than others. An outer membrane vesicle vaccine against meningococcal B disease was developed at the Norwegian Institute of Public Health in the late eighties ${ }^{15-117}$. A similar vaccine has been developed in New Zealand, based on the work from Norway, but with an antigen more suitable to the New Zealand outbreaks ${ }^{118}$.

\section{PNEUMOCOCCAL DISEASE}

Streptococcus pneumoniae is a Gram-positive diplococci responsible for a vast array of infections, including sinusitis, otitis media and pneumonia (non-invasive) as well as meningitis and bacteremia (invasive). It is also the main bacteria causing community acquired pneumonia $^{119}$. In the very young and in the elderly, the bacteria can cause severe morbidity and mortality ${ }^{120}$. S.pneumococci is also categorized according to its polysaccharide capsule, 
and more than 90 different serogroups have been documented. Available vaccines include 23valent pneumococcal polysaccharide vaccines against the 23 most common serogroups, such as Pneumovax (Sanofi Pasteur MSD) and one 13-valent pneumococcal conjugatedpolysaccharide vaccine called Prevenar (Wyeth) ${ }^{119}$. Prevenar is in many countries part of the children's vaccination regime, whilst Pneumovax is a polysaccharide vaccine used in adults. As the main subclass produced following immunization with a polysaccharide vaccine, such a vaccine would cause little effect in children under the age of 2 years as their immune system is not capable of producing $\operatorname{IgG} 2$ antibodies ${ }^{121}$.

\section{INFLUENZA}

Influenza is a viral infection with an incubation period of 1.5 to 3 days, but can be as long as 7 days $^{122}$. Symptoms include fever, chills, myalgia, headache and cough, usually lasting for one or two weeks. For the elderly, the very young and the immunocompromised patients it can be a serious matter with increased morbidity and mortality ${ }^{123,123,124}$. The influenza virus has two types of surface proteins, hemagglutinin (HA) and neuraminidase (NA), and the name of the virus will be determined by the subtypes of these surface proteins, hence the pandemic influenza of 2009 was of the H1N1 strain whilst the avian influenza virus was of the H5N1 strain $^{124,125}$. The virus changes slightly from one year to the next by antigenic drift, where point mutations in the viral RNA lead to new strains, hence a new seasonal influenza vaccine is made for each season ${ }^{125}$. The choice of strains used for the current year's vaccine is based on which viruses circulate at the time and how they spread, as well as the protection level of the current vaccine strains ${ }^{126}$. The influenza vaccines are usually formulated with inactivated virus, consisting of three different virus strains, influenza A H1N1, influenza A H3N2 and influenza B, not subtyped ${ }^{124,125}$. Following an influenza vaccination, the antibodies produced against the hemagglutinin proteins provide the best protection, and the antibody response will typically be measurably after 2-4 weeks ${ }^{125}$. In the spring of 2009, a new influenza virus, H1N1, originated in Mexico and soon spread throughout the world. This virus originally came from swine, but was antigenically dissimilar to other H1N1 viruses from either man or swine $^{122}$. A vaccine was produced with the strain A/California/7/2009, and later samples from pandemic H1N1 patients from all over the world were found to be similar to that strain ${ }^{125}$. This caused a mass vaccination, and in Norway the vaccine used was Pandemrix ${ }^{\circledR}$, produced by GlaxoSmithKline, a split killed/inactivated antigen vaccine, based on A/California/7/2009, 
containing squalene as an adjuvant ${ }^{127}$. About $40 \%$ of the population in Norway received at least one dose of this vaccine ${ }^{128}$.

\section{VACCINES USED IN THIS THESIS}

There are currently several delivery routes available for vaccinations, mainly different forms of injections, oral or nasal. The vaccine types used in the volunteers in this experiment had antigens formulated as follows: inactivated influenza virus with adjuvant (pandemic influenza), inactivated influenza-virus without adjuvant (seasonal influenza), unconjugated polysaccharide (pneumococcal disease) and outer membrane vesicle (meningococcal disease). The pneumococcal vaccine induces a B-cell response, no T-cell response, and is hence not recommended for children under the age of 2 years, as their immune system is not developed enough to start a T-cell independent B-cell response ${ }^{129}$. The main subclass of antibodies produced from a polysaccharide vaccine is $\operatorname{IgG} 2$, unlike the other vaccines that mainly produce an $\mathrm{IgG1}$ response ${ }^{129,130}$. The presence of an adjuvant in a vaccine can increase the antibody titer; hence a difference might be seen between the vaccine serum from volunteers receiving the pandemic influenza vaccine compared to the seasonal influenza vaccine ${ }^{131}$. The outer membrane vesicle (OMV) vaccine is another way of formulating vaccines and the pneumococcal vaccine used in this experiment is of such a type. OMVs are spherical lipid bilayer vesicle found in the outer membrane of gram negative bacteria. The outer membrane of Gram-negative bacteria consists of an outer layer with lipopolysaccharide and proteins and the inner layer of lipoproteins and phospholipids ${ }^{132}$. For use as a vaccine, the OMVs can be purified by centrifugation to remove any macroparticles causing contamination, cells and cell debris, and are then ultra-centrifuged to produce pellets ${ }^{133}$. An adjuvant is often added to enhance the response, for the vaccine used here aluminium hydroxide was used ${ }^{130}$. This may lead to a different glycosylation pattern compared to the others.

\section{VACCINE RESPONSE}

Vaccination is the most effective cost-benefit medical drug on the market, and ever since Edward Jenner used cowpox to prevent small pox infection in 1798, vaccines have saved millions of lives ${ }^{134,135}$. A robust IgG response is generally a hallmark of an effective vaccine against invasive pathogens. Hepatitis B, meningococcal disease, rubella, pneumococcal and influenza are amongst the infectious diseases that vaccines have been developed for ${ }^{136}$. A large portion of the elderly population and those that are immuno-compromised benefit each 
year from the seasonal influenza vaccine, with an average of 500000 in Norway being vaccinated each year, around $10 \%$ of the population (personal communication, Kjersti Rydland, Norwegian Institute of Public Heath, Department of Vaccine delivery).

The effectiveness of vaccines have been analyzed categorically ${ }^{137-139}$, while the impact of glycosylation is only just starting. The glycosylation pattern following vaccination have just been published and showed that IgG following influenza and tetanus vaccination had an increased level of sialic acid and galactose, while the total IgG in these patients were unaltered $^{140}$. Changes in the glycosylation pattern over the time course of vaccination would thus greatly influence vaccine effect. Detailed analysis of change in glycosylation is therefore crucial for a more comprehensive understanding of vaccine immune protection. Information about the $\operatorname{IgG}$ glycosylation during vaccination could also expose possibilities for glycosylation manipulation in vaccine formulation and adjusting vaccine schedules in order to maximize vaccine protective effects. Combining this knowledge with biological tests may provide answers as to the effectiveness and functions of the antibodies, possibly indicating the most effective vaccination schedule.

\section{IgG MUTANTS RELEVANT TO EFFECTOR FUNCTIONS}

Recombinant monoclonal IgG antibodies are used to study structure-function relationships and also therapeutically as treatment for cancer and for diseases of the immune system ${ }^{141-147}$. Two methods can be used to produce recombinant antibodies, either transient gene expression (TGE) or stable gene expression $(\mathrm{SGE})^{148}$. In SGE, the nucleic acids become part of the genome by the way they are introduced in to the cell, leading to long term expression. This process is however time consuming because tedious cloning procedures are necessary to isolate a stable and effective cell line. Transient transfection is simpler and quicker, though the DNA added is not becoming a part of the genome and the cell will thus only produce antibodies as long as there is DNA present, resulting in a short-term expression.

HEK 293E, a human embryonic epithelial fibroblast cell line is often chosen to produce recombinant proteins such as antibodies. For permanent transfection, mouse cell lines such as NS-0 and J558L can be used. NS-0 is a mouse myeloma cell line with a high yield that does not secret neither light chains nor heavy chains, and is extensively used as fusion partner to produce mouse hybridoma cell lines ${ }^{149-152}$. J558L is mouse B myeloma cells that is unable to produce heavy chains, but produces a mouse $\lambda 1$ light chain ${ }^{153}$.

Analysis of differences in glycosylation pattern between cell lines, transfection types and effect of point mutations in recombinant antibodies have been done to some degree, but not 
extensively. Point mutations in different amino acids could for instance lead to changes in glycosylation which could affect effector functions. IgG3 produced in Chinese hamster ovary cells with certain amino acids replaced with alanine showed increasing galactosylation and sialylation, providing a possibility for specific modulation of immunoglobulin production to optimize treatments ${ }^{154}$. Glycosylation pattern from recombinant $\alpha$-NIP chimeric mousehuman antibodies from J558L cells have been analyzed previously without showing great differences between IgG1 and IgG3, apart from glycoforms G0F and G2F. IgG2 showed a similar glycosylation pattern to $\operatorname{IgG} 3$ and $\operatorname{IgG} 4$ to $\operatorname{IgG} 1^{155,155}$.

\section{MASS SPECTROMETRY}

Mass spectrometry is an analytical method used to determine molecular weight of both organic and inorganic compounds. The molecules are ionized and the ions are separated according to their mass to charge ratio, $\mathrm{m} / \mathrm{z}$. They can be detected either qualitatively or quantitatively, both according to their $\mathrm{m} / \mathrm{z}$ and their abundance ${ }^{156}$. As the field of proteomics and genomics surge, the use of mass spectrometry is also on the up-rise, and hence a desire to develop faster and more accurate equipment follows ${ }^{157}$.

There are several ways to ionize compounds and there is a wide variety of equipment available to separate and to detect the ions, and a description of the ionization method and equipment used in this thesis only is included. We used liquid chromatography coupled to an Orbitrap, using electrospray ionization, ESI. Formic acid is included in the mobile phases to aid ionization as the sample is let in through the sample inlet, usually a needle. It is transformed from the liquid phase to the gas phase by vaporization. This takes place at atmospheric pressure or vacuum, while everything from the ion source to the end takes place under high vacuum ${ }^{67,158-160}$. This is to allow the ions a chance to travel from one end of the instrument to the other without being hindered or colliding with air molecules. ESI is an accurate, soft ionization technique that is ideal for large and fragile molecules, can be used for proteins and carbohydrates and allows for ionization of molecules directly from solution ${ }^{159}$. As ESI allows for several charges, not only one like matrix-assisted laser desorption/ionization (MALDI), ESI-MS allows for molecular weight determination of proteins exceeding 100000 Dalton in weight ${ }^{158}$. After the ionization step, the charged particles enter the mass analyser, where they are sorted according to their $\mathrm{m} / \mathrm{z}$. There are several mass analysers available; we have used ion trap and Orbitrap. Ion traps trap the ions within a field, detecting the unstable ions. Orbitrap is also an ion trap, but a constant electrostatic field is used to trap the ions ${ }^{161}$. 
For our work, the mass spectrometer of choice has been the Orbitrap, coupled with Liquid Chromatography (LC) and Electron Spray Ionization (ESI); LC-ESI-Orbitrap. The Orbitrap traps the ions in an electrostatic field created by two electrodes, one axial central and one outer coaxial electrode. These two electrodes make the ions travel both around and up and down along the axial electrode (See figure 7). Ions of different mass-to-charge ratios will travel differently, and the ion image current is only possible as long as the ions keep travelling in a stable spatial pattern along the axial direction. The ion image current is collected and is converted by analogue to digital conversion and further processed through acquisition software. When coupled to an electrospray ion source, this provides a sensitive and accurate mass spectrometer ${ }^{157,161,162}$.

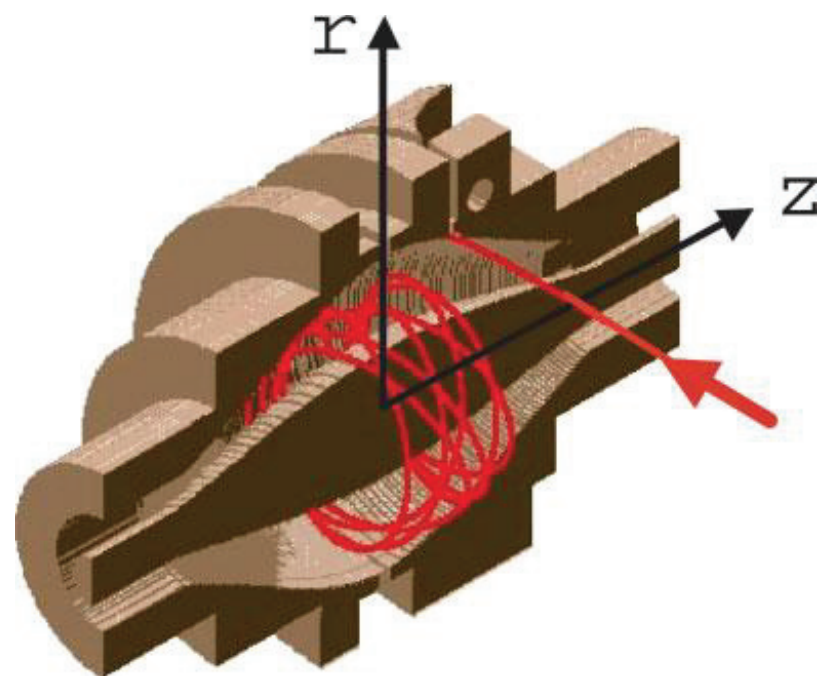

Figure 7: The orbitrap mass analyzer. The arrow indicates where the ions are injected. $\mathrm{R}$ and $\mathrm{z}$ are cylindrical coordinates, and the stable ions move both around the central electrode, as well as in the direction of the Z. ${ }^{157}$

The final step is the detector, where the ion current is amplified, and the transmitted signal is converted to a mass spectrum. In a mass spectrum, the $m / z$ values are shown, as well as the intensity, the molecular weight and the abundance. Using this information, a data system provides the user with detailed knowledge of which components are there and how much of each type are present ${ }^{156}$. For complex mixtures, multiple-stage mass spectrometry or tandem mass spectrometry can be used ${ }^{157}$.

We have used two types of fragmentation, both collision induced dissociation (CID) and higher energy C-cell dissociation (HCD). For both types of fragmentation, the ions collide 
with a neutral gas and kinetic energy is converted to internal energy, and as this internal energy is spread throughout the compound, the ions dissociate. HCD takes place in a specific designated collision cell outside of the mass analyser while CID takes place within the mass analyser. The fragments created after HCD are transferred back in to the mass analyser directly and higher dissociation energies can be used as the low-mass cut off seen with CID is avoided, enabling a wider range of fragmentation pathways. The time aspect is of importance as HCD fragmentation may take up to twice as long compared to CID fragmentation ${ }^{163,164}$. The two fragmentation methods have been compared, though the results are inconclusive, and there is hence no obvious choice of which method to use ${ }^{165}$. For our studies, both methods were used, but mainly CID. HCD is more suitable for glycan fragmentation, as the mass at $\mathrm{m} / \mathrm{z}$ 204, HexNAc, often is lost when using CID. Creating, separating and detecting ions can be done in several different ways, and the different elements used can be combined in different ways. This leaves a large variety of choices for analysis, each with different strengths and weaknesses. 


\section{AIMS OF THE STUDY}

Immunoglobulin $\mathrm{G}, \mathrm{IgG}$, is the major serum immunoglobulin, responsible for recognizing, neutralizing and eliminating toxic antigens as well as pathogens. Carbohydrates situated on asparagine 297 on the Fc portion of the IgG molecule have a substantial impact on the effector functions of IgG. In particular are the carbohydrates galactose, fucose and sialic acid of interest, as galactose is required to activate $\mathrm{C} 1 \mathrm{q}$, the first step in activation of the complement system. A lack of fucose leads to an increase in antibody dependent cellular cytotoxicity, ADCC and the presence of sialic acid is thought to be the main reason for the anti-inflammatory effect seen with intravenous immunoglobulin. To increase our understanding of this carbohydrate influence further, we set out to investigate the IgG glycosylation pattern in different settings. We were interested in seeing what effect, if any, amino acid point mutations, harvest time and choice of cell line and type of transfection had on the glycosylation pattern, and combined this with biological tests (paper I). We continued to compare the glycosylation pattern of antibodies isolated from serum from volunteers receiving different vaccines, analysed from blood samples drawn at different time points after vaccination (paper II). And finally the glycosylation patterns seen in the condition fetal and neonatal alloimmune thrombocytopenia (FNAIT) were investigated, where pregnant women develop antibodies against the platelets of their fetus (paper III). 


\section{SUMMARY OF PUBLICATIONS}

\section{PAPER I}

\section{Different glycosylation pattern of human IgG1 and IgG3 antibodies isolated from transiently as well as permanently transfected cell lines}

The aim of this study was to analyze IgG1 and IgG3 wild type and mutants produced in cells by both transient and permanent transfection. IgG1 and IgG3 are the most protective IgG subclasses, and as their effector functions depend on the presence of a carbohydrate moiety at asparagine 297 in the Fc portion, detailed structural carbohydrate analysis is therefore crucial to better understand and exploit the protective potential. Recombinant wild type and mutant IgG1 and IgG3 antibodies produced from three cell lines were analyzed for their glycosylation profile by a newly developed isolation technique with a high resolution, sensitive LC-ESIOrbitrap method. We detected clear differences between IgG1 and IgG3 glycoforms, where IgG1 generally contained fucosylated glycoforms whilst IgG3 mainly were non-fucosylated. IgG1 glycoforms differed between two permanent transfected cell lines, NS-0 and J558L. Transiently transfected HEK 293E cells produced IgG with a simpler and less developed glycosylation structure at the late harvest compared to the early harvest. Some of the transiently transfected antibodies showed higher ADCML activity from the early harvest compared to the late harvest. Generally, the glycosylation pattern of the mutants tested, including a hinge truncate mutant of IgG3, did not differ significantly from the wild type IgG. The striking difference in glycosylation pattern of IgG1 compared to IgG3 therefore appears not to be due to the long hinge region of IgG3 (62 amino acids) relative to the IgG1 hinge region (15 amino acids).

This work demonstrated that differences in glycosylation pattern are seen between IgG subclasses, between cell lines and with different harvest times, which can influence effector functions. 


\section{PAPER II}

\section{Differences in glycosylation pattern of IgG subclasses induced by pneumococcal, meningococcal and two types of influenza vaccines}

The objective of this study was to analyze serum or plasma taken at different time points, from volunteers receiving different vaccines to establish the IgG glycosylation pattern and look for changes with time and differences between vaccines. As glycosylation is essential for IgG effector functions, detailed structural carbohydrate analysis is therefore crucial to better understand and exploit the protective potential. Four different vaccines were used, a pneumococcal capsule polysaccharide vaccine, a meningococcal outer membrane vesicle vaccine, a seasonal influenza vaccine and a pandemic influence vaccine. Antibodies against specific vaccine antigens were captured using microtiter wells coated with the individual vaccines and analyzed for their glycosylation profile by a high resolution, sensitive LC-ESIOrbitrap method. Following immunization, the IgG subclass dominating the response showed an increase in galactose. The level of sialic acid levels increased slightly with time for most vaccines, but a large increase in sialic acid, the hallmark for anti-inflammatory activity, was not observed, not even from serum collected up to a year after immunization. Fucose levels did increase for some vaccinees, but for the majority fucose was unaltered. The total background IgG glycosylation varied little with time, and hence the changes seen were caused by immunization. The minor IgG subclass response varied between vaccine formulations. The presence of an adjuvant in the pandemic influenza vaccine seemed to produce simpler and fewer glycoforms compared to the seasonal influenza vaccine. This work demonstrated that detailed IgG glycosylation pattern analysis might be a necessary step in addition to biological testing for optimizing vaccine development and strategies. 


\section{PAPER III}

\section{A prominent lack of Fc-fucosylation of platelet alloantibodies in pregnancy}

In this study we considered the glycosylation pattern of IgG antibodies from pregnant women against human platelet antigens (HPA) of the fetus. This is termed fetal and neonatal alloimmune thrombocytopenia (FNAIT) and can result in various clinical scenarios, from asymptomatic to petechiae to major organ bleedings including intracranial haemorrhages. The $\mathrm{N}$-glycans from the anti-HPA-1A IgG from 48 pregnant women were isolated and analysed to acquire more insight in to the pathogenesis. Fucose was of particular interest, as a lack of core-fucose can lead to a substantial increase in antibody dependent cellular cytotoxicity, ADCC. The specific IgG were analysed using mass spectrometry, and a slight increase in galactosylation was seen, whilst fucosylation was markedly decreased compared to the total IgG1 in the same patients. To ascertain whether this skewing towards non-fucosylated IgG antibodies was unique to FNAIT patients, N-glycans from anti-HLA antibodies formed after platelet transfusion (refractory thrombocytopenia) and antibodies against platelet glycoprotein IIb/IIIa from immune thrombocytopenia were also analysed, but the response was only seen in FNAIT patients.

The study showed that the atypical fucosylation seen in anti-platelet responses can be related to the immune milieu defined by pregnancy or the specific stimulating antigen. This influences IgG effector functions, including ADCC activity and may have a profound effect on disease severity and prognosis of alloimmune-mediated reactions against fetal cells and tissues. 


\section{METHODOLOGICAL CONSIDERATIONS}

\section{ANTIBODY GENE TRANSFECTION}

Two methods can be used when producing antibodies, either transient or permanent transfection of antibody genes, with both its advantages and disadvantages. Transient transfection is carried out by inserting DNA into the nucleus, but as it is not assimilated into the chromosomes, the cells will produce antibodies only as long as there is DNA left. Permanent transfection is carried out by inserting the DNA into the nucleus, but in this case it is assimilated into the chromosomal DNA, and can therefore produce antibodies as long as the cells live. Cells with permanent transfected DNA can therefore be frozen and thawed when more antibodies are required, whilst the transient transfected cells only provide short term production. On the other hand, production of antibodies following transient transfection gets started quickly and with large quantities of product, whilst achieving optimum production from permanent transfection is both time- and labor-consuming. We have used antibodies from both types of transfection in this study, but only the transient transfection was carried out by us, the permanent transfected antibodies were already produced and kept frozen. Glycosylation studies of both transfection types provided excellent results (paper I).

\section{ANTIBODY CAPTURE BEFORE MS ANALYSIS}

The specific antibodies were isolated from microtiter plates coated with vaccine antigens (paper II). When antibody subclass typing and quantitation is carried out with microtiter plate for ELISA studies in our lab, the wash between incubations usually includes PBS/tween. As tween can interfere with mass spectrometry results, we avoided the use of this reagent and washed with either distilled water or with $1 \mathrm{M} \mathrm{NaCl}$ followed by distilled water.

Other methods for isolation includes using protein A and protein G Sepharose on filter plates and using vacuum to elute the antibodies ${ }^{110}$. In our experiments, we attempted to use Whatman 96 well $350 \mu 1$ UNIFILTER microplate as a way of eluting antibodies. As the plates would make a higher vaccine antigen concentration or protein A or G Sepharose concentration, assumptions were made that the concentration of eluted antibodies would be higher than when using microtiter plates. A few alterations were made to the manufacturer's specifications, and briefly, the filters were saturated with vaccine antigen or protein $A / G$ sepharose, the serum was added and incubated at room temperature, and formic acid was used to elute the antibodies. A Whatman UNIPLATE Collection Microplate was placed underneath 
the filterplate, and centrifuged at $1000 \mathrm{G}$ for 4 minutes to collect the eluted antibodies. The concentration of antibodies obtained was too low to analyze further, and this method was disregarded.

\section{IN WELL TRYPSIN DIGESTION BEFORE MS ANALYSIS}

Trypsin digestion was carried out by overnight digestion (paper I, I and III). $120 \mu 1$ of $50 \mathrm{mM}$ ammonium bicarbonate buffer with $15 \%$ acetonitrile was added to each well in the microtiter plates or to each NanoSep $\subset$ device to obtain a basic $\mathrm{pH}$ value. The mixture was heated at $80^{\circ} \mathrm{C}$ for 5 minutes followed by 30 seconds of sonication in a water bath to make sure the $\mathrm{pH}$ of the antibodies were thoroughly adjusted. Trypsin was added to each well and NanoSep(C) device, sonicated for a further 30 seconds, and left at $37^{\circ} \mathrm{C}$ degrees overnight. Overnight trypsin digestion is the preferred method of choice to ensure full enzymatic digestion has occurred $^{166,167} .4$ hour long digestion have also been used ${ }^{168}$.

\section{MASS SPECTROMETRY CONSIDERATIONS}

When studying IgG glycosylation using mass spectrometry, different apparatus can be used, but the common types are matrix-assisted laser desorption/ionization (MALDI)-MS/MS and different versions of ion traps such as the Orbitrap ${ }^{167,169,170}$. The work included in this thesis has been carried out using LC-MS-ESI Orbitrap for paper I and paper II, and using nano liquid chromatography-tandem mass spectrometry (LC-MS/MS) coupled to an Esquire HCT ultra ESI-ion trap-MS for paper III. For paper I and III we have used CID fragmentation and for paper II we started out using HCD, but changed to CID fragmentation, and all samples were digested with trypsin overnight.

Analysis can be carried out using whole glycoproteins, glycopeptides or only glycans that are chemically or enzymatically released. Proteolytic digestion, either in solution or in-gel, provides detailed glycan structural information providing an accurate representation of glycopeptides ${ }^{171,172}$. Liquid chromatography is usually combined with mass spectrometry and coupled with LC-electrospray ionization, like we have done in all three papers, chromatographic separation of the glycopeptides is done before MS analysis. C18-reverse phase HPLC is often used to achieve good chromatographic separation ${ }^{173}$.

Quantitative proteomics can be done using stable isotope labeling or it can be done labelfree $^{174}$. We have focused on label-free analysis, which again can be done using area under the curve (AUC) or signal intensity based on precursor ions, or by counting the number of 
peptides assigned to a protein in an MS/MS experiment ${ }^{175}$. Label-free glycopeptide analysis is relatively straightforward, but a few features must be considered. Large retention times can cause overlap with peptides eluting at the same time, and if these have the same mass/charge ratio, it will not be possible to identify each peptide ${ }^{174}$. In our case, the glycopeptides from IgG2 and IgG3 have the same mass/charge ratio, and can hence not be differentiated between. For our vaccine response study (paper II), we overcame this by quantitating the sera first using ELISA. Based on which vaccine had caused the response, we found there to be either minute amounts of IgG3 compared to IgG2 (the pneumococcal vaccine), or vice versa (the other three vaccines), meaning the glycopeptides found could be assigned to the right IgG subclass based on the vaccine administered. For the total background IgG, we separated IgG2 and IgG3 by using protein A and protein G columns. Differences in MS intensity and sample background noise were resolved by using albumin as a standard that was run before and after each sample sequence run. MS/MS scans were run for some samples to verify their identity. To compare different integration methods both the area of the peaks (AUC) and the signal intensity of average height were tried, but as these gave the same results, the two methods can be used interchangeably and the signal intensity of average height was used. Before the actual samples were analyzed, several test-runs were carried out to make sure the results were reproducible from one analysis to the next. Statistical analysis was carried out using the Friedman test to evaluate differences between the visits and the Wilcoxon test to evaluate differences between specific $\operatorname{IgG}$ and total background $\mathrm{IgG}$, both with a p-value of $<0.05$ considered statistically significant.

Spectral counting is another way of quantitating glycopeptides where the peptides present in higher abundance are fragmented and the MS/MS spectra will reflect the protein amount ${ }^{176}$. This method is used for comparing different samples, hence not suitable for IgG analysis where the amounts of different glycoforms in the same sample are compared to each other.

Labeling the glycopeptides with stable isotopes is another way of quantitating the samples and is considered a precise and accurate method for quantitation. Isobaric tags can be used, isotope-coded tags and also incorporating the isotope labels in the actual amino acid in the cell culture are all ways this can be carried out ${ }^{177-179}$. The method is however expensive and requires special training, the number of samples in each experiment is limited and not all samples may be eligible for isotope labeling ${ }^{174}$. This method for quantitation was therefore not an option for our analysis. 


\section{MEASUREMENT OF EFFECTOR FUNCTIONS}

$\mathrm{ADCC}$ and $\mathrm{ADCML}$ are in vitro methods used to study the effector functions of antibodies by reflecting immunoreactions taking place in vivo (paper I). These are approaches that measure the ability of antibodies to bind to the target cells and achieve lysis, and the success of this is measured by the emitted radioactivity. In ADCML, human complement from a healthy donor is added as the effector cell source and IgG that are bound to the target cells can further bind to $\mathrm{C} 1 \mathrm{q}$, the globular heads that make up the first step in the complement cascade ${ }^{180}$. In ADCC, human mononuclear leukocytes from a healthy donor are used as effector cells and the antibodies bound to the target cells can interact with Fc $\gamma$ Rs on for instance natural killer cells,

resulting in both lysis and the release of effector cytokines ${ }^{181}$. The two methods measure the effector functions in different ways, as the ADCML only measure the interaction with complement receptors, while the ADCC measure the ability to achieve lysis through Fc $\gamma$ RIIIa. The results obtained from In vitro testing cannot be directly transferred to in vivo, as the settings for in vitro analysis are controlled in a whole different way compared to in vivo. It can however give a good indication of the mechanisms of action and the likely outcome following administration of for instance monoclonal antibodies. Both ADCC and ADCML have been studied in vitro, and the results have been used to give a representation of the in vivo activity for both vaccine design and monoclonal antibodies used in cancer ${ }^{182-184}$.

\section{HUMAN SERUM COLLECTED FOLLOWING IMMUNIZATION}

Blood was collected from the volunteers following vaccinations at several time points following vaccination, not only the typical day 0 , day 30 and day 10 that have been presented for most vaccinees (paper II). Some vaccinees had serum from additional time points analyzed, but the trends were similar to the time points chosen for paper II and did therefore not give supplementary information. The time points close to day 30 were similar to day 30 , and after about day 60, the trends were as day 100 . For vaccinees receiving the pandemic influenza vaccine, three samples apart from day 0 , day 30 and day 100 were analysed and included paper II. For these, an increase in galactose for seen in both IgG1 and IgG3 for two of the younger vaccinees, while a decrease in galactose was seen for IgG1 and IgG3 in one vaccine belonging to the $65+$ group. No changes in fucose or sialic acid were seen at these very late time points, hence we feel that the analysis from day 0 , day 30 and day 100 give a good representation of the changes in glycosylation following vaccination. 


\section{IgG SUBCLASS DETERMINATION}

The antibodies obtained from the vaccine response studies were quantitated using microtiter plates coated with vaccine antigen (paper II). IgG subclass specific antibodies obtained from the WHO/International Union of Immunological Societies (IUIS) immunoglobulin Subcommittee, and this gave relative values of concentration. As we did not have specific antibodies for each vaccine, exact $\mu \mathrm{g} / \mathrm{ml}$ concentrations could not be obtained, and the amount of one IgG subclass was compared to another. For the meningococcal antibodies, we had IgG1 and IgG3 directed towards the meningococcal antigen, and could therefore quantitate precisely in $\mu \mathrm{g} / \mathrm{ml}$.

\section{PROTEIN A AND PROTEIN G COLUMNS WERE USED TO ISOLATE TOTAL}

\section{BACKGROUND IgG}

When using mass spectrometry to determine glycosylation patterns, it is difficult to distinguish between the IgG2 and the IgG3 subclass, as the trypsin cuts the protein so that the remaining amino acids are identical, and therefore will result in the same mass to charge values on the mass spectrogram. For the recombinant antibodies (paper I), this was not a problem as they were IgG1 and IgG3. For the FNAIT samples (paper III), this was also not a problem as these are IgG1 antibodies. For the vaccine response antibodies (paper II), and especially the pneumococcal vaccine, that produces an IgG2 response, this caused problems. It did not matter for the specific IgG response, as ELISA quantitation studies showed negligible amounts of IgG3 compared to IgG2. It was however a problem for the total background IgG, as we wanted to compared the specific IgG2 vaccine antibodies to the background IgG2 antibodies. This was solved by coupling together protein A (binding IgG1, IgG2 and IgG3) and protein G (binding all four IgG subclasses), and eluting the antibodies from each column. Several test runs were carried out where different amounts of serum samples were injected in to the columns and eluted, and the eluates were quantitated using ELISA methods. In this way, we found the amount that provided an accurate and clean separation of the different subclasses, without overloading the columns so that all of the IgG1, IgG2 and IgG4 antibodies bound to the protein A column, and only IgG3 antibodies were left to the transferred to the protein $G$ column. The columns were then separated, and the antibodies eluted from each column and analyzed using mass spectrometry. 


\section{PATIENT SAMPLING FOR FETAL AND NEONATAL ALLOIMMUNE THROMBOCYTOPENIA (FNAIT)}

Anti-HPA-1A allo-antibodies were collected and diagnosed at three different locations, but the methods were the same and the criteria for selection were the same, hence these results are comparable. To compare the glycosylation pattern with other types of immune responses, such as IgG formed after platelet transfusion or after immunization against HLA in earlier pregnancies as well as autoantibodies from immune thrombocytopenia (ITP) patients. The analysis on the last patient groups were all done at one location, Sanquin in Amsterdam. The spread of these patient groups will provide a good indication of whether the glycosylation patterns observed are only seen in pregnancy, or also in other immune responses.

\section{PURIFICATION OF ANTI-PLATELET ANTIBODIES FROM SERUM}

Early on in the FNAIT studies, the HPA-1A specific allo-antibodies were captured using human platelets ${ }^{110}$. Even though the results were reproducible, the background signals could still be improved. Using plates already coated with GPIIb/IIa antigens to capture the HPA-1A specific allo-antibodies was deemed suitable, and the background signals were eliminated and the results even clearer (paper III). PAK12 from GTI Diagnostics, Waukesha, USA were used. As a negative control, blank wells were used. Formic acid was used to elute the antibodies, followed by drying of the eluates and overnight incubation with trypsin, similar to the methods used for the recombinant antibodies and the vaccine response antibodies (paper I and II). This way of capturing allo-antibodies improved sensitivity, eliminated background and simplified the procedure. 


\section{GENERAL DISCUSSION}

\section{THE IMPORTANCE OF GLYCOSYLATION}

Glycosylation of proteins is the most common covalent modification occurring in living organisms ${ }^{185}$. An enormous variety of glycans is possible, both with regard to the amino acid they are attached to and the composition of the monosaccharides. This biological diversity stems from proteins being primary gene products and the glycans being secondary gene products. Methyl, acetyl or sulfate groups can attach covalently to the glycans, hence chemical diversity is also a factor to be considered. The biological variety makes glycosylation primarily species- and cell-specific ${ }^{186}$. The processing of the glycan moiety is a complex procedure involving numerous enzymes and systems, thus the possibilities for abnormalities and defects increase exponentially. A complete lack of N-glycans is lethal, but even diseases where only a single enzyme is lacking can be very debilitating ${ }^{187}$. Nglycosylation of immunoglobulin $\mathrm{G}$ influence both structure and effector function immensely $^{72,80,188,189}$. Glycosylation is associated with activities as far apart as participation in neurodegenerative diseases such as Parkinson's Disease through sodium channel glycosylation to affecting the organic anion transporting polypeptides that regulate absorption, distribution, metabolism and excretion (ADME) of a variety of drugs and toxins ${ }^{190,191}$. Even the human pathogen Streptococcus pyogenes has understood the importance of glycosylation, as it secrets an enzyme, EndoS, that hydrolyzes the sugar moiety on human IgG and thereby reduces its ability to activate complement and bind to Fc-receptors, thereby improving its own bacterial survival in human blood ${ }^{192,193}$. Glycosylation is therefore of immense importance for immunoglobulins, but can the information obtained from glycosylation profile analysis be used in a safe and efficient way to aid in predicting and manipulating these monosaccharides to aid in diagnosing and treating different immunological conditions, without interfering with other parts of IgG effector functions? When and where are they used and can the designed recombinant IgG antibodies be altered and used without problems?

\section{THERAPY AND DIAGNOSTICS}

Intravenous immunoglobulin (IVIG) has for long been administered as a treatment for various immunological conditions and the anti-inflammatory effect of IVIG is largely attributed to sialic acid ${ }^{55,194-197}$. IgG autoantibodies are substantial contributors to autoimmune diseases, 
meaning that the same class of molecules that promote a disease can also be used to cure it, for instance idiopathic thrombocytopenic purpura, and this is termed the intravenous IgG paradox $^{89}$. The results obtained from studies in mice or other model systems may not always be transferrable to humans, but as IVIG has been used clinically for over 30 years, the results from mice models can be reasonably compared with human studies, This is a great advantage when trying to understand IVIG's mechanisms of action ${ }^{198}$. Several recombinant antibody therapeutics (rMAbs) are on the market today, all of them of the IgG isotype and glycosylation has an enormous impact on their mechanisms of action. When using rMAbs, several results may be sought after; including neutralizing and killing of molecules and cells, inducing apoptosis or acting as an antagonist or agonist of cellular activity, but also delivering molecules ${ }^{199}$. Natural Killer (NK) cells express the receptor Fc $\gamma$ RIIIa, and this receptor is responsible for ADCC activity. The receptor exists in two isoforms, $158 \mathrm{Val}$ and $158 \mathrm{Phe}$, and the 158 Val isoform has higher binding affinity for IgG1, and therefore a higher ADCC activity $^{200,201}$. In accordance with this, the $\alpha$-CD20 chimeric IgG1 Rituxan was found to be more effective in treating follicular non-Hodgkin lymphoma in patients with the 158Val isoform compared to the $158 \mathrm{Phe}$ isoform ${ }^{202}$.

Glycosylation is not only important for allo-immune diseases and the immune response; it can also affect other conditions. The majority of diseases involving glycosylation are hereditary, but a few are acquired. Congenital disorders of glycosylation (CDG) are a group of genetic autosomal recessive diseases involving an abnormal glycosylation of mainly $\mathrm{N}$ - and O-linked oligosaccharides, but also involve other types of glycosylation defects ${ }^{203}$. Abnormalities in glycosylation will have large clinical consequences, involving several organ systems, especially development of certain parts the brain, the nervous system, liver, eye-sight, the immune system as well as parts of the gastrointestinal system ${ }^{187}$.

This abnormal glycosylation is caused by defects in one or more of the 21 enzymes involved in the synthesis of the glycan portion, or the way in which carbohydrates are added to either proteins or lipids ${ }^{187,204}$. CDG is confirmed by measuring transferrin, as transferrin has two sites for N-glycosylation, and healthy controls will usually have sialic acids attached to each site, while CDG type I patients usually have un-sialylated transferrin and type II patients have an altered glycan structure with the N-linked occupied glycosylation sites $^{187}$. The clinical presentation of CDG type II usually includes more severe psychomotor retardation than type I, but usually fewer cases of neurological defects, though mutations often occur amongst glycosyltransferases ${ }^{187,203}$. CDG-1b is a type of CDG with low levels of mannose phosphatase 
isomerase, and is one of few CDG that can be treated, as administration of $1 \mathrm{~g} / \mathrm{kg} / \mathrm{day}$ of mannose is an effective treatment ${ }^{204}$.

Some diseases involving glycosylation are acquired. Chronic alcoholics see an increase in disialylated TRF, a human glycoprotein, whilst the tetra-sialylated TRF decreases and tumorassociated antigens express a high level of carbohydrates that are being investigated for diagnostic value in certain types of cancer ${ }^{205}$. Haptoglobin is an acute-phase protein that often is seen at higher levels in different diseases and also portrays increased levels of fucose as well as changes in sialic acid, which could potential clinical markers ${ }^{206}$. Using HPLC, carbohydrate groups were determined for several diseases, and rheumatoid arthritis and juvenile chronic arthritis patients had mainly a-galactosylated structures, while ankylosing spondylitis and systemic lupus erythematosus patients mainly had di-galactosylated structures, indicating glycosylation alterations triggered by specific diseases ${ }^{207}$. When using electrophoresis analysis as a diagnostic and prognostic test, differences in glycosylation patterns between different autoimmune diseases were found ${ }^{208}$.

In the condition fetal and neonatal alloimmune thrombocytopenia (FNAIT), a lack of fucose was seen in the specific HPA-1A antibodies for most of the volunteers tested, but not in their total IgG (Paper III). This alteration was not seen in patients with refractory thrombocytopenia or idiopathic thrombocytopenic purpura (ITP), even though they too are mediated by antibodies. This skewing of fucosylation has not been observed in other immune responses, and could possibly be due to the specific HPA-1A response, the anti-platelet response or the pregnancy milieu dominated by $\mathrm{TH} 2$, either alone or combined. During pregnancy, a shift occurs where levels of T helper 1 cells (TH1) are down-regulated and therefore also production of for instance IFN- $\gamma$ and IL-2, while T helper 2 cells (TH2) levels are up-regulated and production of cytokines, including IL-4 and IL-10 are increased consequently $^{209}$. When platelets are transfused, anti-HLA class I (Human leukocyte antigen) antibodies may be generated, making future platelet transfusions problematic ${ }^{210}$. In our studies, no significant changes were seen in the fucosylation of these antibodies (paper III).

Levels of galactose change with age and in different diseases ${ }^{64,74-76}$. Patients developing antiHPA-1A allo-antibodies after pregnancies and anti-HLA-antibodies in patients receiving platelet transfusion displayed increased levels of galactose compared to total background IgG, an occurrence not observed previously (paper III). Transport of IgG from mother to child is mainly mediated by the neonatal Fc-receptor FcRn and this receptor also regulates the halflife of $\operatorname{IgG}^{52}$. In mice, the half-life of $\operatorname{IgG}$ is reduced if the amount of galactose is high, which again could affect the IgG transport between mother and child, even though Fc-glycosylation 
not seems to influence the binding to $\mathrm{FcRn}^{211,212}$. As a-fucosylated $\operatorname{IgG}$ is more proinflammatory, the increased level of galactose may counteract the effects of reduced fucose, indicating a tight regulation of the immune response in FNAIT. These increased levels of galactose also predispose the glycan moiety for augmented levels of sialic acid. The patient group in the FNAIT studies was too heterogeneous to correlate glycosylation patterns with disease severity, but is likely that a-fucosylated anti-HPA-1A antibodies increase platelet phagocytosis via increased binding to Fc-receptors, hence screening and monitoring of these antibodies could possibly be used for prevention and diagnosis. There are therefore numerous examples of the influence and involvement of glycosylation, and in all of these, extended knowledge of glycosylation patterns would be beneficial.

\section{ARE THERE COMPREHENSIVE DIFFERENCES IN ANTIBODY GLYCOSYLATION BETWEEN DISEASES, ISOTYPES AND ORIGIN?}

\section{DIFFERENCES IN GLYCOSYLATION BETWEEN IMMUNOGLOBULIN ISOTYPES}

The glycosylation of IgG has been studied extensively over the last years but is not the only immunoglobulin isotype with influence from glycosylation in both structure and function. IgA displays both $\mathrm{N}$ - and O-glycosylation on the Fab and the Fc portion of the molecule ${ }^{213}$. In contrast to IgG, over $90 \%$ of the IgA N-glycans are sialylated and the N-glycosylation sites of IgA are less constricted compared to the more confined IgG N-glycosylation sites. This more spacious arrangement could be the reason for the increased IgA sialylation and also the lack of a-galactosylated IgG often seen in pregnancy ${ }^{214}$. IgE portrays $\mathrm{N}$-glycosylation and this glycosylation seems to affect both the structure and the function of $\operatorname{IgE}$, as removing or increasing sialic acid levels affected binding to anti-IgE monoclonal antibodies. Some carbohydrates strengthened the binding to FceRI and others masked epitope expression ${ }^{215,216}$. IgE is mainly involved in type I hypersensitivity reactions, manifesting itself as allergic reactions or as anaphylactic shock - a life-threatening immune reaction ${ }^{25}$. IgE has also been shown to cause delayed anaphylactic reactions by interacting with carbohydrate moieties in red meat, galactose- $\alpha-1,3$-galactose ${ }^{217}$. IgD seems to have one site for $\mathrm{N}$-glycosylation on each heavy chain and with glycans at both Asn354 and Asn445, MBL binding to Asn354 is not possible because this has restricted accessibility due to the glycans at position Asn $445^{218}$. IgM portrays N-glycosylation, and has three glycosylation sites for complex glycans, and two for oligomannose glycans. It is not possible for $\operatorname{IgM}$ to activate complement via the lectin 
pathway, as once IgM has bound to an antigen, the glycans become unreachable by the IgMantigen complex ${ }^{219}$. Glycosylation can therefore affect all immunoglobulin isotypes, but as IgG is the main antibody involved in recognizing, neutralizing and killing toxic antigens and pathogens, and the current recombinant antibodies on the market for use in therapy are IgG, they have not been studied to the same extent as IgG.

\section{DIFFERENCES IN GLYCOSYLATION OF RECOMBINANT IgG1 AND IgG3 COMPARED TO HUMAN SERUM IgG1 AND IgG3}

Analyzing recombinant $\operatorname{IgG} 1$ and $\operatorname{IgG} 3$ antibodies produced in various cell lines we found that mutations in one or more amino acids did not influence glycosylation pattern much compared to the respective IgG wild type (Paper I). However, the glycosylation pattern did vary considerably between $\operatorname{IgG} 1$ and $\operatorname{IgG} 3$ as the $\operatorname{IgG} 3$ antibodies all were non-fucosylated, whilst the IgG1 antibodies were fucosylated. When analyzing antibodies following immunization with different types of vaccines, the specific antibodies directed towards vaccine antigens did not show this distinction except for the IgG3 produced following immunization with the seasonal influenza vaccine (paper II). There could be several reasons for this. As the non-fucosylated IgG3 was only seen after immunization with the seasonal influenza vaccine, vaccine formulation must be taken into consideration. Two of the vaccines contained adjuvants and the third is a polysaccharide vaccine producing mainly an IgG2 response. The pandemic influenza vaccine contained a squalene adjuvant, an important cholesterol precursor with squalene synthase catalysing its biosynthesis ${ }^{220}$. It has previously been shown that a squalene synthase inhibitor improved $N$-glycosylation in Congenital disorders of glycosylation ${ }^{221,222}$. This could possibly affect the N-glycosylation following vaccination. The meningococcal OMV vaccination also included an adjuvant, $\mathrm{Al}(\mathrm{OH}) 3$, and although this adjuvant does not have contain synthase inhibitors like squalene does, as an adjuvant it could affect the degree of non-fucosylation for IgG3. The third vaccine is a polysaccharide vaccine that produces $\operatorname{IgG} 2$ as the main responding subclass, and as recombinant $\mathrm{IgG} 2$ was not included in the recombinant IgG analysis (paper I) and it showed similar profiles to main responding subclass from the other vaccines (paper II), we can assume that non-fucosylation would not be seen here.

From a transfection point of view, both permanent and transient transfection were used and the different cell lines gave the same result regarding non-fucosylated IgG3, hence transfection in itself, or enzymes within the cells may give the answers to the lack of fucose 
for IgG3. Fucosyltransferases are enzymes responsible for fucose being transferred from donor guanosine-diphosphate fucose to glycoproteins ${ }^{223}$. As our recombinant IgG1 contained fucose, the enzymes required were present, but distinguished between IgG subclass. Structurally, the main difference between IgG1 and IgG3 is the hinge region, with 15 amino acids for IgG1 and 62 amino acids for IgG3 $3^{224,225}$. Analysing chimeric-human NP-antibodies for ADCC activity, IgG3 showed a stronger ADCC activity compared to $\operatorname{IgG} 1^{226}$. ADCC is mainly activated through FcyRIIIa and a 50-fold increase in receptor-binding was seen when fucose was removed, hence the non-fucosylated IgG3 we found (paper I) were consistent with IgG3's stronger ADCC activity ${ }^{80,226}$. Mammalian cell lines used for production of recombinant antibodies possess intrinsic enzyme activity that is responsible for the corefucose $\mathrm{e}^{227}$. In human tissue, fucosylation is usually a result of several different activities and several fucosyltransferases have been cloned ${ }^{228}$.

In a subset of IgG plasma cells there was a difference in interaction with the cell adhesion molecules selectin, as the interaction with E-selectin was strong and P-selectin was weak. This corresponded to increased levels of $\alpha 1,2$-fucosyltransferase-VII messenger RNA and down-regulation of $2 \beta 1-6-N$-glucosaminyltransferase compared to B-cells ${ }^{229}$. Hence differences in fucosyltransferases have been seen between cells and could possibly explain the fucosylation differences between the recombinant IgG compared to the IgG antibodies produced after immunization. Whether cells possess some fucosyltransferases or fucosylases that are more active towards one IgG subclass compared to another is not known, but that could possibly explain the skewing towards non-fucosylation seen in the recombinant IgG3 antibodies. A 50-fold increase in ADCC activity was seen in an $\alpha$-CD20 chimeric IgG1 when produced in rat hybridoma YB2/o cells compared to CHO cells. The expression of FUT8, required for fucosylation, was found to be much higher in $\mathrm{CHO}$ cells compared to $\mathrm{YB} 2 / \mathrm{O}$ cells, resulting in a highly fucosylated $\alpha$-CD20 chimeric IgG1 when produced in CHO cells, leading to lower ADCC activity ${ }^{31}$.

The sera from the FNAIT patients (paper III) generally showed a lack of fucose in HPA-1A specific IgG1 antibodies, a phenomenon that has not previously been described for this subclass. As the total IgG1 did not show this trend, it seems to be related to the pregnancy or possibly to specific platelet antigens. Fc-glycosylation can be affected by various B-cell stimuli, as all-trans retinoic acid decreases galactose and sialic acid, while Fc-galactosylation has been increased and bisecting GlcNAc has been decreased by the TLR9 ligand CpG oligodeoxynucleotide and IL-21 and could hence also be an explanation ${ }^{230}$. This skewing 
towards non-fucosylation has not been seen in other conditions, but that does not dismiss its existence.

\section{GLYCOSYLATION INDUCED AFTER IMMUNIZATION - HUMANS VS. MICE}

The IgG antibodies produced after immunization showed no distinct difference in level of fucosylation, apart from the IgG3 antibodies produced after immunization with the seasonal influenza, while the recombinant antibodies were non-fucosylated for IgG3. The carbohydrate distribution of the naturally occurring antibodies in the body show that sialic acid is found on $1-3 \%$ of total IgG antibodies, core-fucose in around $70 \%$ and galactose in around $85 \%$ of total human serum $\operatorname{IgG}^{54,73}$. Experiments in $\mathrm{IgG}$ mice have indicated that especially sialic acid is increasing very late in the immune response, compatible with the notion that IgG act antiinflammatory when the acute risk phase during infection is over. In an experiment where mice were pre-sensitized with sheep IgG and challenged with a nephrotoxic serum, NTS, sialylation for total $\operatorname{IgG}$ was reduced by $40 \%$ and for specific anti-sheep $\operatorname{IgG}$ by $50-60 \%{ }^{74,74}$. This lead to the notion that an IgG immune response has two phases, one pro-inflammatory phase that is shown in the acute phase during infection and possibly also right after a primary vaccination. This pro-inflammatory IgG activity could be caused by a lack of core-fucose, favoring ADCC activity and phagocytosis ${ }^{89,89,197,197,231,231}$. Mice that were immunized with bovine serum albumin (BSA) resulted in anti-BSA titres with reduced levels of galactosylation, while increased fucosylation were seen after each ovalbumin immunizations $232,232,233,233$. The experiments this hypothesis is based on mainly are carried out in mice and not in humans; hence results from human immunizations are needed to clarify if a two-phase biological activity could be observed following immunization in humans as well.

When humans were vaccinated, we did not observe a striking lack of IgG core-fucose shortly after immunization compared to later time points (paper II). We also did not observe a striking increase in terminal sialic acid late in the response for any of the vaccines used. Human IgG1 responses after influenza and tetanus vaccination have recently been reported, and the same lack of non-fucose in the beginning and increased sialic acid at later stages following vaccination were seen, but instead increased galactose and sialic acid shortly after vaccination was seen. When two doses of the same vaccine were administered and serum was collected 3-5 weeks after each dose, the levels of sialic acid did not change with time ${ }^{140,140}$. We see the same increase in sialic acid shortly after vaccination, but at later time points, the values vary from stable (pneumococcal IgG2), decreasing to pre-vaccination levels (seasonal influenza IgG1) or increasing with each booster dose (meningococcal IgG1) (paper II). We do 
not disagree that IgG can have two-phases, a pro-inflammatory and an anti-inflammatory, but the basis of inducing and balancing these striking opposite IgGs may not be as straightforward for humans as it seems for mice. Even though the anti-inflammatory activity of sialic acid rich human IgG seems well documented, glycosylation may not be solely responsible for these two IgG variants. It has recently been shown that immune complexes containing galactoserich mouse IgG1 asserted anti-inflammatory properties by supporting the association of Fc $\gamma$ RIIb with dectin-1 $19,79,140,234,234$.

\section{MANIPULATION OF GLYCOSYLATION}

$\alpha$-L-fucosidase is an enzyme responsible for hydrolysis of fucose from glycoproteins, while fucosyltransferase is necessary for the addition of fucose to a carbohydrate moiety ${ }^{235,236}$. These types of enzymes might not be easily manipulated, but $\alpha$-1,6-fucosyltransferase (FUT8) is an enzyme that has been removed successfully to produce FUT8 knockout mice, producing antibodies without fucose for effector function analysis, but removing FUT8 also led to down-regulation of growth factor receptors in these mice ${ }^{237}$. A-fucosylated antibodies results in a drastically increased ADCC, making them exceptionally pro-inflammatory ${ }^{80}$. When producing antibodies for use in therapy, a non-fucosylated structure is therefore desirable for protection, and different approaches can be used to achieve this. The first glycoengineered antibody to reach the market was mogamulizumab, marketed as Poteligeo ${ }^{(}$in Japan in 2012. This antibody is produced in FUT8 knock out CHO cells and therefore has enhanced ADCC activity by its lack of fucose ${ }^{238}$. Manipulating the N-glycosylation pathway in non-mammalian cells in to a non-fucosylation mammalian type is one way, inactivating the fucosylation pathway or interfering with enzymes or chemical synthesis to remove fucose are other methods ${ }^{227}$. When using Chinese Hamster Ovary (CHO) cells, the enzyme GDP-6deoxy-D-lyxo-4-hexulose reductase can disturb the fucosylation pathway and the produced antibody will be without fucose ${ }^{239}$. The removal of fucose caused in increase in ADCC activity not only for intact IgG, but also for Fc-fusion molecules, such as single-chain Fv connected to $\mathrm{Fc}(\mathrm{scFv}-\mathrm{Fc})^{240}$. An engineered antibody produced in FUT8 knock out CHO cells consisting of the $\mathrm{CH} 1$ and the hinge region from IgG1 and the Fc portion from IgG3, with the $\mathrm{COOH}$-terminal $\mathrm{CH} 3$ domain substituted with $\mathrm{IgG} 1$ to enable protein A binding, provided increased cytotoxicity through both ADCML and ADCC ${ }^{241}$. 
Sialidase is an enzyme that hydrolyses sialic acid in glycoproteins and glycolipids ${ }^{242}$. Sialyltransferase on the other hand, can increase the expression of $\alpha-2,6$ sialic acid. cDNA of STA6Gal I ( $\beta$-galactosyl- $\alpha$-2,6 sialyltransferase) was cloned from $\mathrm{CHO}$ cells (even though not thought to be expressed endogenously in this cell line), expressed in E.coli and applied to a recombinant antibody. This lead to $70 \%$ of the N-glycosylation being $\alpha-2,6$ sialylated, compared to no sialylation in the non-transfected line, easing production of sialic acid rich recombinant antibodies for therapy ${ }^{243}$.

These modifications and manipulations must though be exercised with care to avoid uncontrollable immunogenicity. The basis of inducing and balancing pro- and an antiinflammatory IgG may be more complex than just glycosylation patterns. The role of sialic acid regarding the anti-inflammatory activity of human IgG seems well documented, but the other monosaccharides may also play a role, as shown in a resent paper where immune complexes with galactose-rich mouse IgG1 asserted anti-inflammatory properties by supporting the association of FcyRIIB with dectin- $1^{79,234}$. This complexity has further been shown in mice infected with the yeast Cryptococcus neoformans. When monoclonal IgG1 antibodies were administered, the result was acute lethal toxicity and cardiovascular collapse due to an increase in platelet activating factor, PAF. This was caused by a complex between C. neoformans glucuronoxylomannan and $\mathrm{IgG1}$, though not seen with administration of $\operatorname{IgG} 3^{244}$. On the other hand, pro-inflammatory responses were diminished and granulocyte production increased to clear the fungal infection when mice received IgG1 before a $C$. neoformans infection ${ }^{245}$. Insufficient amount of antibodies may not cause the desired response, but excessive amounts may be counterproductive. Very high concentrations of antibodies on the capsule surface showed interference with oxidative killing of $C$. neoformans ${ }^{246}$. The same antibody may exhibit both pro- and anti-inflammatory properties depending upon the type of microbe, the state of infection and the amount of antibody. All these factors contribute to the existence of a more complex picture than one where glycosylation is the only foundation for the two-phase IgG. The majority of successful vaccines today mediate an effectiveness that is proportional to the amount of antibodies they induce, but these findings could indicate a possibility for vaccine failure by inducing a too high antibody response ${ }^{247}$. Three different monoclonal antibodies against Streptococcus pneumoniae were analyzed in vitro and two of them were found to promote killing with different requirements regarding presence of components and host FcR. In vivo, on the other hand, all three antibodies promoted killing, and with different requirements regarding host receptors and components ${ }^{248}$. 
Inhibiting or removing transferases can be used to reduce expression of certain sugar molecules. Mice lacking ST6Gal sialyltransferase, an enzyme responsible for the production of a trisaccharide that is the ligand for the lectin CD22, a glycoprotein involved in activation of B lymphocytes, were found to have reduced immune function as antibody production was diminished by reduced B- lymphocyte activation ${ }^{249}$. Fluorinated analogues of fucose and sialic acid can cross the cell membrane to enter cells, metabolise to donors for inhibitors of these monosaccharides and prevent their expression on the surface of the cell. Reduced sialic acid and fucose expression on myeloid cells can prevent selectin binding and weaken leukocyte rolling ${ }^{250}$. This does require very accurate engineering to make sure that the analogues are taken up in only the specific target cells to avoid a defective immune system. Mice deficient in several types of fucosyltransferases involved in functionalization of the protective responses of selectin ligands in chronic inflammation and bacterial infections turned out to die quicker than wild type mice when infected with Mycobacterium tuberculosis ${ }^{251}$.

Another way of altering the carbohydrate composition is by endoglycosidases. Streptococcus pyogenes is a pathogen in humans that cause infection and autoimmune diseases and it secrets an enzyme, EndoS that hydrolyzes the sugar moiety on human IgG. EndoS hydrolysis may affect several IgG effector functions, such as no phagocytosis, no $\mathrm{C} 3 \mathrm{a}$ deposition and hence

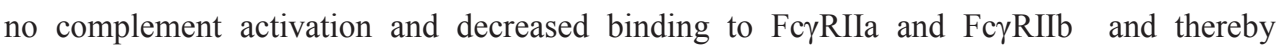
improving its own bacterial survival in human blood ${ }^{192,193,252}$. In a model of antibody-induced thrombocytopenia (ITP), platelet specific 6A6 antibodies were investigated, to see whether EndoS treatment would give different results in different IgG subclasses. 6A6-IgG1, 6A6$\operatorname{IgG} 2 \mathrm{a}$ and $6 \mathrm{~A} 6-\mathrm{IgG} 2 \mathrm{~b}$ were tested, as IgG3 have been found not to have any activity in this model. Whereas IgG1 and IgG2b showed a marked reduction in their ability to clear thrombocytes, IgG2a did not, implying that the remainder of the sugar moiety after EndoS treatment, one GlcNAc and possibly one fucose, was enough for this particular subclass to display functional activity ${ }^{253}$. All four human IgG subclasses were tested for binding to different Fc $\gamma$ Rs before and after treatment with EndoS. IgG1 bound to Fc $\gamma$ RIIa and Fc $\gamma$ RIIb, but following EndoS treatment this binding had almost disappeared. This was not the case for

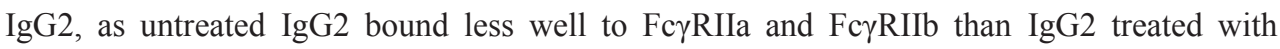
EndoS ${ }^{254}$. This shows that EndoS might not be suitable as a general medicinal treatment for infections, as all IgG subclasses are not affected. The mouse IgG subclasses 1, 2a, $2 \mathrm{~b}$ and 3 were tested against a lactate dehydrogenase-elevating virus (LDV), and IgG2a proved the strongest response, by delaying onset and progression more than the other 3 subclasses $^{255}$. A 
similar result had previously been seen for panel of virus, including mouse hepatitis virus (MHV, A59 strain), pneumonia virus of mice (PVM, strain 15) and Mengo virus (C50L strain $)^{256}$. As the entire panel of IgG subclasses are not incapacitated by EndoS, the likelihood of opportunistic infections could be reduced if EndoS was used as an immunosuppressant compared to more traditional treatments. On the other hand, if EndoS was to be used as treatment of autoimmune conditions, the lack of response from some subclasses could also lead to a failed therapy as not all subclasses would respond ${ }^{253}$.

\section{DIFFERENCES IN GLYCOSYLATION BETWEEN CELL TYPES}

The recombinant antibodies on the market today are produced in either Chinese hamster ovary cells or one of two mouse cell lines, NS-0 or Sp2/0 ${ }^{199}$. CHO cells and human cells have a very similar way of making glycoforms, but there are some differences. A main difference is that $\mathrm{CHO}$ cells do not possess the enzyme $\mathrm{N}$-acetylglucosaminyltransferase-III(GnTIII) that is needed to produce bisecting GlcNAc ${ }^{257,258}$. As the levels of bisecting GlcNAc in human IgG generally do not exceed $10 \%$ of total $\mathrm{IgG}$, it might not be expected to have a great effect on bioactivity $^{259}$. However, when the levels of bisecting GlcNAc in a chimeric mouse/human $\alpha$ CD20 IgG1 antibody reached 48-71\% of total IgG through co-expression of GnTIII in CHO cells, this caused an increase in ADCC activity. More specifically, a 10-20 fold lowering of the concentration of antibodies required for ADCC through their higher affinity for Fc $\gamma$ RIII were observed, as the effect was blocked by an $\alpha$-Fc $\gamma$ RIII antibody. The $\alpha$-CD20 antibody used here was licenced for treatment of non-Hodgkin's lymphoma, meaning a lower dose could be administered without a reduction in effect ${ }^{188}$. Rituximab and trastuzumab are two recombinant monoclonal IgG1 antibodies used therapeutically for the treatment of NonHodgkin's lymphoma and rheumatoid arthritis, and breast cancer, respectively. Addition of a bisecting GlcNAc and removal of a terminal $\beta 1,4$-linked galactose were the changes made to alter their carbohydrate composition, and it was carried out by a soluble recombinant rat $\beta$ 1,4- $N$-acetylglucosaminyltransferase III (rGnTIII), produced in baculovirus-infected insect cells. The addition of bisecting GlcNAc caused a 10-fold increase in ADCC, while a lack of galactose caused a 3 -fold decrease in $\mathrm{ADCML}^{260}$.

Another major difference is sialic acid. In human $\operatorname{IgG}, \alpha-2,6$-linked sialic acid is seen, while CHO cells produce $\alpha-2,3$-linked sialic acid ${ }^{261}$. This does also represent a large percentage of total $\operatorname{IgG}$, as human IgG usually have less than 1-3\% sialic acid ${ }^{54}$. Sialic acid is however important for an antibody's anti-inflammatory properties, and this needs to be $\alpha-2,6$-linked 
sialic acid, so a recombinant IgG used as a therapeutic agent produced in CHO cells may therefore not provide the same anti-inflammatory properties as human IgG would ${ }^{54,74}$.

The rMAB cetuximab is produced in NS-0 cells and has low levels of sialic acid and terminal galactose found in the Fab region, termed the gal epitope ${ }^{262}$. As it is common to possess antigal antibodies, this should not cause huge disturbance in the body, but hypersensitivity and IgE antibodies against cetuximab have been observed, though the anti-gal epitope antibodies were present in the serum before therapy started for the majority of patients ${ }^{263,264}$, and as a result of this, NS-0 cells may not be considered an appropriate cell line for rMAB production. $\mathrm{CHO}$ cells do not seem to have this problem with gal epitope expression; though a single report has shown that $20 \%$ of human CD4 produced in CHO cells carried the gal epitope ${ }^{265}$. By the addition of different enzymes, glycosylation can be altered by adding or removing a specific carbohydrate, such as FUT8 ( $\alpha 1,6$-fucosyltransferase, an enzyme needed to produce fucose) knock-out mice or by using specific conditions for the cells to grow in ${ }^{266}$. Mousehuman chimeric IgG1 antibodies expressed in Chinese Hamster Ovary (CHO) cells where defects have been inserted in to the biosynthesis of the carbohydrates were grown to determine whether changes in the glycosylation would cause a change in functional properties $^{267}$. The cell lines used were Lec-1 CHO (high mannose intermediate attached), Lec$2 \mathrm{CHO}$ (sialic acid attached) and Lec-8 CHO (galactose attached). The antibodies produced in Lec-1 cells had difficulties binding to $\mathrm{C} 1 \mathrm{q}$ and activating complement, had a reduced half-life, and showed a lowered affinity for FcyRI receptors. Antibodies from both Lec-2 and Lec-8, showed no difference in affinity for Fc $\gamma \mathrm{RI}$ receptors, in vivo half-life, ability to activate complement lysis or complement activation measured by ELISA ${ }^{267,268}$.

A monoclonal human IgG1, Campath-1H, was stripped of its carbohydrate moiety, leading to abolishment of ADCC and complement lysis activity. When removing only sialic acid, no change in IgG activity was seen.By removal of sialic acid and most of the galactose, a reduction in complement lysis activity was observed, but ADCC was not affected ${ }^{77}$. Point mutations in IgG where different amino acids were exchanged for alanine caused an increase in galactosylation and sialylation compared to wild type $\operatorname{IgG}^{154}$. Sodium butyrate can affect gene expression, and when added to the cell culture of CHO-K1 cells, an increase in the amount of human chimeric antibodies was seen, while the glycosylation profile remained the same. High concentrations of sodium butyrate can give different apoptotic responses in different cell lines, as $2 \mathrm{mM}$ butyrate killed NS-0 cells within 24 hours, whilst CHO cells could survive for at least a month longer at the same concentration, as long as fresh medium was supplied every two days ${ }^{269}$. 
Tetracycline in culture medium is another way of engineering glycosylation pattern, as an increased concentration of tetracycline can cause over-expression of glycosyltransferases, leading to growth inhibition and cell toxicity. The right amount of tetracycline can however increase the bisecting GlcNAc glycoforms, thought to influence ADCC ${ }^{270}$.

To conclude; increased expression of GlcNAc and removal of fucose to lead to an increase in ADCC activity, while an increase in sialic acid enhances an anti-inflammatory effect, a function that has also recently been seen with galactose ${ }^{74,79,80,91,188,260}$. Increased knowledge about glycosylation patterns and its consequences for the immune response, combined with the ability to alter the carbohydrate composition can be used to control the therapeutic use of these antibodies in a safe manner. 


\section{REFERENCES}

\section{Reference List}

1. Arnold, J. N.; Wormald, M. R.; Sim, R. B.; Rudd, P. M.; Dwek, R. A. The impact of glycosylation on the biological function and structure of human immunoglobulins. Annu. Rev Immunol 2007, 25, 21-50.

2. Jhunjhunwala, S.; van Zelm, M. C.; Peak, M. M.; Cutchin, S.; Riblet, R.; van Dongen, J. J.; Grosveld, F. G.; Knoch, T. A.; Murre, C. The 3D structure of the immunoglobulin heavy-chain locus: implications for long-range genomic interactions. Cell 2008, 133 (2), 265-279.

3. Hopper, J. E.; Cera, L. The structure of human immunoglobulins. Ann. Clin. Lab Sci. 1978, 8 (3), 201-208.

4. Braden, B. C.; Goldman, E. R.; Mariuzza, R. A.; Poljak, R. J. Anatomy of an antibody molecule: structure, kinetics, thermodynamics and mutational studies of the antilysozyme antibody D1.3. Immunol. Rev. 1998, 163, 45-57.

5. Williamson, A. R. The biological origin of antibody diversity. Annu. Rev. Biochem. 1976, 45, 467-500.

6. Schroeder, H. W., Jr.; Cavacini, L. Structure and function of immunoglobulins. $J$. Allergy Clin. Immunol. 2010, 125 (2 Suppl 2), S41-S52.

7. Wesolowski, J.; Alzogaray, V.; Reyelt, J.; Unger, M.; Juarez, K.; Urrutia, M.; Cauerhff, A.; Danquah, W.; Rissiek, B.; Scheuplein, F.; Schwarz, N.; Adriouch, S.; Boyer, O.; Seman, M.; Licea, A.; Serreze, D. V.; Goldbaum, F. A.; Haag, F.; Koch-Nolte, F. Single domain antibodies: promising experimental and therapeutic tools in infection and immunity. Med. Microbiol. Immunol. 2009, 198 (3), 157-174.

8. Baral, T. N.; Chao, S. Y.; Li, S.; Tanha, J.; Arbabi-Ghahroudi, M.; Zhang, J.; Wang, S. Crystal structure of a human single domain antibody dimer formed through $\mathrm{V}(\mathrm{H})-\mathrm{V}(\mathrm{H})$ non-covalent interactions. PLoS. One. 2012, 7 (1), e30149.

9. Joosten, V.; Lokman, C.; Van Den Hondel, C. A.; Punt, P. J. The production of antibody fragments and antibody fusion proteins by yeasts and filamentous fungi. Microb. Cell Fact. 2003, 2 (1), 1.

10. Liu, H.; May, K. Disulfide bond structures of IgG molecules: structural variations, chemical modifications and possible impacts to stability and biological function. MAbs. 2012, 4 (1), 17-23.

11. Aase, A.; Bjune, G.; Hoiby, E. A.; Rosenqvist, E.; Pedersen, A. K.; Michaelsen, T. E. Comparison among opsonic activity, antimeningococcal immunoglobulin $\mathrm{G}$ response, and serum bactericidal activity against meningococci in sera from vaccinees after immunization with a serogroup B outer membrane vesicle vaccine. Infect. Immun. 1995, 63 (9), 3531-3536. 
12. Palmeira, P.; Quinello, C.; Silveira-Lessa, A. L.; Zago, C. A.; Carneiro-Sampaio, M. IgG placental transfer in healthy and pathological pregnancies. Clin. Dev. Immunol. 2012, 2012, 985646.

13. Dullaers, M.; De, B. R.; Ramadani, F.; Gould, H. J.; Gevaert, P.; Lambrecht, B. N. The who, where, and when of IgE in allergic airway disease. J. Allergy Clin. Immunol. 2012, 129 (3), 635-645.

14. Stapleton, N. M.; Andersen, J. T.; Stemerding, A. M.; Bjarnarson, S. P.; Verheul, R. C.; Gerritsen, J.; Zhao, Y.; Kleijer, M.; Sandlie, I.; de, H. M.; Jonsdottir, I.; van der Schoot, C. E.; Vidarsson, G. Competition for FcRn-mediated transport gives rise to short half-life of human IgG3 and offers therapeutic potential. Nat. Commun. 2011, 2, 599.

15. Duarte-Rey, C.; Bogdanos, D. P.; Leung, P. S. C.; Anaya, J. M.; Gershwin, M. E. IgM predominance in autoimmune disease: Genetics and gender. Autoimmunity Reviews 2012, 11 (6ГÇô7), A404-A412.

16. Boes, M.; Prodeus, A. P.; Schmidt, T.; Carroll, M. C.; Chen, J. A critical role of natural immunoglobulin $\mathrm{M}$ in immediate defense against systemic bacterial infection. J. Exp. Med. 1998, 188 (12), 2381-2386.

17. Ochsenbein, A. F.; Fehr, T.; Lutz, C.; Suter, M.; Brombacher, F.; Hengartner, H.; Zinkernagel, R. M. Control of early viral and bacterial distribution and disease by natural antibodies. Science 1999, 286 (5447), 2156-2159.

18. Finkelman, F. D.; van Boxel, J. A.; Asofsky, R.; Paul, W. E. Cell membrane IgD: demonstration of IgD on human lymphocytes by enzyme-catalyzed iodination and comparison with cell surface Ig of mouse, guinea pig, and rabbit. $J$. Immunol. 1976, 116 (4), 1173-1181.

19. ROWE, D. S.; FAHEY, J. L. A NEW CLASS OF HUMAN IMMUNOGLOBULINS. II. NORMAL SERUM IGD. J. Exp. Med. 1965, 121, 185-199.

20. Chen, K.; Cerutti, A. The function and regulation of immunoglobulin D. Curr. Opin. Immunol. 2011, 23 (3), 345-352.

21. Macpherson, A. J.; McCoy, K. D.; Johansen, F. E.; Brandtzaeg, P. The immune geography of IgA induction and function. Mucosal. Immunol. 2008, 1 (1), 11 22.

22. Conley, M. E.; Delacroix, D. L. Intravascular and mucosal immunoglobulin A: two separate but related systems of immune defense? Ann. Intern. Med. 1987, 106 (6), 892-899.

23. Mestecky, J.; Russell, M. W.; Elson, C. O. Intestinal IgA: novel views on its function in the defence of the largest mucosal surface. Gut 1999, 44 (1), 2-5.

24. Cerutti, A.; Rescigno, M. The biology of intestinal immunoglobulin A responses. Immunity. 2008, 28 (6), 740-750. 
25. Potaczek, D. P.; Kabesch, M. Current concepts of IgE regulation and impact of genetic determinants. Clin. Exp. Allergy 2012, 42 (6), 852-871.

26. Hellman, L. Regulation of IgE homeostasis, and the identification of potential targets for therapeutic intervention. Biomed. Pharmacother. 2007, 61 (1), 34-49.

27. Lefranc, M. P.; Lefranc, G. Human Gm, Km, and Am allotypes and their molecular characterization: a remarkable demonstration of polymorphism. Methods Mol Biol 2012, 882, 635-680.

28. Jefferis, R.; Lefranc, M. P. Human immunoglobulin allotypes: possible implications for immunogenicity. MAbs. 2009, 1 (4), 332-338.

29. Dugoujon, J. M.; Hazout, S.; Loirat, F.; Mourrieras, B.; Crouau-Roy, B.; SanchezMazas, A. GM haplotype diversity of 82 populations over the world suggests a centrifugal model of human migrations. Am. J. Phys. Anthropol. 2004, 125 (2), 175-192.

30. Oxelius, V. A.; Aurivillius, M.; Carlsson, A. M.; Musil, K. Serum Gm allotype development during childhood. Scand. J. Immunol. 1999, 50 (4), 440-446.

31. Shinkawa, T.; Nakamura, K.; Yamane, N.; Shoji-Hosaka, E.; Kanda, Y.; Sakurada, M.; Uchida, K.; Anazawa, H.; Satoh, M.; Yamasaki, M.; Hanai, N.; Shitara, K. The absence of fucose but not the presence of galactose or bisecting Nacetylglucosamine of human IgG1 complex-type oligosaccharides shows the critical role of enhancing antibody-dependent cellular cytotoxicity. $J$ Biol Chem 2003, 278 (5), 3466-3473.

32. Vivier, E.; Ugolini, S.; Blaise, D.; Chabannon, C.; Brossay, L. Targeting natural killer cells and natural killer T cells in cancer. Nat. Rev. Immunol. 2012, 12 (4), 239252.

33. Vivier, E.; Raulet, D. H.; Moretta, A.; Caligiuri, M. A.; Zitvogel, L.; Lanier, L. L.; Yokoyama, W. M.; Ugolini, S. Innate or adaptive immunity? The example of natural killer cells. Science 2011, 331 (6013), 44-49.

34. Orange, J. S.; Ballas, Z. K. Natural killer cells in human health and disease. Clin Immunol 2006, 118 (1), 1-10.

35. Caligiuri, M. A. Human natural killer cells. Blood 2008, 112 (3), 461-469.

36. Leibson, P. J. Signal transduction during natural killer cell activation: inside the mind of a killer. Immunity. 1997, 6 (6), 655-661.

37. Cooley, S.; Burns, L. J.; Repka, T.; Miller, J. S. Natural killer cell cytotoxicity of breast cancer targets is enhanced by two distinct mechanisms of antibodydependent cellular cytotoxicity against LFA-3 and HER2/neu. Exp. Hematol. 1999, 27 (10), 1533-1541.

38. Michaelsen, T. E.; Thommesen, J. E.; Ihle, O.; Gregers, T. F.; Sandin, R. H.; Brekke, O. H.; Sandlie, I. A mutant human IgG molecule with only one C1q binding 
site can activate complement and induce lysis of target cells. Eur. J. Immunol. 2006, 36 (1), 129-138.

39. Michaelsen, T. E.; Aase, A.; Norderhaug, L.; Sandlie, I. Antibody dependent cellmediated cytotoxicity induced by chimeric mouse-human IgG subclasses and IgG3 antibodies with altered hinge region. Mol. Immunol. 1992, 29 (3), 319326.

40. Michaelsen, T. E.; Aase, A.; Westby, C.; Sandlie, I. Enhancement of complement activation and cytolysis of human IgG3 by deletion of hinge exons. Scand. J. Immunol. 1990, 32 (5), 517-528.

41. Aase, A.; Hoiby, E. A.; Michaelsen, T. E. Opsonophagocytic and bactericidal activity mediated by purified IgG subclass antibodies after vaccination with the Norwegian group B meningococcal vaccine. Scand. J. Immunol. 1998, 47 (4), 388-396.

42. Romero-Steiner, S.; Frasch, C. E.; Carlone, G.; Fleck, R. A.; Goldblatt, D.; Nahm, M. $\mathrm{H}$. Use of opsonophagocytosis for serological evaluation of pneumococcal vaccines. Clin. Vaccine Immunol. 2006, 13 (2), 165-169.

43. Granoff, D. M. Relative importance of complement-mediated bactericidal and opsonic activity for protection against meningococcal disease. Vaccine 2009, 27 Suppl 2, B117-B125.

44. MUSCHEL, L. H. Serum bactericidal actions. Ann. N. Y. Acad. Sci. 1960, 88, $1265-$ 1272 .

45. Rosenqvist, E.; Hoiby, E. A.; Wedege, E.; Bryn, K.; Kolberg, J.; Klem, A.; Ronnild, E.; Bjune, G.; Nokleby, H. Human antibody responses to meningococcal outer membrane antigens after three doses of the Norwegian group B meningococcal vaccine. Infect. Immun. 1995, 63 (12), 4642-4652.

46. Nimmerjahn, F.; Ravetch, J. V. Fc + , Receptors: Old Friends and New Family Members. Immunity 2006, 24 (1), 19-28.

47. Nimmerjahn, F.; Ravetch, J. V. Fcgamma receptors as regulators of immune responses. Nat Rev Immunol 2008, 8 (1), 34-47.

48. Nimmerjahn, F.; Ravetch, J. V. Divergent immunoglobulin g subclass activity through selective Fc receptor binding. Science 2005, 310 (5753), 1510-1512.

49. Brambell, F. W. The transmission of immune globulins from the mother to the foetal and newborn young. Proc. Nutr. Soc. 1969, 28 (1), 35-41.

50. Rath, T.; Kuo, T. T.; Baker, K.; Qiao, S. W.; Kobayashi, K.; Yoshida, M.; Roopenian, D.; Fiebiger, E.; Lencer, W. I.; Blumberg, R. S. The Immunologic Functions of the Neonatal Fc Receptor for IgG. J. Clin. Immunol. 2012.

51. Huber, A. H.; Kelley, R. F.; Gastinel, L. N.; Bjorkman, P. J. Crystallization and stoichiometry of binding of a complex between a rat intestinal $\mathrm{Fc}$ receptor and Fc. J. Mol. Biol. 1993, 230 (3), 1077-1083. 
52. Roopenian, D. C.; Akilesh, S. FcRn: the neonatal Fc receptor comes of age. Nat Rev Immunol 2007, 7 (9), 715-725.

53. Bayry, J.; Bansal, K.; Kazatchkine, M. D.; Kaveri, S. V. DC-SIGN and alpha2,6sialylated IgG Fc interaction is dispensable for the anti-inflammatory activity of IVIg on human dendritic cells. Proc Natl. Acad. Sci U S A 2009, 106 (9), E24.

54. Anthony, R. M.; Wermeling, F.; Karlsson, M. C.; Ravetch, J. V. Identification of a receptor required for the anti-inflammatory activity of IVIG. Proc. Natl. Acad. Sci. U. S. A 2008, 105 (50), 19571-19578.

55. Anthony, R. M.; Nimmerjahn, F.; Ashline, D. J.; Reinhold, V. N.; Paulson, J. C.; Ravetch, J. V. Recapitulation of IVIG anti-inflammatory activity with a recombinant IgG Fc. Science 2008, 320 (5874), 373-376.

56. Neill, D. R.; Wong, S. H.; Bellosi, A.; Flynn, R. J.; Daly, M.; Langford, T. K.; Bucks, C.; Kane, C. M.; Fallon, P. G.; Pannell, R.; Jolin, H. E.; McKenzie, A. N. Nuocytes represent a new innate effector leukocyte that mediates type-2 immunity. Nature 2010, 464 (7293), 1367-1370.

57. Anthony, R. M.; Wermeling, F.; Ravetch, J. V. Novel roles for the IgG Fc glycan. Ann N Y Acad. Sci 2012, 1253, 170-180.

58. Carroll, M. C.; Isenman, D. E. Regulation of humoral immunity by complement. Immunity. 2012, 37 (2), 199-207.

59. Chen, M.; Daha, M. R.; Kallenberg, C. G. M. The complement system in systemic autoimmune disease. Journal of Autoimmunity 2010, 34 (3), J276-J286.

60. Ricklin, D.; Hajishengallis, G.; Yang, K.; Lambris, J. D. Complement: a key system for immune surveillance and homeostasis. Nat. Immunol. 2010, 11 (9), 785 797.

61. Ricklin, D. Manipulating the mediator: Modulation of the alternative complement pathway $\mathrm{C} 3$ convertase in health, disease and therapy. Immunobiology 2012, $217(11), 1057-1066$.

62. Eklund, E. A.; Freeze, H. H. Essentials of glycosylation. Semin. Pediatr Neurol 2005, $12(3), 134-143$.

63. Jaeken, J.; Carchon, H. Glycosylation: General Overview. In Encyclopedia of Neuroscience, Editor-in-Chief:-á-áLarry, R. S., Ed.; Academic Press: Oxford, 2009; pp 935-942.

64. Wuhrer, M.; Stam, J. C.; van de Geijn, F. E.; Koeleman, C. A.; Verrips, C. T.; Dolhain, R. J.; Hokke, C. H.; Deelder, A. M. Glycosylation profiling of immunoglobulin G (IgG) subclasses from human serum. Proteomics. 2007, 7 (22), 4070-4081. 
65. Andersen, J. T.; Sandlie, I. The versatile MHC class I-related FcRn protects IgG and albumin from degradation: implications for development of new diagnostics and therapeutics. Drug Metab Pharmacokinet. 2009, 24 (4), 318-332.

66. Wormald, M. R.; Rudd, P. M.; Harvey, D. J.; Chang, S. C.; Scragg, I. G.; Dwek, R. A. Variations in oligosaccharide-protein interactions in immunoglobulin $\mathrm{G}$ determine the site-specific glycosylation profiles and modulate the dynamic motion of the Fc oligosaccharides. Biochemistry (Mosc). 1997, 36 (6), 13701380 .

67. Mimura, Y.; Ashton, P. R.; Takahashi, N.; Harvey, D. J.; Jefferis, R. Contrasting glycosylation profiles between Fab and Fc of a human IgG protein studied by electrospray ionization mass spectrometry. J. Immunol. Methods 2007, 326 (12), 116-126.

68. Rich, J. R.; Withers, S. G. Emerging methods for the production of homogeneous human glycoproteins. Nat. Chem. Biol. 2009, 5 (4), 206-215.

69. Stanley, P.; Schachter, H.; Taniguchi, N. N-Glycans. 2009.

70. Roth, J. Protein N-glycosylation along the secretory pathway: relationship to organelle topography and function, protein quality control, and cell interactions. Chem Rev 2002, 102 (2), 285-303.

71. Coloma, M. J.; Clift, A.; Wims, L.; Morrison, S. L. The role of carbohydrate in the assembly and function of polymeric IgG. Mol Immunol 2000, 37 (18), 10811090 .

72. Raju, T. S. Terminal sugars of Fc glycans influence antibody effector functions of IgGs. Curr Opin. Immunol 2008, 20 (4), 471-478.

73. Butler, M.; Quelhas, D.; Critchley, A. J.; Carchon, H.; Hebestreit, H. F.; Hibbert, R. G.; Vilarinho, L.; Teles, E.; Matthijs, G.; Schollen, E.; Argibay, P.; Harvey, D. J.; Dwek, R. A.; Jaeken, J.; Rudd, P. M. Detailed glycan analysis of serum glycoproteins of patients with congenital disorders of glycosylation indicates the specific defective glycan processing step and provides an insight into pathogenesis. Glycobiology 2003, 13 (9), 601-622.

74. Kaneko, Y.; Nimmerjahn, F.; Ravetch, J. V. Anti-inflammatory activity of immunoglobulin G resulting from Fc sialylation. Science 2006, 313 (5787), 670-673.

75. Matsumoto, A.; Shikata, K.; Takeuchi, F.; Kojima, N.; Mizuochi, T. Autoantibody activity of IgG rheumatoid factor increases with decreasing levels of galactosylation and sialylation. J Biochem 2000, 128 (4), 621-628.

76. Rook, G. A.; Steele, J.; Brealey, R.; Whyte, A.; Isenberg, D.; Sumar, N.; Nelson, J. L.; Bodman, K. B.; Young, A.; Roitt, I. M.; . Changes in IgG glycoform levels are associated with remission of arthritis during pregnancy. J Autoimmun. 1991, 4 (5), 779-794. 
77. Boyd, P. N.; Lines, A. C.; Patel, A. K. The effect of the removal of sialic acid, galactose and total carbohydrate on the functional activity of Campath-1H. Mol. Immunol. 1995, 32 (17-18), 1311-1318.

78. Kumpel, B. M.; Rademacher, T. W.; Rook, G. A.; Williams, P. J.; Wilson, I. B. Galactosylation of human IgG monoclonal anti-D produced by EBVtransformed B-lymphoblastoid cell lines is dependent on culture method and affects Fc receptor-mediated functional activity. Hum. Antibodies Hybridomas 1994, $5(3-4), 143-151$.

79. Karsten, C. M.; Pandey, M. K.; Figge, J.; Kilchenstein, R.; Taylor, P. R.; Rosas, M.; McDonald, J. U.; Orr, S. J.; Berger, M.; Petzold, D.; Blanchard, V.; Winkler, A.; Hess, C.; Reid, D. M.; Majoul, I. V.; Strait, R. T.; Harris, N. L.; Kohl, G.; Wex, E.; Ludwig, R.; Zillikens, D.; Nimmerjahn, F.; Finkelman, F. D.; Brown, G. D.; Ehlers, M.; Kohl, J. Anti-inflammatory activity of IgG1 mediated by Fc galactosylation and association of FcgammaRIIB and dectin-1. Nat. Med. 2012, 18 (9), 1401-1406.

80. Shields, R. L.; Lai, J.; Keck, R.; O'Connell, L. Y.; Hong, K.; Meng, Y. G.; Weikert, S. H.; Presta, L. G. Lack of fucose on human IgG1 N-linked oligosaccharide improves binding to human Fcgamma RIII and antibody-dependent cellular toxicity. J Biol Chem 2002, 277 (30), 26733-26740.

81. Nose, M.; Heyman, B. Inhibition of processing of asparagine-linked carbohydrate chains on IgG2a by using swainsonine has no influence upon antibody effector functions in vitro. J. Immunol. 1990, 145 (3), 910-914.

82. Rothman, R. J.; Perussia, B.; Herlyn, D.; Warren, L. Antibody-dependent cytotoxicity mediated by natural killer cells is enhanced by castanospermine-induced alterations of IgG glycosylation. Mol. Immunol. 1989, 26 (12), 1113-1123.

83. Schuster, M.; Umana, P.; Ferrara, C.; Brunker, P.; Gerdes, C.; Waxenecker, G.; Wiederkum, S.; Schwager, C.; Loibner, H.; Himmler, G.; Mudde, G. C. Improved effector functions of a therapeutic monoclonal Lewis $\mathrm{Y}$-specific antibody by glycoform engineering. Cancer Res. 2005, 65 (17), 7934-7941.

84. Kanda, Y.; Yamada, T.; Mori, K.; Okazaki, A.; Inoue, M.; Kitajima-Miyama, K.; Kuni-Kamochi, R.; Nakano, R.; Yano, K.; Kakita, S.; Shitara, K.; Satoh, M. Comparison of biological activity among nonfucosylated therapeutic IgG1 antibodies with three different N-linked Fc oligosaccharides: the highmannose, hybrid, and complex types. Glycobiology 2007, 17 (1), 104-118.

85. Matsumiya, S.; Yamaguchi, Y.; Saito, J.; Nagano, M.; Sasakawa, H.; Otaki, S.; Satoh, M.; Shitara, K.; Kato, K. Structural comparison of fucosylated and nonfucosylated Fc fragments of human immunoglobulin G1. J Mol. Biol. 2007, 368 (3), 767-779.

86. Iida, S.; Kuni-Kamochi, R.; Mori, K.; Misaka, H.; Inoue, M.; Okazaki, A.; Shitara, K.; Satoh, M. Two mechanisms of the enhanced antibody-dependent cellular cytotoxicity (ADCC) efficacy of non-fucosylated therapeutic antibodies in human blood. BMC Cancer 2009, 9, 58. 
87. Sturla, L.; Fruscione, F.; Noda, K.; Miyoshi, E.; Taniguchi, N.; Contini, P.; Tonetti, M. Core fucosylation of N-linked glycans in leukocyte adhesion deficiency/congenital disorder of glycosylation IIc fibroblasts. Glycobiology 2005, 15 (10), 924-934.

88. Niwa, R.; Natsume, A.; Uehara, A.; Wakitani, M.; Iida, S.; Uchida, K.; Satoh, M.; Shitara, K. IgG subclass-independent improvement of antibody-dependent cellular cytotoxicity by fucose removal from Asn297-linked oligosaccharides. J Immunol Methods 2005, 306 (1-2), 151-160.

89. Nimmerjahn, F.; Ravetch, J. V. The antiinflammatory activity of IgG: the intravenous IgG paradox. $J$ Exp. Med 2007, 204 (1), 11-15.

90. Bruhns, P.; Samuelsson, A.; Pollard, J. W.; Ravetch, J. V. Colony-Stimulating Factor1-Dependent Macrophages Are Responsible for IVIG Protection in AntibodyInduced Autoimmune Disease. Immunity 2003, 18 (4), 573-581.

91. Jefferis, R. Glycosylation as a strategy to improve antibody-based therapeutics. Nat Rev Drug Discov 2009, 8 (3), 226-234.

92. Risson, D. C.; Davies, M. W.; Williams, B. A. Review of neonatal alloimmune thrombocytopenia. J. Paediatr. Child Health 2012, 48 (9), 816-822.

93. Ghevaert, C.; Wilcox, D. A.; Fang, J.; Armour, K. L.; Clark, M. R.; Ouwehand, W. H.; Williamson, L. M. Developing recombinant HPA-1a-specific antibodies with abrogated Fcgamma receptor binding for the treatment of fetomaternal alloimmune thrombocytopenia. J Clin Invest 2008, 118 (8), 2929-2938.

94. Blanchette, V. S.; Johnson, J.; Rand, M. The management of alloimmune neonatal thrombocytopenia. Baillieres Best. Pract. Res. Clin. Haematol. 2000, 13 (3), 365-390.

95. Bessos, H.; Killie, M. K.; Seghatchian, J.; Skogen, B.; Urbaniak, S. J. The relationship of anti-HPA-1a amount to severity of neonatal alloimmune thrombocytopenia Where does it stand? Transfus. Apher. Sci 2009, 40 (2), 75-78.

96. Bennett, J. A.; Palmer, L. J.; Musk, A. W.; Erber, W. N. Gene frequencies of human platelet antigens 1-5 in indigenous Australians in Western Australia. Transfus. Med. 2002, 12 (3), 199-203.

97. Anani, S. G.; Moss, M.; Barker, R. N.; Urbaniak, S. J. Naturally processed peptides spanning the HPA-1a polymorphism are efficiently generated and displayed from platelet glycoprotein by HLA-DRB3*0101-positive antigen-presenting cells. Blood 2009, 114 (9), 1954-1957.

98. Turner, M. L.; Bessos, H.; Fagge, T.; Harkness, M.; Rentoul, F.; Seymour, J.; Wilson, D.; Gray, I.; Ahya, R.; Cairns, J.; Urbaniak, S. Prospective epidemiologic study of the outcome and cost-effectiveness of antenatal screening to detect neonatal alloimmune thrombocytopenia due to anti-HPA-1a. Transfusion 2005, 45 (12), 1945-1956. 
99. Arnold, D. M.; Smith, J. W.; Kelton, J. G. Diagnosis and management of neonatal alloimmune thrombocytopenia. Transfus. Med. Rev. 2008, 22 (4), 255-267.

100. Kiefel, V.; Santoso, S.; Weisheit, M.; Mueller-Eckhardt, C. Monoclonal antibody-specific immobilization of platelet antigens (MAIPA): a new tool for the identification of platelet-reactive antibodies. Blood 1987, 70 (6), 1722-1726.

101. Kjaer, K. M.; Jaegtvik, S.; Husebekk, A.; Skogen, B. Human platelet antigen 1 (HPA 1) genotyping with 5 ' nuclease assay and sequence-specific primers reveals a single nucleotide deletion in intron 2 of the HPA 1a allele of platelet glycoprotein IIIa. Br. J. Haematol. 2002, 117 (2), 405-408.

102. Kjeldsen-Kragh, J.; Killie, M. K.; Tomter, G.; Golebiowska, E.; Randen, I.; Hauge, R.; Aune, B.; Oian, P.; Dahl, L. B.; Pirhonen, J.; Lindeman, R.; Husby, H.; Haugen, G.; Gronn, M.; Skogen, B.; Husebekk, A. A screening and intervention program aimed to reduce mortality and serious morbidity associated with severe neonatal alloimmune thrombocytopenia. Blood 2007, $110(3), 833-839$.

103. Panzer, S.; Mayr, W. R.; Eichelberger, B. Light chain phenotypes of HLA antibodies in cases with suspected neonatal alloimmune thrombocytopenia. Vox Sang. 2005, 89 (4), 261-264.

104. Brand, A.; van, L. A.; Eernisse, J. G.; van Rood, J. J. Platelet transfusion therapy. Optimal donor selection with a combination of lymphocytotoxicity and platelet fluorescence tests. Blood 1978, 51 (5), 781-788.

105. McQuilten, Z. K.; Wood, E. M.; Savoia, H.; Cole, S. A review of pathophysiology and current treatment for neonatal alloimmune thrombocytopenia (NAIT) and introducing the Australian NAIT registry. Aust. N. Z. J. Obstet. Gynaecol. 2011, 51 (3), 191-198.

106. Jaegtvik, S.; Husebekk, A.; Aune, B.; Oian, P.; Dahl, L. B.; Skogen, B. Neonatal alloimmune thrombocytopenia due to anti-HPA 1a antibodies; the level of maternal antibodies predicts the severity of thrombocytopenia in the newborn. BJOG. 2000, 107 (5), 691-694.

107. Killie, M. K.; Husebekk, A.; Kaplan, C.; Taaning, E.; Skogen, B. Maternal human platelet antigen-1a antibody level correlates with the platelet count in the newborns: a retrospective study. Transfusion 2007, 47 (1), 55-58.

108. Bertrand, G.; Martageix, C.; Jallu, V.; Vitry, F.; Kaplan, C. Predictive value of sequential maternal anti-HPA-1a antibody concentrations for the severity of fetal alloimmune thrombocytopenia. J. Thromb. Haemost. 2006, 4 (3), 628637.

109. Killie, M. K.; Husebekk, A.; Kjeldsen-Kragh, J.; Skogen, B. A prospective study of maternal anti-HPA 1a antibody level as a potential predictor of alloimmune thrombocytopenia in the newborn. Haematologica 2008, 93 (6), 870-877.

110. Wuhrer, M.; Porcelijn, L.; Kapur, R.; Koeleman, C. A.; Deelder, A.; de, H. M.; Vidarsson, G. Regulated glycosylation patterns of IgG during alloimmune 
responses against human platelet antigens. J Proteome Res 2009, 8 (2), 450456.

111. Stephens, D. S.; Greenwood, B.; Brandtzaeg, P. Epidemic meningitis, meningococcaemia, and Neisseria meningitidis. The Lancet 369 (9580), 21962210 .

112. Harrison, L. H.; Pelton, S. I.; Wilder-Smith, A.; Holst, J.; Safadi, M. A. P.; Vazquez, J. A.; Taha, M. K.; LaForce, F. M.; von Gottberg, A.; Borrow, R.; Plotkin, S. A. The Global Meningococcal Initiative: Recommendations for reducing the global burden of meningococcal disease. Vaccine 2011, 29 (18), 3363-3371.

113. World Health Organization Weekly Epidemiological Record. World Health Organization 2002.

114. Rouphael, N. G.; Zimmer, S. M.; Stephens, D. S. Chapter 53 - Neisseria meningitidis. In Vaccines for Biodefense and Emerging and Neglected Diseases, Alan, D. T. B., Lawrence, R. S., Eds.; Academic Press: London, 2009; pp 1061-1079.

115. Bjune, G.; Hoiby, E. A.; Gronnesby, J. K.; Arnesen, O.; Fredriksen, J. H.; Halstensen, A.; Holten, E.; Lindbak, A. K.; Nokleby, H.; Rosenqvist, E.; . Effect of outer membrane vesicle vaccine against group B meningococcal disease in Norway. Lancet 1991, 338 (8775), 1093-1096.

116. Rosenqvist, E.; Hoiby, E. A.; Bjune, G.; Bryn, K.; Closs, O.; Feiring, B.; Klem, A.; Nokleby, H.; Frolm, L. O. Human antibody responses after vaccination with the Norwegian group B meningococcal outer membrane vesicle vaccine: results from ELISA studies. NIPH Ann 1991, 14 (2), 169-179.

117. Hoiby, E. A.; Bjune, G.; Froholm, L. O.; Eng, J.; Halstensen, A.; Rosenqvist, E.; Ronnild, E.; Wedege, E. The Norwegian meningococcal serogroup B outer membrane vesicle vaccine protection trials: case tracing, meningococcal antigen detection and serological diagnosis. NIPH Ann 1991, 14 (2), 107-121.

118. Oster, P.; Lennon, D.; O'Hallahan, J.; Mulholland, K.; Reid, S.; Martin, D. MeNZB: a safe and highly immunogenic tailor-made vaccine against the New Zealand Neisseria meningitidis serogroup B disease epidemic strain. Vaccine 2005, 23 (17-18), 2191-2196.

119. Pitsiou, G. G.; Kioumis, I. P. Pneumococcal vaccination in adults: Does it really work? Respiratory Medicine 2011, 105 (12), 1776-1783.

120. Vila-C+'rcoles, A. Advances in Pneumococcal Vaccines: What are the Advantages for the Elderly? Drugs \& Aging 2007, 24 (10).

121. Mackell, S. M. Vaccinations for the Pediatric Traveler. Clinical Infectious Diseases 2003, 37 (11), 1508-1516.

122. Bautista, E.; Chotpitayasunondh, T.; Gao, Z.; Harper, S. A.; Shaw, M.; Uyeki, T. M.; Zaki, S. R.; Hayden, F. G.; Hui, D. S.; Kettner, J. D.; Kumar, A.; Lim, M.; Shindo, N.; Penn, C.; Nicholson, K. G. Clinical aspects of pandemic 2009 influenza A (H1N1) virus infection. N Engl J Med 2010, 362 (18), 1708-1719. 
123. Young, F.; Marra, F. A systematic review of intradermal influenza vaccines. Vaccine 2011, 29 (48), 8788-8801.

124. Kaur, K.; Sullivan, M.; Wilson, P. C. Targeting B cell responses in universal influenza vaccine design. Trends in Immunology 2011, 32 (11), 524-531.

125. World Health Organization Recommended composition of influenza virus vaccines for use in the 2010 influenza season (southern hemisphere winter). Wkly Epidemiol Rec. 2009, 84 (41), 421-431.

126. Gerdil, C. The annual production cycle for influenza vaccine. Vaccine 2003, 21 (16), $1776-1779$.

127. Ott, U.; Sauerbrei, A.; Lange, J.; Sch+ñfler, A.; Walther, M.; Wolf, G.; Wutzler, P.; Zell, R.; Krumbholz, A. Serological response to influenza A H1N1 vaccine (Pandemrix\&lt;sup\&gt;-«\&lt;/sup\&gt;) and seasonal influenza vaccine 2009/2010 in renal transplant recipients and in hemodialysis patients. Medical Microbiology and Immunology, 1-6.

128. Registration of pandemic flu vaccinations. Norwegian Institute of Public Health 2011.

129. Pittet, L. F.; Posfay-Barbe, K. M. Pneumococcal vaccines for children: a global public health priority. Clin Microbiol Infect 2012.

130. Naess, L. M.; Aarvak, T.; Aase, A.; Oftung, F.; Hoiby, E. A.; Sandin, R.; Michaelsen, T. E. Human IgG subclass responses in relation to serum bactericidal and opsonic activities after immunization with three doses of the Norwegian serogroup B meningococcal outer membrane vesicle vaccine. Vaccine 1999, 17 (7-8), 754-764.

131. Lai, R. P.; Seaman, M. S.; Tonks, P.; Wegmann, F.; Seilly, D. J.; Frost, S. D.; LaBranche, C. C.; Montefiori, D. C.; Dey, A. K.; Srivastava, I. K.; Sattentau, Q.; Barnett, S. W.; Heeney, J. L. Mixed adjuvant formulations reveal a new combination that elicit antibody response comparable to Freund's adjuvants. PLoS One 2012, 7 (4), e35083.

132. Mashburn-Warren, L.; McLean, R. J.; Whiteley, M. Gram-negative outer membrane vesicles: beyond the cell surface. Geobiology. 2008, 6 (3), 214-219.

133. Danzig, L. Meningococcal vaccines. Pediatr Infect Dis J 2004, 23 (12 Suppl), S285S292.

134. Kennedy, R. B.; Ovsyannikova, I. G.; Jacobson, R. M.; Poland, G. A. The immunology of smallpox vaccines. Curr Opin. Immunol 2009, 21 (3), 314320 .

135. Willis, N. J. Edward Jenner and the eradication of smallpox. Scott Med J 1997, 42 (4), $118-121$

136. Rappuoli, R.; Miller, H. I.; Falkow, S. Medicine. The intangible value of vaccination. Science 2002, 297 (5583), 937-939. 
137. Wang, S. M.; Tsai, M. H.; Lei, H. Y.; Wang, J. R.; Liu, C. C. The regulatory T cells in anti-influenza antibody response post influenza vaccination. Hum Vaccin. Immunother. 2012, 8 (9).

138. Treanor, J. J.; Talbot, H. K.; Ohmit, S. E.; Coleman, L. A.; Thompson, M. G.; Cheng, P. Y.; Petrie, J. G.; Lofthus, G.; Meece, J. K.; Williams, J. V.; Berman, L.; Breese, H. C.; Monto, A. S.; Griffin, M. R.; Belongia, E.; Shay, D. K. Effectiveness of Seasonal Influenza Vaccines in the United States During a Season With Circulation of All Three Vaccine Strains. Clin Infect Dis 2012.

139. Westerink, M. A.; Schroeder, H. W., Jr.; Nahm, M. H. Immune Responses to pneumococcal vaccines in children and adults: Rationale for age-specific vaccination. Aging Dis 2012, 3 (1), 51-67.

140. Selman, M. H.; de Jong, S. E.; Soonawala, D.; Kroon, F. P.; Adegnika, A. A.; Deelder, A. M.; Hokke, C. H.; Yazdanbakhsh, M.; Wuhrer, M. Changes in antigenspecific IgG1 Fc N-glycosylation upon influenza and tetanus vaccination. Mol Cell Proteomics. 2011.

141. Jefferis, R. Isotype and glycoform selection for antibody therapeutics. Arch. Biochem. Biophys. (0).

142. Chames, P.; Van, R. M.; Weiss, E.; Baty, D. Therapeutic antibodies: successes, limitations and hopes for the future. Br. J. Pharmacol. 2009, 157 (2), 220-233.

143. Beckman, R. A.; Weiner, L. M.; Davis, H. M. Antibody constructs in cancer therapy: protein engineering strategies to improve exposure in solid tumors. Cancer 2007, 109 (2), 170-179.

144. Cartron, G.; Dacheux, L.; Salles, G.; Solal-Celigny, P.; Bardos, P.; Colombat, P.; Watier, H. Therapeutic activity of humanized anti-CD20 monoclonal antibody and polymorphism in IgG Fc receptor FcgammaRIIIa gene. Blood 2002, 99 (3), 754-758.

145. Beck, A.; Wagner-Rousset, E.; Ayoub, D.; Van, D. A.; Sanglier-Cianferani, S. Characterization of therapeutic antibodies and related products. Anal. Chem. 2012.

146. Beck, A.; Wurch, T.; Bailly, C.; Corvaia, N. Strategies and challenges for the next generation of therapeutic antibodies. Nat. Rev. Immunol. 2010, 10 (5), 345352.

147. Reichert, J. M. Which are the antibodies to watch in 2012? MAbs. 2012, 4 (1), 1-3.

148. Nallet, S.; Fornelli, L.; Schmitt, S.; Parra, J.; Baldi, L.; Tsybin, Y. O.; Wurm, F. M. Glycan variability on a recombinant $\mathrm{IgG}$ antibody transiently produced in HEK-293E cells. New Biotechnology 2012, 29 (4), 471-476.

149. Gorfien, S.; Paul, B.; Walowitz, J.; Keem, R.; Biddle, W.; Jayme, D. Growth of NS0 cells in protein-free, chemically defined medium. Biotechnol. Prog. 2000, 16 (5), 682-687. 
150. Selman, M. H.; Derks, R. J.; Bondt, A.; Palmblad, M.; Schoenmaker, B.; Koeleman, C. A.; van de Geijn, F. E.; Dolhain, R. J.; Deelder, A. M.; Wuhrer, M. Fc specific IgG glycosylation profiling by robust nano-reverse phase HPLC-MS using a sheath-flow ESI sprayer interface. J Proteomics. 2012, 75 (4), 13181329.

151. Birch, J. R.; Froud, S. J. Mammalian cell culture systems for recombinant protein production. Biologicals 1994, 22 (2), 127-133.

152. Lasunskaia, E. B.; Fridlianskaia, I. I.; Darieva, Z. A.; da Silva, M. S.; Kanashiro, M. M.; Margulis, B. A. Transfection of NS0 myeloma fusion partner cells with HSP70 gene results in higher hybridoma yield by improving cellular resistance to apoptosis. Biotechnol. Bioeng. 2003, 81 (4), 496-504.

153. Oi, V. T.; Morrison, S. L.; Herzenberg, L. A.; Berg, P. Immunoglobulin gene expression in transformed lymphoid cells. Proc Natl. Acad. Sci U S A 1983, 80 (3), 825-829.

154. Lund, J.; Takahashi, N.; Pound, J. D.; Goodall, M.; Jefferis, R. Multiple interactions of IgG with its core oligosaccharide can modulate recognition by complement and human Fc gamma receptor I and influence the synthesis of its oligosaccharide chains. J Immunol 1996, 157 (11), 4963-4969.

155. Lund, J.; Takahashi, N.; Nakagawa, H.; Goodall, M.; Bentley, T.; Hindley, S. A.; Tyler, R.; Jefferis, R. Control of IgG/Fc glycosylation: a comparison of oligosaccharides from chimeric human/mouse and mouse subclass immunoglobulin Gs. Mol. Immunol. 1993, 30 (8), 741-748.

156. Gross, J. Mass Spectrometry A Textbook; 1 ed.; Springer: 2004; Vol. 1;.pp. 1-12.

157. Hu, Q.; Noll, R. J.; Li, H.; Makarov, A.; Hardman, M.; Graham, C. R. The Orbitrap: a new mass spectrometer. J Mass Spectrom. 2005, 40 (4), 430-443.

158. Smith, R. D.; Loo, J. A.; Edmonds, C. G.; Barinaga, C. J.; Udseth, H. R. New developments in biochemical mass spectrometry: electrospray ionization. Anal. Chem. 1990, 62 (9), 882-899.

159. Fenn, J. B.; Mann, M.; Meng, C. K.; Wong, S. F.; Whitehouse, C. M. Electrospray ionization for mass spectrometry of large biomolecules. Science 1989, 246 (4926), 64-71.

160. Fuerstenau, S. D.; Benner, W. H.; Thomas, J. J.; Brugidou, C.; Bothner, B.; Siuzdak, G. Mass Spectrometry of an Intact Virus The authors gratefully acknowledge Jennifer Boydston for her helpful comments and suggestions. G.S. is grateful for support from the NIH (GM55775). The work at LBL was supported by the Director, Office of Energy Research, Office of Health and Environmental Research, Human Genome Program, U.S. Department of Energy under contract number DE-AC03-76SF00098. Angew. Chem. Int. Ed Engl. 2001, 40 (6), 9822 .

161. Makarov, A. Electrostatic axially harmonic orbital trapping: a high-performance technique of mass analysis. Anal Chem 2000, 72 (6), 1156-1162. 
162. Hardman, M.; Makarov, A. A. Interfacing the orbitrap mass analyzer to an electrospray ion source. Anal. Chem. 2003, 75 (7), 1699-1705.

163. Olsen, J. V.; Macek, B.; Lange, O.; Makarov, A.; Horning, S.; Mann, M. Higherenergy C-trap dissociation for peptide modification analysis. Nat. Methods 2007, 4 (9), 709-712.

164. Jedrychowski, M. P.; Huttlin, E. L.; Haas, W.; Sowa, M. E.; Rad, R.; Gygi, S. P. Evaluation of HCD- and CID-type fragmentation within their respective detection platforms for murine phosphoproteomics. Mol. Cell Proteomics. 2011, 10 (12), M111.

165. Nagaraj, N.; D'Souza, R. C.; Cox, J.; Olsen, J. V.; Mann, M. Feasibility of large-scale phosphoproteomics with higher energy collisional dissociation fragmentation. J. Proteome. Res. 2010, 9 (12), 6786-6794.

166. Chicooree, N.; Griffiths, J. R.; Connolly, Y.; Tan, C. T.; Malliri, A.; Eyers, C. E.; Smith, D. L. A novel approach to the analysis of SUMOylation with the independent use of trypsin and elastase digestion followed by database searching utilising consecutive residue addition to lysine. Rapid Commun. Mass Spectrom. 2013, 27 (1), 127-134.

167. Wuhrer, M.; Stam, J. C.; van de Geijn, F. E.; Koeleman, C. A.; Verrips, C. T.; Dolhain, R. J.; Hokke, C. H.; Deelder, A. M. Glycosylation profiling of immunoglobulin $\mathrm{G}(\mathrm{IgG})$ subclasses from human serum. Proteomics. 2007, 7 (22), 4070-4081.

168. Huynh, M. L.; Russell, P.; Walsh, B. Tryptic digestion of in-gel proteins for mass spectrometry analysis. Methods Mol. Biol. 2009, 519, 507-513.

169. Stadlmann, J.; Pabst, M.; Kolarich, D.; Kunert, R.; Altmann, F. Analysis of immunoglobulin glycosylation by LC-ESI-MS of glycopeptides and oligosaccharides. Proteomics. 2008, 8 (14), 2858-2871.

170. Wuhrer, M.; Catalina, M. I.; Deelder, A. M.; Hokke, C. H. Glycoproteomics based on tandem mass spectrometry of glycopeptides. J Chromatogr. B Analyt. Technol Biomed. Life Sci 2007, 849 (1-2), 115-128.

171. Zauner, G.; Selman, M. H.; Bondt, A.; Rombouts, Y.; Blank, D.; Deelder, A. M.; Wuhrer, M. Glycoproteomic analysis of antibodies. Mol. Cell Proteomics. 2013.

172. Kolarich, D.; Jensen, P. H.; Altmann, F.; Packer, N. H. Determination of site-specific glycan heterogeneity on glycoproteins. Nat. Protoc. 2012, 7 (7), 1285-1298.

173. Huhn, C.; Selman, M. H.; Ruhaak, L. R.; Deelder, A. M.; Wuhrer, M. IgG glycosylation analysis. Proteomics. 2009, 9 (4), 882-913.

174. Neilson, K. A.; Ali, N. A.; Muralidharan, S.; Mirzaei, M.; Mariani, M.; Assadourian, G.; Lee, A.; van Sluyter, S. C.; Haynes, P. A. Less label, more free: approaches in label-free quantitative mass spectrometry. Proteomics. 2011, 11 (4), 535553. 
175. Zhu, W.; Smith, J. W.; Huang, C. M. Mass spectrometry-based label-free quantitative proteomics. J. Biomed. Biotechnol. 2010, 2010, 840518.

176. Liu, H.; Sadygov, R. G.; Yates, J. R., III A model for random sampling and estimation of relative protein abundance in shotgun proteomics. Anal. Chem. 2004, 76 (14), 4193-4201.

177. Ross, P. L.; Huang, Y. N.; Marchese, J. N.; Williamson, B.; Parker, K.; Hattan, S.; Khainovski, N.; Pillai, S.; Dey, S.; Daniels, S.; Purkayastha, S.; Juhasz, P.; Martin, S.; Bartlet-Jones, M.; He, F.; Jacobson, A.; Pappin, D. J. Multiplexed protein quantitation in Saccharomyces cerevisiae using amine-reactive isobaric tagging reagents. Mol. Cell Proteomics. 2004, 3 (12), 1154-1169.

178. Gygi, S. P.; Rist, B.; Gerber, S. A.; Turecek, F.; Gelb, M. H.; Aebersold, R. Quantitative analysis of complex protein mixtures using isotope-coded affinity tags. Nat. Biotechnol. 1999, 17 (10), 994-999.

179. Ong, S. E.; Blagoev, B.; Kratchmarova, I.; Kristensen, D. B.; Steen, H.; Pandey, A.; Mann, M. Stable isotope labeling by amino acids in cell culture, SILAC, as a simple and accurate approach to expression proteomics. Mol. Cell Proteomics. 2002, 1 (5), 376-386.

180. Burton, D. R.; Boyd, J.; Brampton, A. D.; Easterbrook-Smith, S. B.; Emanuel, E. J.; Novotny, J.; Rademacher, T. W.; van Schravendijk, M. R.; Sternberg, M. J.; Dwek, R. A. The Clq receptor site on immunoglobulin G. Nature 1980, 288 (5789), 338-344.

181. Wren, L. H.; Chung, A. W.; Isitman, G.; Kelleher, A. D.; Parsons, M. S.; Amin, J.; Cooper, D. A.; Stratov, I.; Navis, M.; Kent, S. J. Specific antibody-dependent cellular cytotoxicity responses associated with slow progression of HIV infection. Immunology 2013, 138 (2), 116-123.

182. Barok, M.; Isola, J.; Palyi-Krekk, Z.; Nagy, P.; Juhasz, I.; Vereb, G.; Kauraniemi, P.; Kapanen, A.; Tanner, M.; Vereb, G.; Szollosi, J. Trastuzumab causes antibodydependent cellular cytotoxicity-mediated growth inhibition of submacroscopic JIMT-1 breast cancer xenografts despite intrinsic drug resistance. Mol. Cancer Ther. 2007, 6 (7), 2065-2072.

183. Gomez-Roman, V. R.; Patterson, L. J.; Venzon, D.; Liewehr, D.; Aldrich, K.; Florese, R.; Robert-Guroff, M. Vaccine-elicited antibodies mediate antibody-dependent cellular cytotoxicity correlated with significantly reduced acute viremia in rhesus macaques challenged with SIVmac251. J. Immunol. 2005, 174 (4), 2185-2189.

184. Costers, S.; Delputte, P. L.; Nauwynck, H. J. Porcine reproductive and respiratory syndrome virus-infected alveolar macrophages contain no detectable levels of viral proteins in their plasma membrane and are protected against antibodydependent, complement-mediated cell lysis. J. Gen. Virol. 2006, 87 (Pt 8), 2341-2351.

185. Lis, H.; Sharon, N. Protein glycosylation. Structural and functional aspects. Eur. J. Biochem. 1993, 218 (1), 1-27. 
186. Dennis, J. W.; Granovsky, M.; Warren, C. E. Protein glycosylation in development and disease. Bioessays 1999, 21 (5), 412-421.

187. Freeze, H. H.; Schachter, H. Genetic Disorders of glycosylation. In Essentials of Glycobiology, 2 ed.; Varki, A., Cummings RD, Esko, J., Eds.; Cold Spring Harbor Lavoratory Press: Cold Spring Harbor, 2009.

188. Davies, J.; Jiang, L.; Pan, L. Z.; LaBarre, M. J.; Anderson, D.; Reff, M. Expression of GnTIII in a recombinant anti-CD20 CHO production cell line: Expression of antibodies with altered glycoforms leads to an increase in ADCC through higher affinity for FC gamma RIII. Biotechnol. Bioeng. 2001, 74 (4), 288-294.

189. Wang, J.; Balog, C. I.; Stavenhagen, K.; Koeleman, C. A.; Scherer, H. U.; Selman, M. H.; Deelder, A. M.; Huizinga, T. W.; Toes, R. E.; Wuhrer, M. Fc-glycosylation of IgG1 is modulated by B-cell stimuli. Mol. Cell Proteomics. 2011, 10 (5), M110.

190. Zhou, T.; Zhang, Z.; Liu, J.; Zhang, J.; Jiao, B. Glycosylation of the Sodium Channel $\hat{I}^{2} 4$ Subunit is Developmentally Regulated and Involves in Neuritic Degeneration. Int. J. Biol. Sci. 2012, 8 (5), 630-639.

191. Yao, J.; Hong, W.; Huang, J.; Zhan, K.; Huang, H.; Hong, M. N-glycosylation Dictates Proper Processing of Organic Anion Transporting Polypeptide 1B1. PLoS. One. 2012, 7 (12), e52563.

192. Allhorn, M.; Olsen, A.; Collin, M. EndoS from Streptococcus pyogenes is hydrolyzed by the cysteine proteinase SpeB and requires glutamic acid 235 and tryptophans for IgG glycan-hydrolyzing activity. BMC Microbiol. 2008, 8, 3.

193. Collin, M.; Shannon, O.; Bjorck, L. IgG glycan hydrolysis by a bacterial enzyme as a therapy against autoimmune conditions. Proc. Natl. Acad. Sci. U. S. A 2008, 105 (11), 4265-4270.

194. Anthony, R. M.; Kobayashi, T.; Wermeling, F.; Ravetch, J. V. Intravenous gammaglobulin suppresses inflammation through a novel $\mathrm{T}(\mathrm{H}) 2$ pathway. Nature 2011, 475 (7354), 110-113.

195. Siragam, V.; Crow, A. R.; Brinc, D.; Song, S.; Freedman, J.; Lazarus, A. H. Intravenous immunoglobulin ameliorates ITP via activating Fe gamma receptors on dendritic cells. Nat. Med 2006, 12 (6), 688-692.

196. Toubi, E.; Etzioni, A. Intravenous immunoglobulin in immunodeficiency states: state of the art. Clin Rev Allergy Immunol 2005, 29 (3), 167-172.

197. Nimmerjahn, F.; Ravetch, J. V. Anti-inflammatory actions of intravenous immunoglobulin. Annu. Rev Immunol. 2008, 26, 513-533.

198. Schwab, I.; Nimmerjahn, F. Intravenous immunoglobulin therapy: how does IgG modulate the immune system? Nat. Rev. Immunol. 2013.

199. Jefferis, R. Recombinant antibody therapeutics: the impact of glycosylation on mechanisms of action. Trends Pharmacol. Sci. 2009, 30 (7), 356-362. 
200. Wu, J.; Edberg, J. C.; Redecha, P. B.; Bansal, V.; Guyre, P. M.; Coleman, K.; Salmon, J. E.; Kimberly, R. P. A novel polymorphism of FcgammaRIIIa (CD16) alters receptor function and predisposes to autoimmune disease. J. Clin. Invest 1997, 100 (5), 1059-1070.

201. Shields, R. L.; Namenuk, A. K.; Hong, K.; Meng, Y. G.; Rae, J.; Briggs, J.; Xie, D.; Lai, J.; Stadlen, A.; Li, B.; Fox, J. A.; Presta, L. G. High resolution mapping of the binding site on human IgG1 for Fc gamma RI, Fc gamma RII, Fc gamma RIII, and FcRn and design of IgG1 variants with improved binding to the Fc gamma R. J. Biol. Chem. 2001, 276 (9), 6591-6604.

202. Cartron, G.; Dacheux, L.; Salles, G.; Solal-Celigny, P.; Bardos, P.; Colombat, P.; Watier, H. Therapeutic activity of humanized anti-CD20 monoclonal antibody and polymorphism in IgG Fc receptor FcgammaRIIIa gene. Blood 2002, 99 (3), 754-758.

203. Sparks, S. E.; Krasnewich, D. M. Congenital Disorders of Glycosylation Overview. 1993.

204. Jaeken, J. Congenital disorders of glycosylation. Ann. N. Y. Acad. Sci. 2010, 1214, 190-198.

205. Durand, G.; Seta, N. Protein glycosylation and diseases: blood and urinary oligosaccharides as markers for diagnosis and therapeutic monitoring. Clin. Chem. 2000, 46 (6 Pt 1), 795-805.

206. Turner, G. A. Haptoglobin. A potential reporter molecule for glycosylation changes in disease. Adv. Exp. Med. Biol. 1995, 376, 231-238.

207. Watson, M.; Rudd, P. M.; Bland, M.; Dwek, R. A.; Axford, J. S. Sugar printing rheumatic diseases: a potential method for disease differentiation using immunoglobulin G oligosaccharides. Arthritis Rheum. 1999, 42 (8), 16821690 .

208. Axford, J. S.; Cunnane, G.; Fitzgerald, O.; Bland, J. M.; Bresnihan, B.; Frears, E. R. Rheumatic disease differentiation using immunoglobulin $\mathrm{G}$ sugar printing by high density electrophoresis. J. Rheumatol. 2003, 30 (12), 2540-2546.

209. Reinhard, G.; Noll, A.; Schlebusch, H.; Mallmann, P.; Ruecker, A. V. Shifts in the TH1/TH2 balance during human pregnancy correlate with apoptotic changes. Biochem. Biophys. Res. Commun. 1998, 245 (3), 933-938.

210. Semple, J. W.; Speck, E. R.; Milev, Y. P.; Blanchette, V.; Freedman, J. Indirect allorecognition of platelets by $\mathrm{T}$ helper cells during platelet transfusions correlates with anti-major histocompatibility complex antibody and cytotoxic T lymphocyte formation. Blood 1995, 86 (2), 805-812.

211. West, A. P., Jr.; Bjorkman, P. J. Crystal structure and immunoglobulin G binding properties of the human major histocompatibility complex-related Fc receptor(,). Biochemistry 2000, 39 (32), 9698-9708. 
212. Newkirk, M. M.; Novick, J.; Stevenson, M. M.; Fournier, M. J.; Apostolakos, P. Differential clearance of glycoforms of $\operatorname{IgG}$ in normal and autoimmune-prone mice. Clin. Exp. Immunol. 1996, 106 (2), 259-264.

213. Royle, L.; Roos, A.; Harvey, D. J.; Wormald, M. R.; van Gijlswijk-Janssen, D.; Redwan, e.; Wilson, I. A.; Daha, M. R.; Dwek, R. A.; Rudd, P. M. Secretory IgA N- and $\mathrm{O}$-glycans provide a link between the innate and adaptive immune systems. J. Biol. Chem. 2003, 278 (22), 20140-20153.

214. Mattu, T. S.; Pleass, R. J.; Willis, A. C.; Kilian, M.; Wormald, M. R.; Lellouch, A. C.; Rudd, P. M.; Woof, J. M.; Dwek, R. A. The glycosylation and structure of human serum IgA1, Fab, and Fc regions and the role of N-glycosylation on Fc alpha receptor interactions. J. Biol. Chem. 1998, 273 (4), 2260-2272.

215. Nettleton, M. Y.; Kochan, J. P. Role of glycosylation sites in the IgE Fc molecule. Int. Arch. Allergy Immunol. 1995, 107 (1-3), 328-329.

216. Bjorklund, J. E.; Karlsson, T.; Magnusson, C. G. N-glycosylation influences epitope expression and receptor binding structures in human IgE. Mol. Immunol. 1999, $36(3), 213-221$.

217. Saleh, H.; Embry, S.; Nauli, A.; Atyia, S.; Krishnaswamy, G. Anaphylactic reactions to oligosaccharides in red meat: a syndrome in evolution. Clin. Mol. Allergy 2012, $10(1), 5$.

218. Arnold, J. N.; Radcliffe, C. M.; Wormald, M. R.; Royle, L.; Harvey, D. J.; Crispin, M.; Dwek, R. A.; Sim, R. B.; Rudd, P. M. The glycosylation of human serum $\mathrm{IgD}$ and $\mathrm{IgE}$ and the accessibility of identified oligomannose structures for interaction with mannan-binding lectin. J. Immunol. 2004, 173 (11), 68316840 .

219. Arnold, J. N.; Wormald, M. R.; Suter, D. M.; Radcliffe, C. M.; Harvey, D. J.; Dwek, R. A.; Rudd, P. M.; Sim, R. B. Human serum IgM glycosylation: identification of glycoforms that can bind to mannan-binding lectin. J. Biol. Chem. 2005, 280 (32), 29080-29087.

220. Pandit, J.; Danley, D. E.; Schulte, G. K.; Mazzalupo, S.; Pauly, T. A.; Hayward, C. M.; Hamanaka, E. S.; Thompson, J. F.; Harwood, H. J., Jr. Crystal structure of human squalene synthase. A key enzyme in cholesterol biosynthesis. J. Biol. Chem. 2000, 275 (39), 30610-30617.

221. Haeuptle, M. A.; Welti, M.; Troxler, H.; Hulsmeier, A. J.; Imbach, T.; Hennet, T. Improvement of dolichol-linked oligosaccharide biosynthesis by the squalene synthase inhibitor zaragozic acid. J. Biol. Chem. 2011, 286 (8), 6085-6091.

222. Welti, M. Regulation of dolichol-linked glycosylation. Glycoconj. J. 2012.

223. Oriol, R.; Mollicone, R.; Cailleau, A.; Balanzino, L.; Breton, C. Divergent evolution of fucosyltransferase genes from vertebrates, invertebrates, and bacteria. Glycobiology 1999, 9 (4), 323-334. 
224. Michaelsen, T. E.; Frangione, B.; Franklin, E. C. Primary structure of the "hinge" region of human IgG3. Probable quadruplication of a 15-amino acid residue basic unit. J Biol Chem 1977, 252 (3), 883-889.

225. Huck, S.; Fort, P.; Crawford, D. H.; Lefranc, M. P.; Lefranc, G. Sequence of a human immunoglobulin gamma 3 heavy chain constant region gene: comparison with the other human C gamma genes. Nucleic Acids Res 1986, 14 (4), 1779-1789.

226. Michaelsen, T. E.; Aase, A.; Norderhaug, L.; Sandlie, I. Antibody dependent cellmediated cytotoxicity induced by chimeric mouse-human IgG subclasses and IgG3 antibodies with altered hinge region. Mol. Immunol. 1992, 29 (3), 319326.

227. Yamane-Ohnuki, N.; Satoh, M. Production of therapeutic antibodies with controlled fucosylation. MAbs. 2009, 1 (3), 230-236.

228. Staudacher, E.; Altmann, F.; Wilson, I. B.; Marz, L. Fucose in N-glycans: from plant to man. Biochim. Biophys. Acta 1999, 1473 (1), 216-236.

229. Underhill, G. H.; Minges Wols, H. A.; Fornek, J. L.; Witte, P. L.; Kansas, G. S. IgG plasma cells display a unique spectrum of leukocyte adhesion and homing molecules. Blood 2002, 99 (8), 2905-2912.

230. Wang, J.; Balog, C. I.; Stavenhagen, K.; Koeleman, C. A.; Scherer, H. U.; Selman, M. H.; Deelder, A. M.; Huizinga, T. W.; Toes, R. E.; Wuhrer, M. Fc-glycosylation of IgG1 is modulated by B-cell stimuli. Mol. Cell Proteomics. 2011, 10 (5), M110.

231. Shibata-Koyama, M.; Iida, S.; Misaka, H.; Mori, K.; Yano, K.; Shitara, K.; Satoh, M. Nonfucosylated rituximab potentiates human neutrophil phagocytosis through its high binding for FcgammaRIIIb and MHC class II expression on the phagocytotic neutrophils. Exp. Hematol. 2009, 37 (3), 309-321.

232. Lastra, G. C.; Thompson, S. J.; Lemonidis, A. S.; Elson, C. J. Changes in the galactose content of IgG during humoral immune responses. Autoimmunity 1998, 28 (1), 25-30.

233. Guo, N.; Liu, Y.; Masuda, Y.; Kawagoe, M.; Ueno, Y.; Kameda, T.; Sugiyama, T. Repeated immunization induces the increase in fucose content on antigenspecific IgG N-linked oligosaccharides. Clin. Biochem. 2005, 38 (2), 149-153.

234. Kazatchkine, M. D.; Kaveri, S. V. Immunomodulation of autoimmune and inflammatory diseases with intravenous immune globulin. N. Engl. J. Med. 2001, 345 (10), 747-755.

235. Laury-Kleintop, L. D.; Damjanov, I.; Alhadeff, J. A. Antibody-affinity purification of novel alpha-L-fucosidase from mouse liver. Biochem. J. 1987, 245 (2), 589593.

236. Buffone, A., Jr.; Mondal, N.; Gupta, R.; McHugh, K. P.; Lau, J. T.; Neelamegham, S. Silencing alpha1,3-Fucosyltransferases in Human Leukocytes Reveals a Role 
for FUT9 Enzyme during E-selectin-mediated Cell Adhesion. J. Biol. Chem. 2013, 288 (3), 1620-1633.

237. Wang, X.; Gu, J.; Miyoshi, E.; Honke, K.; Taniguchi, N. Phenotype changes of Fut8 knockout mouse: core fucosylation is crucial for the function of growth factor receptor(s). Methods Enzymol. 2006, 417, 11-22.

238. Beck, A.; Reichert, J. M. Marketing approval of mogamulizumab: a triumph for glycoengineering. MAbs. 2012, 4 (4), 419-425.

239. von Horsten, H. H.; Ogorek, C.; Blanchard, V.; Demmler, C.; Giese, C.; Winkler, K.; Kaup, M.; Berger, M.; Jordan, I.; Sandig, V. Production of non-fucosylated antibodies by co-expression of heterologous GDP-6-deoxy-D-lyxo-4-hexulose reductase. Glycobiology 2010, 20 (12), 1607-1618.

240. Natsume, A.; Wakitani, M.; Yamane-Ohnuki, N.; Shoji-Hosaka, E.; Niwa, R.; Uchida, K.; Satoh, M.; Shitara, K. Fucose removal from complex-type oligosaccharide enhances the antibody-dependent cellular cytotoxicity of single-gene-encoded antibody comprising a single-chain antibody linked the antibody constant region. J. Immunol. Methods 2005, 306 (1-2), 93-103.

241. Natsume, A.; In, M.; Takamura, H.; Nakagawa, T.; Shimizu, Y.; Kitajima, K.; Wakitani, M.; Ohta, S.; Satoh, M.; Shitara, K.; Niwa, R. Engineered antibodies of IgG1/IgG3 mixed isotype with enhanced cytotoxic activities. Cancer Res. 2008, 68 (10), 3863-3872.

242. Bilyy, R.; Tomin, A.; Mahorivska, I.; Shalay, O.; Lohinskyy, V.; Stoika, R.; Kit, Y. Antibody-mediated sialidase activity in blood serum of patients with multiple myeloma. J. Mol. Recognit. 2011, 24 (4), 576-584.

243. Onitsuka, M.; Kim, W. D.; Ozaki, H.; Kawaguchi, A.; Honda, K.; Kajiura, H.; Fujiyama, K.; Asano, R.; Kumagai, I.; Ohtake, H.; Omasa, T. Enhancement of sialylation on humanized IgG-like bispecific antibody by overexpression of alpha2,6-sialyltransferase derived from Chinese hamster ovary cells. Appl. Microbiol. Biotechnol. 2012, 94 (1), 69-80.

244. Lendvai, N.; Qu, X. W.; Hsueh, W.; Casadevall, A. Mechanism for the isotype dependence of antibody-mediated toxicity in Cryptococcus neoformansinfected mice. J. Immunol. 2000, 164 (8), 4367-4374.

245. Feldmesser, M.; Mednick, A.; Casadevall, A. Antibody-mediated protection in murine Cryptococcus neoformans infection is associated with pleotrophic effects on cytokine and leukocyte responses. Infect. Immun. 2002, 70 (3), 1571-1580.

246. Taborda, C. P.; Rivera, J.; Zaragoza, O.; Casadevall, A. More is not necessarily better: prozone-like effects in passive immunization with IgG. J. Immunol. 2003, 170 (7), 3621-3630.

247. Casadevall, A.; Pirofski, L. A. A new synthesis for antibody-mediated immunity. Nat. Immunol. 2012, 13 (1), 21-28. 
248. Tian, H.; Weber, S.; Thorkildson, P.; Kozel, T. R.; Pirofski, L. A. Efficacy of opsonic and nonopsonic serotype 3 pneumococcal capsular polysaccharide-specific monoclonal antibodies against intranasal challenge with Streptococcus pneumoniae in mice. Infect. Immun. 2009, 77 (4), 1502-1513.

249. Hennet, T.; Chui, D.; Paulson, J. C.; Marth, J. D. Immune regulation by the ST6Gal sialyltransferase. Proc. Natl. Acad. Sci. U. S. A 1998, 95 (8), 4504-4509.

250. Rillahan, C. D.; Antonopoulos, A.; Lefort, C. T.; Sonon, R.; Azadi, P.; Ley, K.; Dell, A.; Haslam, S. M.; Paulson, J. C. Global metabolic inhibitors of sialyl- and fucosyltransferases remodel the glycome. Nat. Chem. Biol. 2012, 8 (7), 661668.

251. Ehlers, S.; Schreiber, T.; Dunzendorfer, A.; Lowe, J. B.; Holscher, C.

Fucosyltransferase IV and VII-directed selectin ligand function determines long-term survival in experimental tuberculosis. Immunobiology 2009, 214 (8), 674-682.

252. Allhorn, M.; Collin, M. Sugar-free antibodies--the bacterial solution to autoimmunity? Ann. N. Y. Acad. Sci. 2009, 1173, 664-669.

253. Albert, H.; Collin, M.; Dudziak, D.; Ravetch, J. V.; Nimmerjahn, F. In vivo enzymatic modulation of IgG glycosylation inhibits autoimmune disease in an IgG subclass-dependent manner. Proc. Natl. Acad. Sci. U. S. A 2008, 105 (39), 15005-15009.

254. Allhorn, M.; Olin, A. I.; Nimmerjahn, F.; Collin, M. Human IgG/Fc gamma R interactions are modulated by streptococcal IgG glycan hydrolysis. PLoS One 2008, 3 (1), e1413.

255. Markine-Goriaynoff, D.; Coutelier, J. P. Increased efficacy of the immunoglobulin G2a subclass in antibody-mediated protection against lactate dehydrogenaseelevating virus-induced polioencephalomyelitis revealed with switch mutants. J. Virol. 2002, 76 (1), 432-435.

256. Coutelier, J. P.; van der Logt, J. T.; Heessen, F. W.; Warnier, G.; Van, S. J. IgG2a restriction of murine antibodies elicited by viral infections. J. Exp. Med. 1987, 165 (1), 64-69.

257. Campbell, C.; Stanley, P. A dominant mutation to ricin resistance in Chinese hamster ovary cells induces UDP-GlcNAc:glycopeptide beta-4-Nacetylglucosaminyltransferase III activity. J. Biol. Chem. 1984, 259 (21), 13370-13378.

258. Stanley, P.; Raju, T. S.; Bhaumik, M. CHO cells provide access to novel N-glycans and developmentally regulated glycosyltransferases. Glycobiology 1996, 6 (7), 695-699.

259. Raju, T. S.; Briggs, J. B.; Borge, S. M.; Jones, A. J. Species-specific variation in glycosylation of IgG: evidence for the species-specific sialylation and branchspecific galactosylation and importance for engineering recombinant glycoprotein therapeutics. Glycobiology 2000, 10 (5), 477-486. 
260. Hodoniczky, J.; Zheng, Y. Z.; James, D. C. Control of recombinant monoclonal antibody effector functions by Fc N-glycan remodeling in vitro. Biotechnol. Prog. 2005, 21 (6), 1644-1652.

261. Shah, P.; Reece-Ford, M.; Dong, S.; Goodall, M.; Pidaparthi, S.; Jefferis, R.; Jenkins, N. Physiological influences on recombinant IgG glycosylation. Biochem. Soc. Trans. 1998, 26 (2), S114.

262. Qian, J.; Liu, T.; Yang, L.; Daus, A.; Crowley, R.; Zhou, Q. Structural characterization of N-linked oligosaccharides on monoclonal antibody cetuximab by the combination of orthogonal matrix-assisted laser desorption/ionization hybrid quadrupole-quadrupole time-of-flight tandem mass spectrometry and sequential enzymatic digestion. Anal. Biochem. 2007, 364 (1), 8-18.

263. Macher, B. A.; Galili, U. The Galalpha1,3Galbeta1,4GlcNAc-R (alpha-Gal) epitope: a carbohydrate of unique evolution and clinical relevance. Biochim. Biophys. Acta 2008, 1780 (2), 75-88.

264. Chung, C. H.; Mirakhur, B.; Chan, E.; Le, Q. T.; Berlin, J.; Morse, M.; Murphy, B. A.; Satinover, S. M.; Hosen, J.; Mauro, D.; Slebos, R. J.; Zhou, Q.; Gold, D.; Hatley, T.; Hicklin, D. J.; Platts-Mills, T. A. Cetuximab-induced anaphylaxis and IgE specific for galactose-alpha-1,3-galactose. N. Engl. J. Med. 2008, 358 (11), 1109-1117.

265. Ashford, D. A.; Alafi, C. D.; Gamble, V. M.; Mackay, D. J.; Rademacher, T. W.; Williams, P. J.; Dwek, R. A.; Barclay, A. N.; Davis, S. J.; Somoza, C.; . Sitespecific glycosylation of recombinant rat and human soluble CD4 variants expressed in Chinese hamster ovary cells. J. Biol. Chem. 1993, 268 (5), 32603267.

266. Wang, X.; Gu, J.; Miyoshi, E.; Honke, K.; Taniguchi, N. Phenotype Changes of Fut8 Knockout Mouse: Core Fucosylation Is Crucial for the Function of Growth Factor Receptor(s). In Methods in Enzymology

Functional Glycomics, Volume 417 ed.; Minoru, F., Ed.; Academic Press: 2006; pp 11-22.

267. Wright, A.; Morrison, S. L. Effect of C2-associated carbohydrate structure on Ig effector function: studies with chimeric mouse-human IgG1 antibodies in glycosylation mutants of Chinese hamster ovary cells. J Immunol 1998, 160 (7), 3393-3402.

268. Wright, A.; Morrison, S. L. Effect of altered CH2-associated carbohydrate structure on the functional properties and in vivo fate of chimeric mouse-human immunoglobulin G1. J Exp Med 1994, 180 (3), 1087-1096.

269. Mimura, Y.; Lund, J.; Church, S.; Dong, S.; Li, J.; Goodall, M.; Jefferis, R. Butyrate increases production of human chimeric IgG in $\mathrm{CHO}-\mathrm{K} 1$ cells whilst maintaining function and glycoform profile. J. Immunol. Methods 2001, 247 (1-2), 205-216.

270. Umana, P.; Jean-Mairet, J.; Bailey, J. E. Tetracycline-regulated overexpression of glycosyltransferases in Chinese hamster ovary cells. Biotechnol. Bioeng. 1999, 65 (5), 542-549. 
I 



\title{
Different glycosylation pattern of human IgG1 and IgG3 antibodies isolated from transiently as well as permanently transfected cell lines
}

\section{Short title: IgG1 and IgG3 glycosylation pattern differences}

\author{
Anne Cathrine Vestrheim ${ }^{1,2}$, Anders Moen ${ }^{3}$, Wolfgang Egge-Jacobsen ${ }^{3}$, Diane Bryant Bratlie ${ }^{1}$, \\ Terje Einar Michaelsen ${ }^{1,2}$ \\ 1. Department of Bacteriology \& Immunology, Norwegian Institute of Public Health, Oslo, Norway \\ 2. School of Pharmacy, Department of Pharmaceutical Chemistry, University of Oslo, Oslo, Norway \\ 3. Department of Molecular Biosciences, University of Oslo, Oslo, Norway
}

Corresponding authors: Anne Cathrine Vestrheim

Terje Einar Michaelsen

Division of Infectious Disease Control

Norwegian Institute of Public Health

P.O. Box 4404 Nydalen, 0403 OSLO

NORWAY

Tel.: +4721076324

Fax: +4721076518

E-mail: Anne.Cathrine.Vestrheim@fhi.no

Terje.e.michaelsen@,fhi.no

t.e.michaelsen@farmasi.uio.no

Word count: 4503

Immunological methods 


\section{Abstract}

The effector functions of IgG depend on the presence of carbohydrates attached to asparagine 297 in the Fc portion. In this report, glycosylation profiles of recombinant wild type and mutant IgG1 and IgG3 antibodies produced from three cell lines were analyzed using LCESI-Orbitrap. Clear differences were detected between IgG1 and IgG3 glycoforms, where IgG1 generally contained fucosylated glycoforms whilst IgG3 mainly were non-fucosylated. When using NS-0 and J558L cells for permanent transfection, IgG1 wt glycoforms differed between the two cell lines, while IgG3 wt glycoforms did not. Transiently transfected HEK 293E cells were used to produce $\mathrm{IgG1}$ and $\mathrm{IgG} 3$ wt and mutants, affecting complement activation. Cell supernatants were harvested at early and late time points and analyzed separately. IgG's harvested late showed simpler and less developed glycosylation structure compared to those harvested early. The IgG harvested early were slightly more effective in complement activation than those harvested late, while the antibody dependent cell-mediated cytotoxicity was unaltered. Generally, the glycosylation pattern of the mutants tested, including a hinge truncate mutant of $\operatorname{IgG} 3$, did not differ significantly from the wild type IgG's. The striking difference in glycosylation pattern of IgG1 compared to $\operatorname{IgG} 3$ therefore appears not to be due to the long hinge region of $\operatorname{IgG} 3$ ( 62 amino acids) relative to the $\operatorname{IgG} 1$ hinge region (15 amino acids). Furthermore, mutation variants at or near the $\mathrm{C} 1 \mathrm{q}$ binding site showed similar glycosylation structure and difference in their complement activation activity observed earlier is thus most likely due to differences in protein structure only. 


\section{Introduction}

IgG is the major serum immunoglobulin and is responsible for recognizing, neutralizing and eliminating toxic antigens as well as pathogens [1]. IgG is divided in four subclasses, IgG1, IgG2, IgG3 and IgG4, with specific and overlapping roles in immune protection, where IgG1 and IgG3 are generally the most important subclasses involved in interaction with Fcreceptors as well as in the capability of activation of the complement system and thereby inactivate or kill the pathogen [2-9].

Carbohydrate groups attached to asparagine 297 in the Fc-portion of IgG have a direct influence on the effector functions of the molecules [10;11]. Recombinant monoclonal IgG antibodies are used to study structure-function relationships and also therapeutically for treatment of cancer and diseases of the immune system, and establishing their glycosylation pattern will therefore be of interest [12-19]. The field of glycosylation analysis of recombinant IgG antibodies described in the literature is very limited and motivated us to undertake the present study.

The carbohydrate molecules attached at asparagine 297 are mannose, $\beta-\mathrm{N}$-acetylglucosamine (GlcNAc), galactose, fucose and sialic acid, and emphasis will be put on the last three in this report. Each of these three carbohydrates affects the immune system and the immune response in different ways. A high degree of galactosylation of IgG is associated with improvement of symptoms during pregnancy for particular auto-immune patients [1;20-25]. Fucose is present as core-fucose and a lack of fucose causes increased antibody-dependent cellular cytotoxicity (ADCC) $[1 ; 26]$. Sialic acid is believed to be responsible for the anti-inflammatory effect of Intravenous immunoglobulin (IVIg), often used to treat autoimmune diseases [1;27-29]. Without any carbohydrates; IgG has a shorter half-life than monomeric a-glycosylated IgG. IgG without carbohydrates bind less well to Fc $\gamma \mathrm{R}$ 's and activate complement less effectively than their carbohydrate containing counterparts [9;20;30]. 
When producing recombinant antibodies either transient gene expression (TGE) or stable gene expression (SGE) is used [31]. The antibodies studied in this paper are produced using both types of expression systems in order to evaluate possible differences in $\operatorname{IgG}$ glycosylation pattern by the two procedures. The cell lines used are HEK 293E, NS-0 and H558L. HEK 293E is a human embryonic epithelial fibroblast cell line broadly used to produce recombinant proteins, including antibodies [32]. J558L is mouse B myeloma cells that is unable to produce heavy chains, but produces a mouse $\lambda 1$ light chain [33]. NS-0 is a mouse myeloma cell line that does not secret neither light chains nor heavy chains, and is extensively used as fusion partner to produce mouse hybridoma cell lines [34-36].

The glycosylation patterns of human serum have previously been determined and both IgG1 and IgG3 displayed heavily fucosylated glycoforms [24]. Recombinant $\alpha$-NIP chimeric mouse-human antibodies from J558L cells have been analyzed previously, and the glycosylation pattern did not show great differences between IgG1 and IgG3, apart from a few glycoforms. IgG2 showed a similar profile to IgG3 while IgG4 was closer to IgG1 [37]. When IgG3 produced in Chinese hamster ovary cells had certain amino acids replaced with alanine, an increase in galactose and sialic acid was observed, providing a possibility for specific modulation of immunoglobulin production to optimize treatments [38]. Apart from this, to our knowledge we found no reports of comparisons of recombinant IgG glycosylation regarding subclass, point mutations, cell lines or transfection type.

We captured IgG1 and IgG3 wild types and mutant molecules by a novel microtiter plate method and analysed the glycoforms by using mass spectrometry analysis of in-well trypsin liberated glycopeptides. The mutant antibodies were produced using HEK 293E cells and two 
different times of harvest were used to study possible variations in glycosylation over time during transient transfection. 


\section{Materials and methods:}

\section{Transient transfection}

10 different IgG1 and IgG3 variants were tested from two different harvest times. This included 6 IgG1 variants; IgG1 wild type, and 5 mutations, IgG1 L234A, IgG1 L235A, IgG1 P329A, IgG1 D270A and IgG1 L234A/L235A. For IgG3, we tested 4 variants; IgG3 wild type, IgG3 m15 (the hinge region had been shortened from 62 amino acids to 15 ), IgG3 D270A and IgG3 P329A1, (see table 1). All the mutations were done using PCR, and the DNA fragments were introduced to the vector. The vector was co-transfected to into the HEK $293 \mathrm{E}$ cell line, and the supernatant collected to carry out the tests as previously described [39]. In this report, the naïve HEK 293E cells used were thawed, transfected and cultivated, and the supernatant was collected at different times, an early collection and a later collection were used, the early collection being 4 days after the transfection and the later collection 10 days after the transfection.

In addition, a further two mutants from HEK 293E cells were tested, but these had been harvested only once on a previous occasion before they were frozen. These were IgG1 H435A and IgG3 N297A (See table 1).

\section{Permanent transfection}

A further 6 variants of IgG1 and IgG3's were analyzed (see table 1). These cells were transfected earlier, the supernatant collected, and the cells and supernatant have been kept frozen in liquid nitrogen for several years, they were therefore not freshly harvested for this exact experiment.

\section{Antibody preparations}


We used either purified antibody preparations isolated as previously described [39] or unpurified cell growth supernatants.

\section{Antibody capture before MS analysis}

We used NIP specific antibodies in this study, and could therefore use microtiter plates coated with $\mathrm{NIP}_{16} \mathrm{BSA}$ to capture the antibodies. Briefly, $100 \mu \mathrm{PBS}$ pH 7.3 containing $1 \mu \mathrm{g} / \mathrm{ml}$ $\mathrm{NIP}_{16} \mathrm{BSA}$ were added to the microtiter wells and left for at least 48 hours at $4{ }^{\circ} \mathrm{C}$, and then washed 4 times with $300 \mu$ d distilled water. $300 \mu$ blocking buffer $(1 \%$ dried milk powder in $\mathrm{PBS} / \mathrm{azid}$ ) was added to each well, and left to incubate for 1 hour at $37^{\circ} \mathrm{C}$. The plate was washed 4 times with distilled water, and $100 \mu$ of each antibody preparation was added in each well, in duplicates. The 10 antibody samples from HEK 293E cells were provided as cell supernatant, and $100 \mu \mathrm{l}$ contained around $1.5 \mu \mathrm{g} / \mathrm{ml}$ from the first harvest, and between 0,8 and $2.6 \mu \mathrm{g} / \mathrm{ml}$ from the second. The other samples were diluted so $100 \mu$ contained approximately $30 \mu \mathrm{g}$ antibody. This was incubated for 2 hours in $37^{\circ} \mathrm{C}$ to allow antigenantibody binding. The plate was then emptied, and washed with $300 \mu 11 \mathrm{M} \mathrm{NaCl} 3$ times, and twice with $300 \mu$ l distilled water. Following the last wash, the plate was knocked vigorously against a bench covered in cell paper, to remove any remaining water. The plate was sealed with tape and refrigerated until trypsin digestion was started.

\section{In well trypsin digestion before MS analysis}

$120 \mu 1$ Trypsin digestion buffer (50 mM ammonium bicarbonate with $15 \%$ acetonitrile) was added to each well, incubated for 5 minutes at $80^{\circ} \mathrm{C}$ and sonicated in a water bath for 30 seconds. $30 \mu 150 \mathrm{mM}$ ammonium bicarbonate containing $600 \mathrm{ng}$ of trypsin in 30 (Sequencing grade modified trypsin from Promega (V5111) or Roche (11418025001)) was added to each well, sonicated for 30 seconds in a water bath and then incubated over night at $37^{\circ} \mathrm{C}$. The 
content of the wells were transferred to Eppendorf tubes (Rainin LiteTouch ${ }^{\mathrm{TM}} 1,7 \mathrm{ml}$ Microcentrifuge Tube LTT-170_B(17011862)), and dried in a Speedvac centrifuge (Maxi dry Iyo F.D.1.0, Heto-Holten, Allerød, Denmark) which took approximately 2 hours. $17 \mu 1$ of $0.1 \%$ formic acid was added to each tube, quickly centrifuged, sonicated for 30 seconds, centrifuged at $16000 \mathrm{G}$ for 10 minutes at $4^{\circ} \mathrm{C}$, and $15 \mu 1$ transferred to MS tubes (VWR International microvials PP, $0.3 \mathrm{ml}$ with short thread, Cat. No 548-0440 and VWR International Screw cap PP transparent, 9 mm silic.white/PTFE r, Cat.No. 548-0034), and the tubes were consequently stored at $-20^{\circ} \mathrm{C}$ until they were analyzed.

\section{Mass spectrometry analysis of trypsin digested IgG samples}

The samples were analyzed on a LC-ESI-Orbitrap. LC separation was carried out on Agilent 1200 series capillary high-performance liquid chromatography (HPLC). $6 \mu \mathrm{l}$ injected in to reverse phase $\left(\mathrm{C}_{18}\right)$ nano online liquid chromatography coupled MS/MS analysis, length $150 \mathrm{~mm}$ and width $0.075 \mathrm{~mm}$, GlycproSIL $\mathrm{C}_{18}-80 \AA$, Glycpromass, Stove, Germany. The peptides were eluted in positive ion mode and CID mode (collision-induced dissociation), where the spectra are isolated and detected in a linear ion trap, providing speed and sensitivity.

Mobile phases were A: water with $0.1 \%$ formic acid and B: acetonitrile with $0.1 \%$ formic acid. LC separation was carried out with a gradient from 10 to $95 \%$, with a flow rate of 0.2 $\mu \mathrm{l} / \mathrm{min}$.

LC system connected to nanoelectrospray source of ThermaScientific LTQ Orbitrap XL mass spectrometer (Thermo Fisher Scientific, Bremen, Germany) operated by Xcalibur 2.0. Nanospray ionization was carried out by applying $1.2 \mathrm{kV}$ between $8 \mu \mathrm{m}$ diameter emitter (PicoTip Emitter, New Objective, Woburn, MA). The capillary temperature was $200^{\circ} \mathrm{C}$ and capillary voltage was $30 \mathrm{~V}$. 


\section{Mass spectrometry data analysis}

Mass spectrometric data were analyzed using Thermo Scientific Xcalibur software version

2.0. The mass tolerance of the parent ion was set at $5 \mathrm{ppm}$. The MS peaks from each glycopeptides were extracted as the maximum peak height within the same retention time window based on parent ion mass, and the MS/MS spectra were manually searched using Qual Browser version 2.0.7. The transiently transfected antibodies with two harvests were all done in duplicates and the permanently transfected and the transiently transfected with one harvest only were analyzed once. Standard deviation was calculated as STDAV in Microsoft Excel 2010. Before the actual samples were analyzed, several test-runs were carried out to make sure the results were reproducible from on analysis to the next.

\section{Measurement of effector functions.}

Antibody dependent complement mediated cell lysis (ADCML) and antibody dependent cell mediated cell lysis (ADCC) were measured as previously described [39;40]. Briefly, $\mathrm{Cr}^{51}$ labeled sheep red blood cells (SRBC) sensitized with rabbit Fab anti-SRBC conjugated with NIP were used as target cells both for ADCML and ADCC. The supernatants were harvested with a harvesting device (Skatron, Norway) and the radioactivity is measured using a gamma counter and the lytic activity is calculated.

The liberation of radioactivity coincided with effector activity. Human serum was used as complement source as previously described and human peripheral blood lymphocytes were used as effector cells for ADCC. 


\section{Results}

The 18 recombinant IgG molecules studied in this report were all analyzed using LC-ESI Orbitrap, searching for 20 different glycoforms [24;41]. The 20 glycoforms were searched for based on the mass of the remaining peptide plus the carbohydrate moiety (see figure 1). The glycoforms can be in different charge states generated during the MS analysis, depending on the number of protons they have, charge state $2(\mathrm{M}+2 \mathrm{H})^{2+}$, when two protons are added, and charge state $3(\mathrm{M}+3 \mathrm{H})^{3+}$, when three protons are added. Even higher charge states are available, but not detected in the experiments reported here. The peaks were integrated and the values for each glycoform in charge state 2 and 3 were combined (see table 2), and the values for all glycoforms added together, and from this the percentage distribution of each glycoform was calculated. A spectrum for IgG1 D270A harvest 1 shows the relative distribution before integration of four of the main glycoforms (see figure 2). Glycoforms that only were present in less than $1.0 \%$ were excluded from the graphs for ease of presentation.

\section{Transient transfection: IgG1 molecules contain strikingly more fucose than IgG3 molecules:}

A clear difference between IgG1 and IgG3 glycoforms was detected. IgG1 wild type and mutants all show rather similar glycoforms and IgG3 wild type and mutants all showed rather similar glycoforms, but these two profiles were opposite to each other, with IgG3 variants having non-fucosylated glycoforms (see figure 3, figure 4 and table 3).

\section{Early harvest at transient transfection contained more complex glycoforms than the late harvest:}

IgG1 wild type and mutants and IgG3 wild type and mutants all showed rather similar profiles within the subclass in the early harvest, and the same is seen in the late harvest, though with a 
decrease in the more complex glycoforms and from IgG1 D270A standing out with more G2F than any of the others (See table 3, figure 3 and figure 4). In the late harvest, wild type and mutants again show a rather similar pattern to each other, but with less complex glycoforms compared to the early harvest (see figure 3). A few stood out in the early harvest, as IgG1 D270A displayed more G2F than any other IgG1, and IgG3D270A also contains a small amount of glycoform G1F, while the presence of G1 was slightly higher in IgG3wt and IgG3D270A (see table 3, figure 3 and figure 4).

\section{Choice of cell line for permanent transfection influences glycosylation pattern for IgG1,}

\section{but not for IgG3}

A further 6 wild types and mutant IgG1 and IgG3's were analyzed, 2 IgG1 and 4 IgG3 (see table 4). The two IgG1 variants differ in their glycoforms, in that chimeric IgG1 from J558L cells hardly has any of the G0F glycoform but a lot of G2F and the exact opposite are seen for chimeric IgG1 from NS-0. The amount of G0 and the presence of G2 also separate the two (see figure 5).

The four IgG3 antibodies from permanently transfected cell lines show similar glycosylation profiles, with only two glycoforms being present, G1 and G2 (see table 4 and figure 6A). Three of the antibodies show a very similar percentage distribution of these two glycoforms, while the last antibody, IgG3 wild type $\alpha$-NIP from J558L deviates from this.

\section{Transient and permanent transfection affects glycosylation pattern of both IgG1 and}

\section{IgG3:}

Chimeric IgG1 chimer from NS-0 portrays a glycosylation profile with a similar trend compared to the other transiently transfected immunoglobulins from harvest 1 (see table 3 and 
table 4). Chimeric IgG1 from J558L on the other hand, has a completely different profile, with G2F as the main glycoform.

IgG3 wild types and IgG3 m15 from transiently transfected HEK 293E cells had equal amounts of G1 and G2 in the first harvest, but mainly G1 in the late harvest, while IgG3 wild type NS-0 and IgG3 m15 NS-0 have G2 as their main glycoform (see figure 6B). Similarities are seen between mutants of different transfection form, such as IgG3 wild type $\alpha$-NIP J558L and IgG3 wild type from NS-0, and IgG3 m15 R435H from NS-0 and IgG3 m15 from NS-0 (see figure 6B). IgG3 glycoforms isolated from NS-0 and J558L are therefore rather similar, but differ from the ones produced by HEK 293E cells.

\section{Some of the transiently transfected IgG mutants from the early harvest displayed higher complement mediated lysis compared to IgG's from the late harvest}

All 10 transiently transfected antibodies from two harvests and the 6 permanently transfected antibodies were tested using ADCML, and some were also tested using ADCC.

ADCML analysis for the 10 transiently transfected antibodies showed that IgG1 P329A, IgG3 P329A and IgG1 L234A/L235A had very low or no cytotoxic activity. IgG1 wild type, IgG3 wild type, IgG3 D270A and IgG3 m15 all gave showed good activity, but with very little variance between the two harvests. IgG1 D270A, IgG1 L234A and IgG1 L235A all showed higher cytotoxic index for the early harvest compared to the late harvest, hence a more active effector function was seen (see figure 7A and 7B).

When the permanently transfected antibodies were tested for ADCML activity, they all gave a high response that did not seem influenced by the choice of cell line. Both chimeric IgG1 $\alpha$ NIP and IgG3 wild type produced in NS-0 cells showed similar results to their J558Lproduced counterparts. The two IgG3 m15 variants, IgG3 m15 and IgG3 m15 R435H, both from NS-0 cells also gave similar results (see figure 7C). 
IgG1 D270A, IgG1 L234A and IgG1 L235A were also tested for ADCC activity and did not show any significant difference between early and late harvest (data not shown).

IgG1 H435A and IgG3 N297A from transiently transfected HEK 293E cells - one harvest only

Two more mutants were transiently transfected from HEK 293E, but these had only been harvested once and then frozen, IgG3 N297A and IgG1 H435A. IgG3 N297A did not contain any glycoforms, as would be expected, as 297 is the position where the sugar moiety is attached.

IgG1 H435A portrays a quite similar pattern to IgG1 chimeric from NS-0 with regards to the major glycoforms (see table 4 and figure 6B). 


\section{Discussion:}

It has lately been accepted that the structure of carbohydrates attached to asparagine 297 in the Fc portion of the IgG molecule has a profound influence on effector functions and thus immune protective capacity. The study of the variation of the glycosylation pattern of recombinant $\mathrm{IgG}$ antibodies is therefore important for a more comprehensive understanding of the relationship between structure and function as DNA-based construction of antibodies is becoming the fastest growing therapeutic category in the pharmaceutical industry. The aim of our study was to reveal possible variation in glycosylation patterns related to differences in subclasses, point mutations, hinge truncation, host cell line, permanent versus transient transfection and the time of harvest for transient transfection. We chose to study IgG1 and IgG3 as they are generally the most immune protective human subclasses. The recombinant antibodies used in this study were chimeric, mouse V-region and human C-region constructed molecules containing a full mouse $\lambda$-1 light chain. Although not formally documented in the literature, it is highly unlikely that neither the V-region nor the light chain will influence the glycosylation structure at position N297 in the Fc-region of IgG and thus our choice of recombinant antibodies anticipate to reflect glycosylation of fully human IgG under the same conditions.

Several striking observations came out of the present study. First of all there was a clear difference in the glycosylation pattern of recombinant human IgG1 and IgG3, revealed by using three different cell lines as host for the production and by using permanent and transient transfection of IgG coding DNA vectors. The most striking difference was a predominant presence of fucosylated glycoforms in IgG1, while IgG3 was mainly non-fucosylated (see figure 3 and figure 4). Observations of human serum IgG did not portray the same trend, as IgG3 did not show this lack of fucose [24]. Similar glycosylation structure analysis of the same IgG1 and IgG3 NIP-antibodies produced from J558L cells has been performed in some 
old studies, but with conflicting results compared to ours. In that analysis, the glycosylation pattern did not show great differences between IgG1 and IgG3, apart from a few glycoforms [37]. They did not detect this heavily fucosylation of IgG1 and non-fucosylation of IgG3. The reason for this is not obvious, but might be due to a different analytical procedure used then, and our state of the art mass spectrometry equipment, giving rise to more accurate and sensitive analysis.

The differences in glycosylation pattern of IgG1 and IgG3 we observed could possibly be due to a very large hinge region of IgG3 (62 amino acids) compared to IgG1 with a hinge of 15 amino $[42 ; 43]$. This was apparently not the case as the hinge truncated mutant $\operatorname{IgG} 3 \mathrm{~m} 15$ containing only one of the hinge exons coding for 15 amino acids exhibits essentially the same glycosylation pattern as wild type IgG3, (See figure 4) [44]. Furthermore, the IgG3 m15 mutant has an enhanced ADCML activity compared to IgG3 wt [45]. The reason for this is not obvious and a possible explanation could be due to an altered glycosylation profile of IgG3 m15. We addressed that question in this report and have clearly shown no major difference in glycosylation structure which can explain the extraordinary high ADCML activity of IgG3 m15.

Secondly, the time of harvest seemed to impact glycosylation. The antibodies produced in transiently transfected cell lines that were harvested 4 days after transfection showed more complex glycoforms compared to the antibodies harvested at 10 days after transfection. Similar observations have been seen previously, as Chinese Hamster Ovary (GS-CHO) cells producing chimeric IgG4 monoclonal antibody cB72.3 showed increasingly shorter chained and simpler glycoforms with increasing growth period [46]. This could possibly be attributed to the different enzymes involved in the glycosylation being put under more strenuous pressure, and not functioning as well as in the beginning of the production, leading to uncompleted sugar composition [46]. When we tested the antibodies for ADCML activity, we 
observed a general trend of higher activity in the early harvest compared to the late harvest (see figure 7A and 7B). Thus the more short-chained carbohydrates observed in the late harvest seem to depress ADCML activity, while this was not the case for ADCC which was unaltered between the two harvests. Apparently $\mathrm{C} 1 \mathrm{q}$ binding or $\mathrm{C} 1$ activation demand more extended carbohydrates to be effective. ADCC, on the other hand seems more independent of this carbohydrate structure variation.

Thirdly, it was clear that choice of permanent cell line affected the glycosylation, as NS-0 and J558L caused different glycosylation profiles for IgG1, while no major differences were seen for IgG3 (see figure 5 and figure 6A). Monoclonal chimeric mouse/human IgG produced in J558L cells caused human heavy chain glycosylation to show typical mouse antibody glycosylation pattern, hence a species specific cell line will in itself affect the glycosylation [47].

Differences in both $\mathrm{O}$ - and $\mathrm{N}$-glycosylation in 12 proteins produced by transient transfection in $\mathrm{CHO}$ and HEK cells have previously been observed, but immunoglobulins were not included. A major difference between the proteins from these two cell lines were that the majority of proteins expressed in $\mathrm{CHO}$ cells had more sialic acid rich glycosylation compared to their HEK counterparts. The differences were found to be caused by the choice of cell line, and not the culture conditions as they varied only slightly between the two cell lines [48]. Sialic acid rich proteins tend to have an extended half-life, as non-sialylated proteins are likely to be eliminated quicker as they bind to a liver receptor [49]. In pilot studies, HEK cells are often used, and when larger quantities are required, a change to CHO cells often occurs, but this transfer may not be as seamless as shown in the study. Whether the glycosylation is determined exclusively by cell type or if post-translational changes are equally important, is not clear [48]. As the list of these 12 proteins did not include immunoglobulins [48], the results can not be directly related to our findings, but we observe with interest the reduced 
sialic acid content in the HEK produced proteins. As the transiently transfected cell lines produced simpler glycoforms as time progressed, possibly because of over-utilization of the enzymes required to make the glycoforms, this could indicate that the same occur for IgG1 in NS-0 cells, but not J558L cells, as that cell line produced more complex glycoforms. A similar observation concerning NS-0 cells was seen with the humanized IgG antibody Campath-1H when expressed in three different cell lines as the glycosylation pattern from NS-0 showed less complex and less overall glycosylation compared to $\mathrm{CHO}$ and $\mathrm{Y} 0$ myeloma cells $[50]$.

Biological activity in the form of complement activation has previously been studied by us using the same wild type and mutant molecules as in this report. The main findings in the previous report was that $\mathrm{IgG} 3$ was more resilient to mutations near the $\mathrm{C} 1 \mathrm{q}$ binding site than IgG1, as point mutations in IgG3 did not affect ADCML whilst for IgG1 particularly the mutant D270A was affected [39]. The difference in ADCML between the mutants could possibly be due to glycosylation differences as the mutations introduced are close to the glycosylation site. Here we show no striking differences in glycoforms when comparing the wild type and mutants and thus the differences in ADCML activity seem only to be due to differences in protein structure.

IgG3 has been showed to possess a stronger ADCC activity compared to IgG1 [51]. As ADCC is mainly activated through Fc $\gamma$ RIIIa and removal of fucose caused a 50-fold increase in receptor-binding, the dominance of non-fucosylated IgG3 we detected in the present report are consistent with IgG3's stronger ADCC activity [26;51]. In conclusion, we used a new isolation technique with a high resolution, sensitive LC-ESIOrbitrap method for glycosylation profile analysis of human IgG and revealed a striking difference between IgG1 and IgG3. IgG1 was mainly fucosylated, while IgG3 was mainly non-fucosylated, probably explaining why IgG3 is often better in ADCC activity than IgG1. 
Furthermore, this difference between IgG1 and IgG3 glycosylation apparently was not due to the very large hinge region of IgG3 and mutations near the C1q binding site did not significantly influence glycosylation. When employing transiently transfected cell lines to produce $\mathrm{IgG}$, the glycosylation structure was more complex earlier in production compared to later. 


\section{Acknowledgements:}

We thank Øistein Ihle, Norwegian Institute of Public Health, Oslo, for construction of the mutants used for transient transfection and Inger Sandlie, Institute of Molecular Bioscience for our joint construction of the IgG3m15 mutant.

This research was supported by a FUGE grant from The Research Council of Norway to Glyconor, grant number 183613. 


\section{Reference List}

1 Kaneko Y, Nimmerjahn F, Ravetch JV. Anti-inflammatory activity of immunoglobulin G resulting from Fc sialylation. Science 2006;313:670-3.

2 Nimmerjahn F, Ravetch JV. Divergent immunoglobulin g subclass activity through selective Fc receptor binding. Science 2005;310:1510-2.

3 Loizou S, Cofiner C, Weetman AP, Walport MJ. Immunoglobulin class and IgG subclass distribution of anticardiolipin antibodies in patients with systemic lupus erythematosus and associated disorders. Clin Exp Immunol 1992;90:434-9.

4 Jefferis R, Pound J, Lund J, Goodall M. Effector mechanisms activated by human IgG subclass antibodies: clinical and molecular aspects. Review article. Ann Biol Clin (Paris) 1994;52:57-65.

5 Ishizaka ST, Piacente P, Silva J, Mishkin EM. IgG subtype is correlated with efficiency of passive protection and effector function of anti-herpes simplex virus glycoprotein D monoclonal antibodies. J Infect Dis 1995;172:1108-11.

6 Jefferis R. Antibody therapeutics: isotype and glycoform selection. Expert Opin Biol Ther 2007;7:1401-13.

7 Burton DR, Woof JM. Human Antibody Effector Function. In: Frank JD, editor. Advances in Immunology. Volume 51 ed. Academic Press; 1992. p. 1-84.

8 Garred P, Michaelsen TE, Aase A. The IgG subclass pattern of complement activation depends on epitope density and antibody and complement concentration. Scand J Immunol 1989;30:379-82.

9 Michaelsen TE, Garred P, Aase A. Human IgG subclass pattern of inducing complement-mediated cytolysis depends on antigen concentration and to a lesser extent on epitope patchiness, antibody affinity and complement concentration. Eur J Immunol 1991;21:11-6.

10 Lis H, Sharon N. Protein glycosylation. Structural and functional aspects. Eur J Biochem 1993;218:1-27.

11 Varki A. Biological roles of oligosaccharides: all of the theories are correct. Glycobiology 1993;3:97-130.

12 Jefferis R. Isotype and glycoform selection for antibody therapeutics. Arch Biochem Biophys.

13 Chames P, Van RM, Weiss E, Baty D. Therapeutic antibodies: successes, limitations and hopes for the future. Br J Pharmacol 2009;157:220-33.

14 Beckman RA, Weiner LM, Davis HM. Antibody constructs in cancer therapy: protein engineering strategies to improve exposure in solid tumors. Cancer 2007;109:170-9. 
15 Cartron G, Dacheux L, Salles G, Solal-Celigny P, Bardos P, Colombat P, et al. Therapeutic activity of humanized anti-CD20 monoclonal antibody and polymorphism in IgG Fc receptor FcgammaRIIIa gene. Blood 2002;99:754-8.

16 Beck A, Wagner-Rousset E, Ayoub D, Van DA, Sanglier-Cianferani S. Characterization of therapeutic antibodies and related products. Anal Chem 2012.

17 Beck A, Wurch T, Bailly C, Corvaia N. Strategies and challenges for the next generation of therapeutic antibodies. Nat Rev Immunol 2010;10:345-52.

18 Reichert JM. Which are the antibodies to watch in 2012? MAbs 2012;4:1-3.

19 Reichert JM. Marketed therapeutic antibodies compendium. MAbs 2012;4:413-5.

20 Tao MH, Morrison SL. Studies of aglycosylated chimeric mouse-human IgG. Role of carbohydrate in the structure and effector functions mediated by the human IgG constant region. J Immunol 1989;143:2595-601.

21 Mimura Y, Sondermann P, Ghirlando R, Lund J, Young SP, Goodall M, et al. Role of oligosaccharide residues of IgG1-Fc in Fc gamma RIIb binding. J Biol Chem 2001;276:45539-47.

22 Tsuchiya N, Endo T, Matsuta K, Yoshinoya S, Aikawa T, Kosuge E, et al. Effects of galactose depletion from oligosaccharide chains on immunological activities of human IgG. J Rheumatol 1989;16:285-90.

23 Matsumoto A, Shikata K, Takeuchi F, Kojima N, Mizuochi T. Autoantibody activity of IgG rheumatoid factor increases with decreasing levels of galactosylation and sialylation. J Biochem 2000;128:621-8.

24 Wuhrer M, Stam JC, van de Geijn FE, Koeleman CA, Verrips CT, Dolhain RJ, et al. Glycosylation profiling of immunoglobulin $\mathrm{G}(\mathrm{IgG})$ subclasses from human serum. Proteomics 2007;7:4070-81.

25 Rook GA, Steele J, Brealey R, Whyte A, Isenberg D, Sumar N, et al. Changes in IgG glycoform levels are associated with remission of arthritis during pregnancy. $\mathrm{J}$ Autoimmun 1991;4:779-94.

26 Shields RL, Lai J, Keck R, O'Connell LY, Hong K, Meng YG, et al. Lack of fucose on human IgG1 N-linked oligosaccharide improves binding to human Fcgamma RIII and antibody-dependent cellular toxicity. J Biol Chem 2002;277:26733-40.

27 Nimmerjahn F, Ravetch JV. The antiinflammatory activity of IgG: the intravenous IgG paradox. J Exp Med 2007;204:11-5.

28 Bruhns P, Samuelsson A, Pollard JW, Ravetch JV. Colony-Stimulating Factor-1Dependent Macrophages Are Responsible for IVIG Protection in Antibody-Induced Autoimmune Disease. Immunity 2003;18:573-81.

29 Jefferis R. Glycosylation as a strategy to improve antibody-based therapeutics. Nat Rev Drug Discov 2009;8:226-34. 
30 Coloma MJ, Clift A, Wims L, Morrison SL. The role of carbohydrate in the assembly and function of polymeric IgG. Mol Immunol 2000;37:1081-90.

31 Nallet S, Fornelli L, Schmitt S, Parra J, Baldi L, Tsybin YO, et al. Glycan variability on a recombinant IgG antibody transiently produced in HEK-293E cells. New Biotechnology 2012;29:471-6.

32 Shaw G, Morse S, Ararat M, Graham FL. Preferential transformation of human neuronal cells by human adenoviruses and the origin of HEK 293 cells. FASEB J 2002;16:86971.

33 Oi VT, Morrison SL, Herzenberg LA, Berg P. Immunoglobulin gene expression in transformed lymphoid cells. Proc Natl Acad Sci U S A 1983;80:825-9.

34 Lasunskaia EB, Fridlianskaia II, Darieva ZA, da Silva MS, Kanashiro MM, Margulis BA. Transfection of NS0 myeloma fusion partner cells with HSP70 gene results in higher hybridoma yield by improving cellular resistance to apoptosis. Biotechnol Bioeng 2003;81:496-504.

35 Selman MH, Derks RJ, Bondt A, Palmblad M, Schoenmaker B, Koeleman CA, et al. Fc specific IgG glycosylation profiling by robust nano-reverse phase HPLC-MS using a sheath-flow ESI sprayer interface. J Proteomics 2012;75:1318-29.

36 Gorfien S, Paul B, Walowitz J, Keem R, Biddle W, Jayme D. Growth of NS0 cells in protein-free, chemically defined medium. Biotechnol Prog 2000;16:682-7.

37 Lund J, Takahashi N, Nakagawa H, Goodall M, Bentley T, Hindley SA, et al. Control of $\mathrm{IgG} / \mathrm{Fc}$ glycosylation: a comparison of oligosaccharides from chimeric human/mouse and mouse subclass immunoglobulin Gs. Mol Immunol 1993;30:741-8.

38 Lund J, Takahashi N, Pound JD, Goodall M, Jefferis R. Multiple interactions of IgG with its core oligosaccharide can modulate recognition by complement and human Fc gamma receptor I and influence the synthesis of its oligosaccharide chains. J Immunol 1996;157:4963-9.

39 Michaelsen TE, Sandlie I, Bratlie DB, Sandin RH, Ihle O. Structural difference in the complement activation site of human IgG1 and IgG3. Scand J Immunol 2009;70:553-64.

40 Aase A, Michaelsen TE. The use of a hapten-Fab conjugate to sensitize target cells for antibody-dependent complement-mediated lysis and antibody-dependent cell-mediated cytotoxicity. J Immunol Methods 1991;136:185-91.

41 Selman MH, Derks RJ, Bondt A, Palmblad M, Schoenmaker B, Koeleman CA, et al. Fc specific IgG glycosylation profiling by robust nano-reverse phase HPLC-MS using a sheath-flow ESI sprayer interface. J Proteomics 2012;75:1318-29.

42 Michaelsen TE, Frangione B, Franklin EC. Primary structure of the "hinge" region of human IgG3. Probable quadruplication of a 15-amino acid residue basic unit. J Biol Chem 1977;252:883-9. 
43 Huck S, Fort P, Crawford DH, Lefranc MP, Lefranc G. Sequence of a human immunoglobulin gamma 3 heavy chain constant region gene: comparison with the other human C gamma genes. Nucleic Acids Res 1986;14:1779-89.

44 Michaelsen TE, Aase A, Westby C, Sandlie I. Enhancement of complement activation and cytolysis of human IgG3 by deletion of hinge exons. Scand J Immunol 1990;32:517-28.

45 Michaelsen TE, Aase A, Westby C, Sandlie I. Enhancement of complement activation and cytolysis of human IgG3 by deletion of hinge exons. Scand J Immunol 1990;32:517-28.

46 Reid CQ, Tait A, Baldascini H, Mohindra A, Racher A, Bilsborough S, et al. Rapid whole monoclonal antibody analysis by mass spectrometry: An ultra scale-down study of the effect of harvesting by centrifugation on the post-translational modification profile. Biotechnol Bioeng 2010;107:85-95.

47 Lund J, Takahashi N, Hindley S, Tyler R, Goodall M, Jefferis R. Glycosylation of human IgG subclass and mouse IgG2b heavy chains secreted by mouse J558L transfectoma cell lines as chimeric antibodies. Hum Antibodies Hybridomas 1993;4:205 .

48 Croset A, Delafosse L, Gaudry JP, Arod C, Glez L, Losberger C, et al. Differences in the glycosylation of recombinant proteins expressed in HEK and $\mathrm{CHO}$ cells. J Biotechnol 2012;161:336-48.

49 Ashwell G, Harford J. Carbohydrate-specific receptors of the liver. Annu Rev Biochem 1982;51:531-54.

50 Lifely MR, Hale C, Boyce S, Keen MJ, Phillips J. Glycosylation and biological activity of CAMPATH-1H expressed in different cell lines and grown under different culture conditions. Glycobiology 1995;5:813-22.

51 Michaelsen TE, Aase A, Norderhaug L, Sandlie I. Antibody dependent cell-mediated cytotoxicity induced by chimeric mouse-human IgG subclasses and IgG3 antibodies with altered hinge region. Mol Immunol 1992;29:319-26. 


\section{Tables}

TABLE 1

Table 1. 18 IgG1 and IgG3 antibodies were analyzed. The first 10 are transiently transfected IgG1 and IgG3 antibodies produced in HEK 293E cells harvested at two time points, one early (4 days) and one late (10 days). The next 2 antibodies are also produced in transiently transfected HEK 293E cells, but there were harvested only once. The last 6 antibodies are produced in permanently transfected NS-0 and J558L cells and were harvested only once. Leu $=$ leucine, $\mathrm{Ala}=$ alanine, $\mathrm{Asp}=$ aspartic acid, Pro $=$ proline, His $=$ histidine, Asn $=$ asparagine, $\operatorname{Arg}=$ arginine

\begin{tabular}{|l|l|l|}
\hline Antibody & Description of mutation & Cell line \\
\hline IgG1 wt & IgG1 wild type & HEK 293E \\
\hline IgG1 L234A & IgG1 where Leu at position 234 is mutated to Ala & HEK 293E \\
\hline IgG1 L235A & IgG1 where Leu at position 235 I smutated to Ala & HEK 293E \\
\hline IgG1 L234S/L235A & $\begin{array}{l}\text { IgG1 where Leu at position 234 and 235 is } \\
\text { mutated to Ala }\end{array}$ & HEK 293E \\
\hline IgG1 D270A & IgG1 where Asp at position 270 is mutated to Ala & HEK 293E \\
\hline IgG1 P329A & IgG1 where Pro at position 329 is mutated to Ala & HEK 293E \\
\hline IgG3 wt & IgG3 wild type & HEK 293E \\
\hline IgG3 D270A & IgG3 where Asp at position 270 is mutated to Ala & HEK 293E \\
\hline IgG3 P329A & IgG3 where Pro at position 329 is mutated to Ala & HEK 293E \\
\hline IgG3 m15 & $\begin{array}{l}\text { IgG3 where the hinge is shortened to 15 amino } \\
\text { acids }\end{array}$ & HEK 293E \\
\hline IgG1 H435A & IgG1 where His at position 435 is mutated to Ala & HEK 293E \\
\hline IgG3 N297A & IgG3 where Asn at position 297 is mutated Ala & HEK 293E \\
\hline IgG1 chimeric & IgG1 chimeric & NS-0 \\
\hline IgG1 chimeric & IgG1 chimeric & J558L \\
\hline IgG3 wt & IgG3 wild type & NS-0 \\
\hline IgG3 m15 chimeric & $\begin{array}{l}\text { IgG3 where the hinge is shortened to 15 amino } \\
\text { acids }\end{array}$ & NS-0 \\
\hline IgG3 wt $\alpha$-NIP & IgG3 wild type & J558L \\
\hline IgG3 m15 R435H & $\begin{array}{l}\text { IgG3 where the hinge is shortened to 15 amino } \\
\text { acids, and Arg at position 435 is mutated to His }\end{array}$ & NS-0 \\
\hline
\end{tabular}


TABLE 2

\begin{tabular}{|c|c|c|c|c|}
\hline & \multicolumn{2}{|c|}{$\lg \mathbf{G 1}$} & \multicolumn{2}{|c|}{$\lg$ G3 } \\
\hline & Charge state 2 & Charge state 3 & Charge state 2 & Charge state 3 \\
\hline & \multicolumn{2}{|c|}{ EEQYNSTYR } & \multicolumn{2}{|c|}{ EEQFNSTFR } \\
\hline G0F & 1317.5270 & 878.6891 & 1301.5320 & 868.0235 \\
\hline G1F & 1398.5530 & 932.7044 & 1382.5581 & 922.0411 \\
\hline G2F & 1479.5794 & 986.7220 & 1463.5848 & 976.0587 \\
\hline G1FS & 1544.1007 & 1029.7362 & 1528.1058 & 1019.0729 \\
\hline G2FS & 1625.1271 & 1083.7538 & 1609.1322 & 1073.0905 \\
\hline GOFN & 1419.0663 & 946.3799 & 1403.0714 & 935.7166 \\
\hline G1FN & 1500.0927 & 1000.3975 & 1484.0978 & 989.7342 \\
\hline G2FN & 1581.1191 & 1054.4151 & 1565.1242 & 1043.7518 \\
\hline G1FNS & 1645.6404 & 1097.4293 & 1629.6455 & 1086.7660 \\
\hline G2FNS & 1726.6668 & 1151.4469 & 1710.6719 & 1140.7836 \\
\hline G0 & 1244.4976 & 830.0008 & 1228.5027 & 819.3375 \\
\hline G1 & 1325.5240 & 884.0184 & 1309.5291 & 873.3551 \\
\hline G2 & 1406.5504 & 938.0360 & 1390.5555 & 927.3727 \\
\hline G1N & 1427.0637 & 951.7115 & 1411.0688 & 941.0483 \\
\hline GON & 1346.0373 & 897.6939 & 1330.0420 & 887.0307 \\
\hline G2N & 1508.0901 & 1005.7291 & 1492.0952 & 1381.2423 \\
\hline G1S & 1471.0717 & 981.0502 & 1455.0768 & 1356.5634 \\
\hline G2S & 1552.0981 & 1035.0678 & 1536.1032 & 1410.5810 \\
\hline G1NS & 1572.6114 & 1048.7433 & 1556.6165 & 1424.2570 \\
\hline G2NS & 1653.6378 & 1102.7609 & 1637.6430 & 1478.2740 \\
\hline
\end{tabular}




\section{TABLE 3}

Table 3. The average percentage distribution for the different glycoforms found for IgG1 and IgG3 produced in transiently transfected HEK 293E cells from two harvest, harvest 1 (early) and harvest 2 (late). The last two IgG antibodies were also produced in HEK 293E cells, but these had only one harvest. Of these, IgG3 N297A had no glycoforms, as would be expected, as the oligosaccharides are situated at asparagine 297. For all of these antibodies, only glycoforms found are presented.

\begin{tabular}{|l|c|c|c|c|c|c|c|c|c|c|}
\hline Glycoforms & G0F & G1F & G2F & G1N & G1 & G2 & G0FN & G1FN & G0 & G2FS \\
\hline $\begin{array}{l}\text { Antibodies from HEK } \\
\text { 293E cells - 2 harvests }\end{array}$ & & & & & & & & & & \\
\hline IgG1 wt Harvest 1 & 51.8 & 45.6 & 2.7 & & & & & & & \\
\hline IgG1 wt Harvest 2 & 86.9 & 13.1 & & & & & & & & \\
\hline IgG1 P329A Harvest 1 & 50.0 & 45.1 & 4.9 & & & & & & & \\
\hline IgG1 P329A Harvest 2 & 81.3 & 16.6 & 1.3 & & & & 0.3 & 0.1 & 0.4 & \\
\hline IgG1 D270A Harvest 1 & 32.8 & 46.5 & 14.9 & & & & 2.2 & 3.6 & & \\
\hline IgG1 D270A Harvest 2 & 66.1 & 26.8 & 2.7 & 0.5 & & & 3.9 & & & \\
\hline IgG1 L234A Harvest 1 & 49.3 & 42.2 & 8.6 & & & & & & & \\
\hline IgG1 L235A Harvest 2 & 76.4 & 20.6 & 1.9 & & & & 0.4 & 0.1 & 0.6 & \\
\hline IgG1 L235A Harvest 1 & 49.6 & 45.2 & 5.2 & & & & & & & \\
\hline IgG1 L235A Harvest 2 & 77.7 & 19.7 & 1.5 & & & & 0.4 & 0.1 & 0.7 & \\
\hline IgG1 L234A/L235A Harvest 1 & 41.9 & 50.9 & 7.1 & & & & & & & \\
\hline IgG1 L234A/L235A Harvest 2 & 75.3 & 22. & 2.0 & & & & 0.1 & 0.2 & 0.4 & \\
\hline IgG3wt Harvest 1 & 0.0 & & & & 60.4 & 39.6 & & & & \\
\hline IgG3wt Harvest 2 & & & & 1.2 & 85.7 & 13.1 & & & & \\
\hline IgG3 P329A Harvest 1 & & & & & 44.1 & 55.9 & & & & \\
\hline IgG3 P329A Harvest 2 & & & & 1.1 & 80.0 & 18.9 & & & & \\
\hline IgG3 D270A Harvest 1 & & 0.3 & 0.1 & 0.1 & 55.0 & 44.6 & & & & \\
\hline IgG3 D270A Harvest 2 & & & & 1.6 & 84.9 & 13.5 & & & & \\
\hline IgG3 m15 Harvest 1 & & & & & 49.5 & 50.5 & & & & \\
\hline IgG3 m15 Harvest 2 & & & & 0.4 & 82.7 & 16.9 & & & & \\
\hline & & & & & & & & & & \\
\hline $\begin{array}{l}\text { Antibodies from HEK 293E } \\
\text { Cells -1 harvest }\end{array}$ & & & & & & & & & \\
\hline IgG1 H435A HEK 293E & 55.8 & 32.4 & 9.2 & & & & & 2.0 & & 0.7 \\
\hline IgG3 N297A HEK 293E & & & & & & & & & & \\
\hline
\end{tabular}


TABLE 4

\begin{tabular}{|c|c|c|c|c|c|c|}
\hline Glycoforms & G0F & G1F & G2F & G1 & G2 & G0 \\
\hline \multicolumn{7}{|c|}{ Permanent cell lines } \\
\hline IgG1 chimer NS-0 & 58.1 & 25.9 & 11.0 & 1.0 & & 4.0 \\
\hline IgG1 chimer J558L & 3.2 & 18.3 & 71.9 & 0.9 & 5.5 & 0.3 \\
\hline IgG3 wt NS-0 & & & & 22.8 & 77.2 & \\
\hline IgG3 m15 NS-0 & & & & 23.6 & 76.4 & \\
\hline IgG3 wt anti-NIP J558L & & & & 33.0 & 67.0 & \\
\hline IgG3 m15 R435H NS-0 & & & & 21.3 & 78.7 & \\
\hline
\end{tabular}




\section{Legends to figures}

Figure 1: The 20 different glycoforms studied in this report. Black square = peptide, blue square $=N$-acetylglucosamine, green circle $=$ mannose, red triangle $=$ fucose, yellow circle $=$ galactose and pink diamond $=$ sialic acid

Figure 2: The MS spectrum of IgG1 D270A from harvest 1 (early) with relative distribution of G0F, G1F, G0FN and G2F. The X-axis shows the mass and the Y-axis shows relative rebundance

Figure 3: IgG1 wild type and mutants from transiently transfected HEK 293E cells from two harvests, displaying percentage distribution of the 5 glycoforms found for harvest 1 (early) and 7 glycoforms found for harvest 2 (late). If an antibody did not present a particular glycoform, that antibody is not displayed on the graph.

Figure 4: IgG3 wild type and mutants from transiently transfected HEK 293E cells from two harvests, displying percentage distribution of the $\mathbf{5}$ glycoforms found for harvest 1 (early) and 4 glycoforms found for harvest 2 (late). If an antibody did not present a particular glycoform, that antibody is not displayed on the graph.

Figure 5: IgG1 produced in permanently transfected NS-0 and J558L cells from one harvest only with the 6 glycoforms found, presented as percentage distribution. If anantibody did not present a particular glycoform, that antibody is not displayed on the graph.

Figure 6: IgG3 antibodies produced in permanently and transiently transfected cells. A. IgG3 produced in permanently transfected NS- 0 and J558L cells from one harvest only with the 2 glycoforms found, presented as percentage distribution. B. IgG3 wild type and mutants from transiently tranfected HEK 293E cells - harvest 1 (early) and from permanently transfected NS-0 and J558 cells. If an antibody did not present a particular glycoform, that antibody is not displayed on the graph.

Figure 7: ADCML results for transiently and permanently transfected antibodies. A. Transiently transfected IgG1 L234A and IgG1 L235A from both early and late harvest where the early harvest is represented by a continuous line and the late harvest by a dotted line. $\mathrm{B}$. Transiently transfected IgG1 wild type and IgG1 D270A from two harvests, where the early harvest is represented by a continuous line and the late harvest by a dotted line. C. Permanently transfected chimeric IgG1 $\alpha$-NIP from NS-0 (continuous line) and J558L (dotted line) and IgG3 wild type $\alpha$-NIP from NS-0 cells (continuous line) and J558L cells (dotted line). 
Figures

FIGURE 1

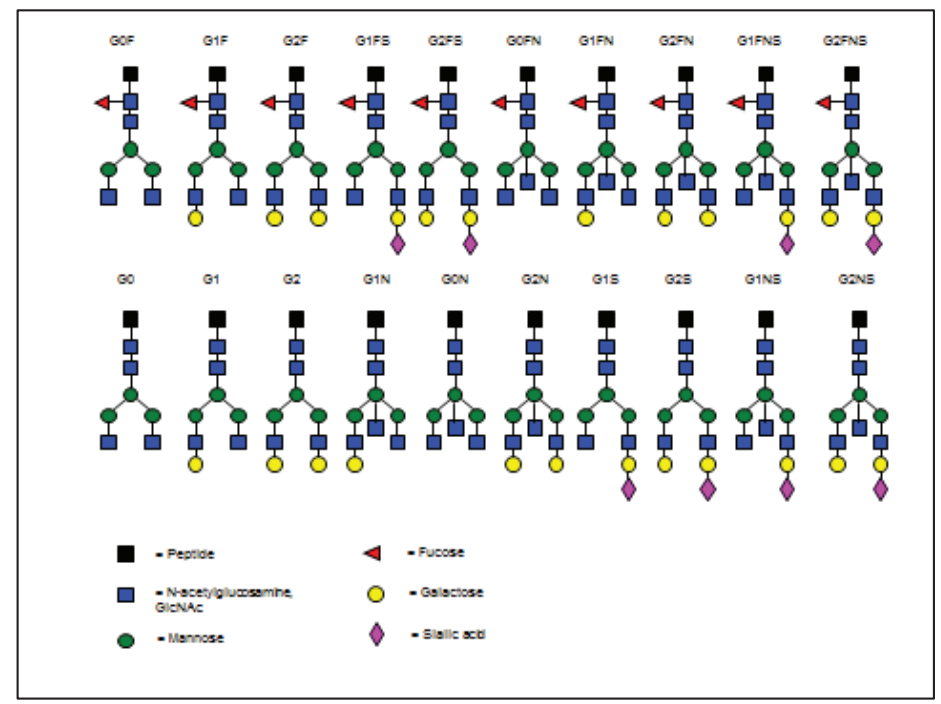

FIGURE 2

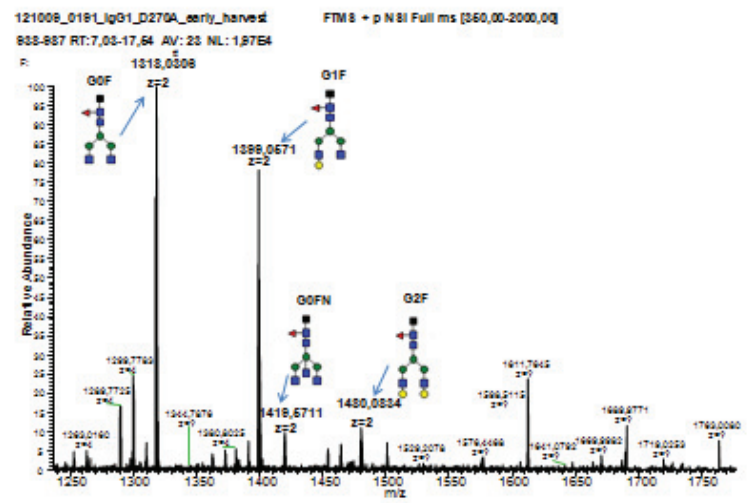


FIGURE 3
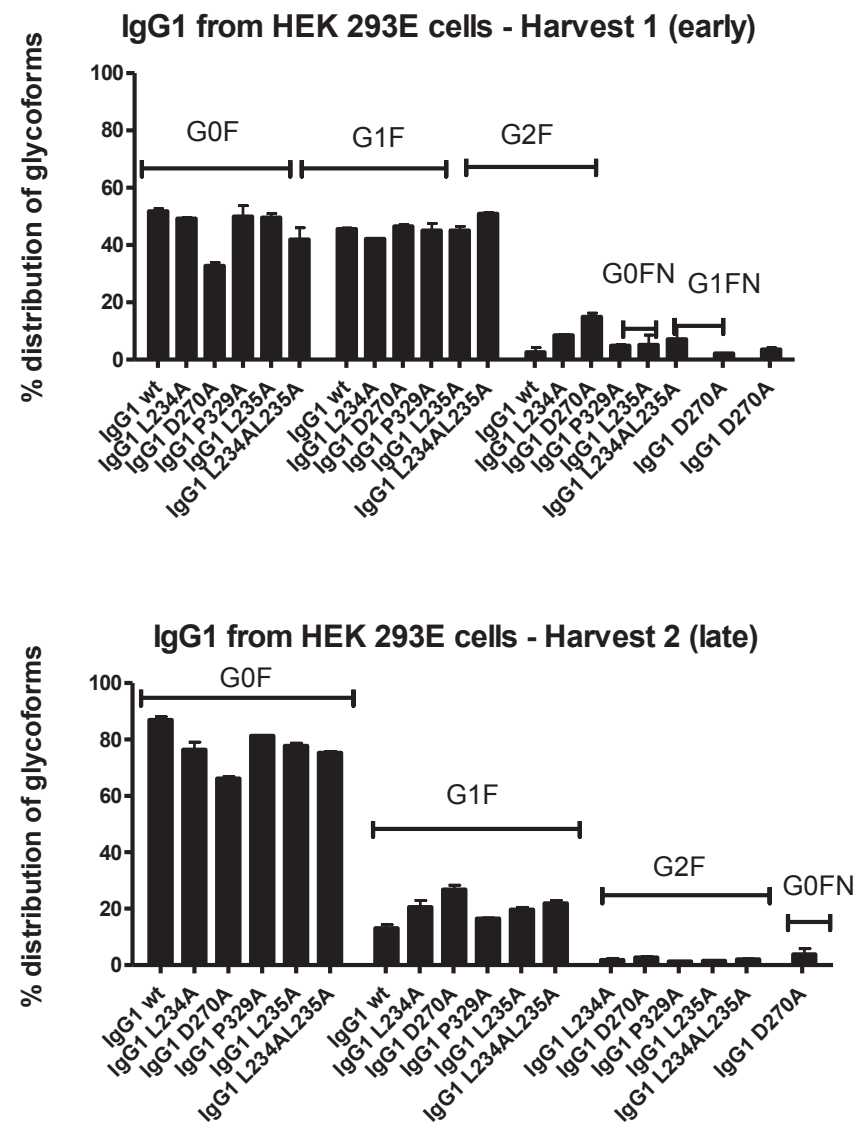
FIGURE 4

IgG3 from HEK 293E cells - Harvest 1 (early)

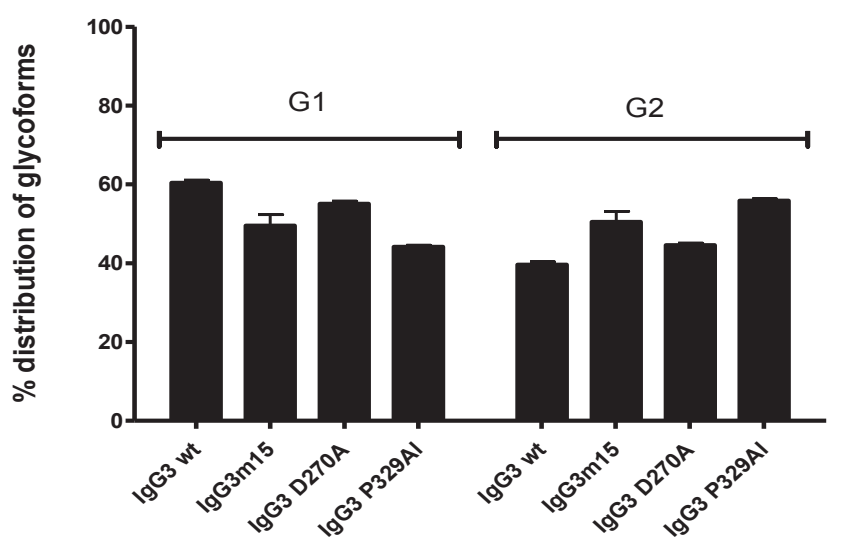

IgG3 from HEK 293E cells - Harvest 2

(late)

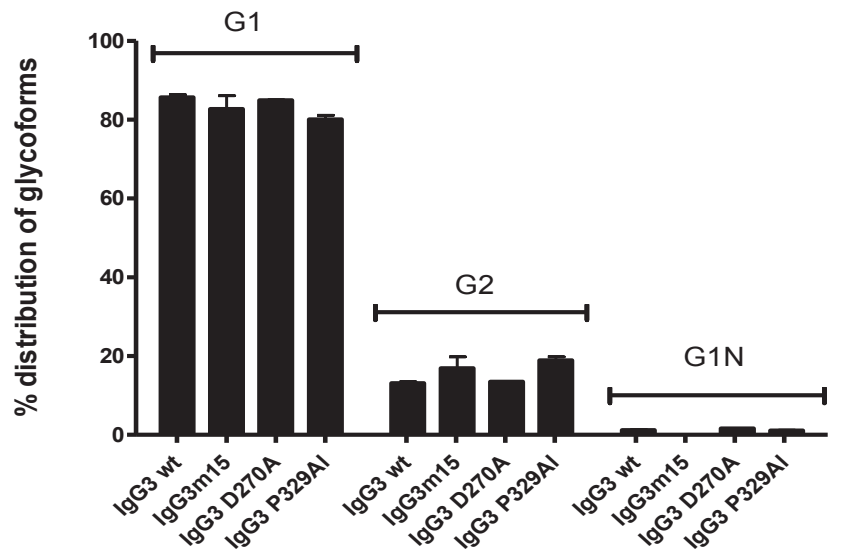


FIGURE 5

\section{IgG1 from different}

permanently

transfected cell lines

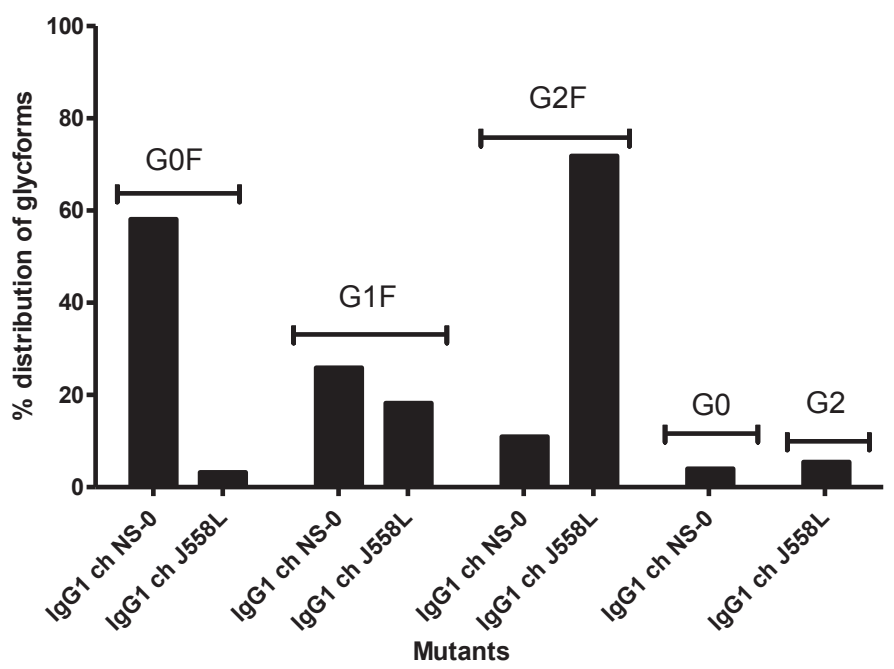


FIGURE 6

A

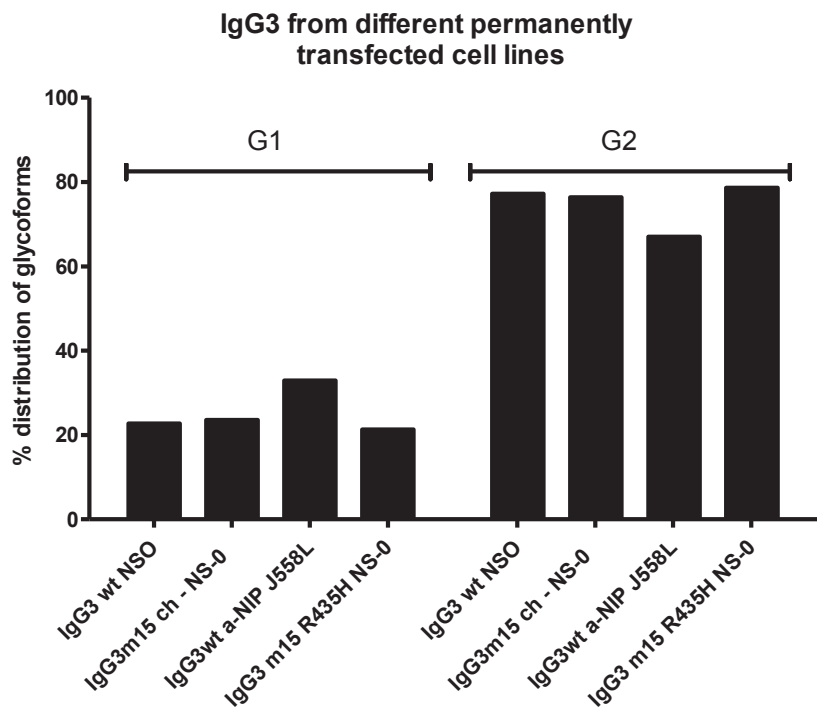

B

IgG3 from transiently and permanently transfected cell lines

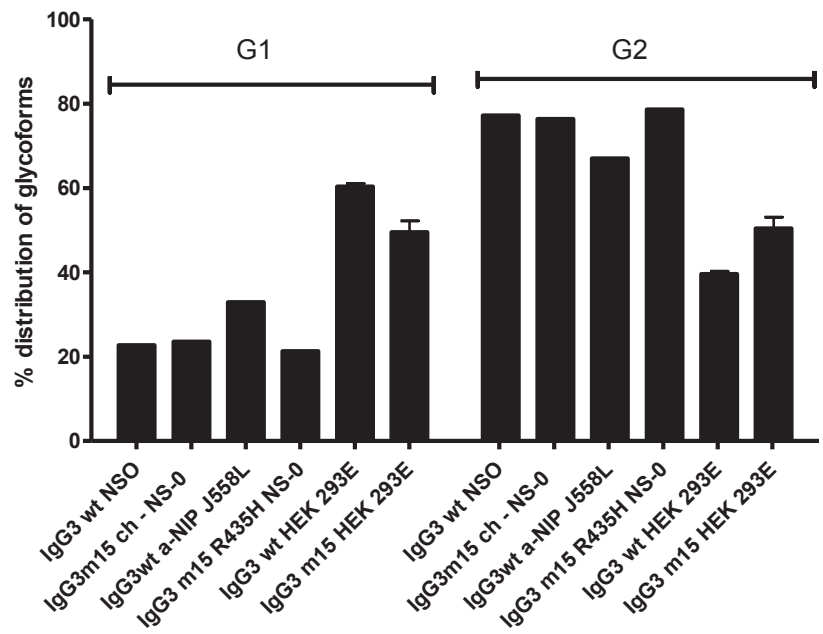


FIGURE 7

A

ADCML

Transiently transfected IgG1

Early harvest vs late harvest

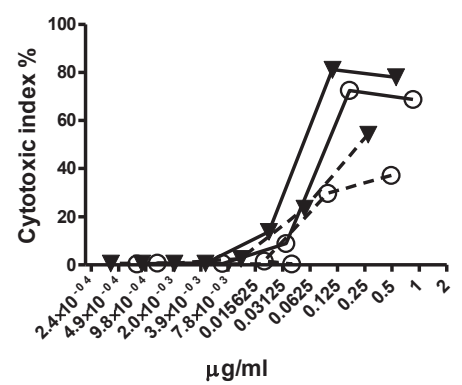

Ө IgG1 L234A, early harvest - IgG1 L235A, early harvest

○ IgG1 L234A, late harvest

₹- IgG1 L235A, late harvest

B

ADCML

Transiently transfected IgG1 Early harvest vs late harvest

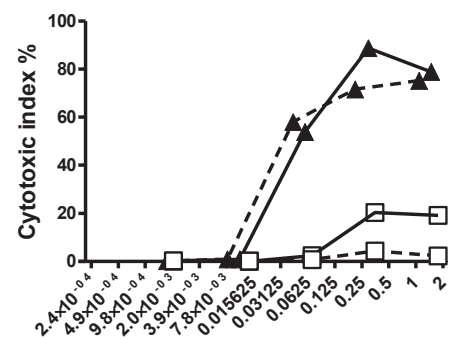

+ IgG1 wt, early harvest

IgG1 D270A, early harvest - IgG1 wt, late harvest

$\square$ IgG1 D270A, late harvest

$\mu \mathrm{g} / \mathrm{ml}$

C

ADCML for IgG1 + IgG3

Permanently transfected NS-O vs J558L cell lines

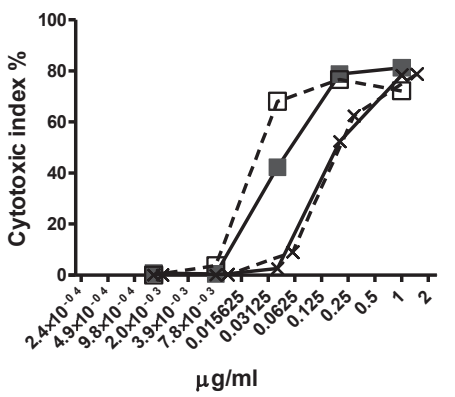

- $\lg$ G1 ch aNIP-NSO

IgG1 ch aNIP-J558L

* IgG3 wt aNIP-NSO

*- IgG3 wt aNIP-J558L

$\mu \mathrm{g} / \mathrm{ml}$ 


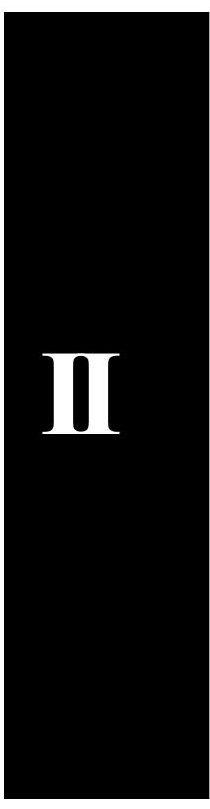





\section{Differences in glycosylation pattern of IgG subclasses induced by pneumococcal, meningococcal and two types of influenza vaccines}

A. C. Vestrheim ${ }^{1,2} \#_{2}$ A. Moen ${ }^{3}$, W. Egge-Jacobsen ${ }^{3}$, L. Reubsaet ${ }^{2}$, T. Grønhaug Halvorsen ${ }^{2}$, D. B. Bratlie$^{1}$, B.S. Paulsen ${ }^{2}$, T. E. Michaelsen ${ }^{1,2} \#$

1. Department of Bacteriology \& Immunology, Norwegian Institute of Public Health, Oslo, Norway

2. School of Pharmacy, Department of Pharmaceutical Chemistry, University of Oslo, Oslo, Norway

3. Department of Molecular Biosciences, University of Oslo, Oslo, Norway

Corresponding authors:

Anne Cathrine Vestrheim

Norwegian Institute of Public Health

P.O. BOX 4404 Nydalen, 0403 OSLO

NORWAY

Tel.: +4721076324

Fax: +4721076518

Anne.cathrine.vestrheim@fhi.no

Terje Einar Michaelsen

Norwegian Institute of Public Health

P.O. Box 4404 Nydalen, 0403 OSLO

NORWAY

Tel.: +4721076324

Fax: +4721076518

t.e.michaelsen@farmasi.uio.no 


\section{Abstract:}

The presence of a carbohydrate moiety on asparagine 297 in the Fc part of the IgG molecule is essential for its effector functions and thus its protective effect by vaccination. In order to better understand and exploit the protective potential of IgG antibodies, detailed structural carbohydrate analysis of vaccine induced IgG's is therefore of interest. In this report, serum or plasma from volunteers receiving vaccines have been collected at different time points and the IgG subclass glycosylation pattern determined. The four vaccines used were a pneumococcal capsule polysaccharide vaccine, a meningococcal outer membrane vesicle vaccine, a seasonal influenza vaccine and a pandemic influenza vaccine. Antibodies against specific vaccine antigens were captured using microtiter wells coated with the individual vaccines and analyzed for their glycosylation profile by a high resolution, sensitive LC-ESI analysis of trypsin generated glycopeptides. Following immunization, the IgG subclass which dominated the response showed an increase in galactose and the level of sialic acid levels increased with time for most vaccines. Fucose levels did increase for some vaccinees, but for the majority fucose was relatively unaltered. The total background IgG glycosylation analyzed in parallel varied little with time, and hence the changes seen were caused by immunization. The presence of an adjuvant in the pandemic influenza vaccine produced simpler and fewer different glycoforms compared to the seasonal influenza vaccine. This pilot study demonstrates that detailed IgG glycosylation pattern analysis might be a necessary step in addition to biological testing for optimizing vaccine development and strategies. 


\section{Introduction:}

A robust IgG response is generally a hallmark of an effective vaccine against invasive pathogens $(54,57,59)$. Several studies have demonstrated that the presence of carbohydrates in the Fc part of the IgG molecule has a direct influence on effector functions and thus its vaccine protective effect. Remarkably, IgG can also have a dramatic anti-inflammatory effect and intravenous immunoglobulin G (IVIg), which is pooled immunoglobulin from healthy donors, is used to treat autoimmune diseases and other chronic inflammatory diseases(35). This anti-inflammatory effect of IVIg seems dependent on the presence of sialic acid at the Fc glycosylation site(3). Galactose is another carbohydrate of interest, and the amount of antibodies with galactose changes during the life cycle and also during disease states, such as Chrohn's disease or rheumatoid arthritis. Patients suffering from these auto-immune diseases display a level of non-galactosylated antibodies that is often twice that of what is seen in healthy controls (28). Strikingly, pregnant women suffering from rheumatoid arthritis often have an increase in galactose-rich IgG in combination with an improvement of disease symptoms (4). Interestingly, mouse IgG1 with high content of galactose has anti-inflammatory activity by engaging the inhibitory FcyRIIb(17), further elucidating the glycan importance for IgG function. Fucose on the other hand appears to have an essential role in antibody dependent cellular cytotoxicity (ADCC) and opsonophagocytosis as monoclonal humanized IgG1 with low levels of corefucose shows dramatic higher ADCC and opsonophagocytosis activity compared to the same antibodies with a higher amount of core-fucose (48). This is due to an increased affinity to FcyRIIla and FcyRIIIb, respectively $(2,13,47)$.

Immunization studies have been carried out in mice, where they were immunized with bovine serum albumin (BSA), resulting in anti-BSA titres with reduced levels of galactosylation, while increased fucosylation were seen after each ovalbumin immunizations $(11,21)$. The glycosylation pattern of IgG1following immunization against influenza and tetanus has recently been published, and showed that IgG1 had increased level of sialic acid and galactose following immunization, while the glycosylation of total background IgG in these volunteers were unaltered (44). Apart from this, we 
have found no other studies investigating IgG glycosylation pattern in humans following immunization. In the spring of 2009, the appearance of a new influenza virus, $\mathrm{H} 1 \mathrm{~N} 1$, originated in Mexico and soon spread throughout the world(5). For the most part, influenza is considered a benign illness, but in particularly the elderly, the very young or immune-compromised patients, it can be a serious disease, with an increase in morbidity and mortality $(18,64)$. Streptococcus pneumoniae is a Gram-Positive diplococcus responsible for a vast array of infectious diseases, including sinusitis, otitis media and pneumonia (non-invasive) as well as meningitis and bacteraemia (invasive). It is also the main bacteria causing community acquired pneumonia (39). In the very young and in the elderly, the bacteria can cause severe morbidity and mortality (55). Meningitidis neisseria is an encapsulated gram negative diplococci bacterium that can cause meningococcal disease, where serogroup $A, B$ and C account for at least $90 \%$ of all meningococcal disease $(51,60)$. Meningococcal vaccines mainly induced an IgG1 and IgG3 response(32), whilst polysaccharide vaccines, such as pneumococcal vaccines, mainly produce an IgG2 response(26). The main IgG subclass for influenza vaccines is likely to be $\lg G 1$.

To determine the glycosylation pattern of immunoglobulin G, IgG, from serum or plasma samples, mass spectrometry is often used $(50,62,63)$. The carbohydrates are covalently linked at asparagine 297 on the Fc region of the antibody(4), and the carbohydrates of interest are fucose, sialic acid and galactose. In our study, the serum IgG glycosylation pattern of all relevant IgG subclasses from volunteers given four different vaccines has been analyzed, a pneumococcal capsule polysaccharide vaccine, a meningococcal outer membrane vesicle vaccine, a seasonal influenza vaccine and a pandemic influenza vaccine Blood samples were taken at different time points following vaccination, and the specific antibodies were captured using microtiter wells coated with vaccine antigens and analyzed for differences in glycosylation pattern. For comparison, the glycosylation pattern of total background IgG was also analyzed. The presence or absence of different carbohydrates may influence the roles of the antibody and its functions. There were 20 glycoforms searched for in this report, (See Fig.1). Our method permitted the differentiation of all the IgG subclasses of interest. 


\section{Methods and Materials:}

\section{Sample collection}

For the pneumococcal and both influenza vaccines, the volunteers involved in the project were set to receive these vaccinations as part of their own vaccination regimes, therefore approval from ethical committees was not necessary. The plasma and serum from the volunteers receiving the meningococcal study were remnants from a previous study that was approved by the Norwegian Medicines Control Authority and the Regional Ethical Committee for Medical Sciences, South East Norway. A new application for use of these samples in our study was approved by the Regional Ethical Committee for Medical Sciences, South East Norway. The vaccine for meningococcal bacteria were given as three (or in some cases four) different doses, whilst the other vaccines were given as just one dose. Pneumovax (Sanofi Pasteur MSD) used in this study, is a 23-valent pneumococcal polysaccharide vaccine used in adults with little effect in children under the age of 2 years as their immune system has not matured enough to start a T-cell independent B-cell response $(26,40,55)$. Outer membrane vesicles (OMV) are spherical lipid bilayer vesicle isolated from the outer membrane of gram negative bacteria by detergent treatment and centrifugation $(8,27,32)$. An outer membrane vesicle vaccine against group B meningococcal (MenBVac ${ }^{\circ}$ ) used in this study has been developed at the Norwegian Institute of Public Health in the late eighties $(6,14,42)$. A vaccine, Pandemrix (GlaxoSmithKline) used in this study was produced, based on strain A/California/7/2009(61).

\section{IgG subclass determination}

A method to quantitate the subclasses of the meningococcal vaccine response has previously been described (32), Shortly, microtiter plates coated with OMV were washed and serum or plasma applied together with specific IgG1 and IgG3 antibodies against OMV and incubated for 2 hours at $37^{\circ} \mathrm{C}$, washed and IgG subclass specific monoclonal antibodies were applied. These were obtained from the WHO/International Union of Immunological Societies (IUIS) Immunoglobulin Subcommittee, IgG1 (HP 6012), IgG2 (HP 6002) and IgG3 (HP 6050)(33). This was incubated for 1 hour at $37^{\circ} \mathrm{C}, \mathrm{ALP}-$ 
anti-mouse IgG is applied and incubated for 1 hour at $37^{\circ} \mathrm{C}$, washed and substrate is applied and the plate read in an ELISA reader (Precision microplate reader from Molecular Devices at $405 \mathrm{~nm}$ ). The same principle was applied to detect the influenza and pneumococcal IgG subclass vaccine response, but as we had no specific antibodies against the other vaccine antigens, only the amount of one IgG subclass compared to another could be measured, not exact $\mu \mathrm{g} / \mathrm{ml}$ values.

\section{Antibody capture:}

A microtiter plate was coated with $100 \mu \mathrm{l}$ antigen in PBS and left for 48 hours at $4^{\circ} \mathrm{C}$. For the meningococcal vaccine serum, $4 \mu \mathrm{g} / \mathrm{ml}$ OMV antigen directed against the Norwegian strain 44/76 was used. For the pneumococcal vaccine serum, $1 \mu \mathrm{g} / \mathrm{ml}$ of Pneumovax pneumococcal capsule polysaccharide vaccine (Sanofi Pasteur MSD) was used. For the influenza serum, $1.5 \mu \mathrm{g} / \mathrm{ml}$ of Begrivac ${ }^{\circledR}$ seasonal influenza vaccine (Novartis) and $2 \mu \mathrm{g} / \mathrm{ml}$ of Pandemrix pandemic influenza vaccine (Glaxo-SmithKline) were used. The plate was then washed x 5 with $300 \mu$ l distilled water. The plate was vigorously knocked against the bench to make sure it was empty. A blocking buffer consisting of $1 \%$ dried milk in PBS/azid was added to each well- $300 \mu \mathrm{l}$, and incubated for 1 hour at $37^{\circ} \mathrm{C}$. The plate was then washed again with $300 \mu$ distilled water $\times 5$. The plasma samples were diluted 1 to 2.5 , and the serum samples 1 in 5 with $5 \mathrm{M} \mathrm{NaCl}$ (plasma samples were already diluted 1 to 1 during the isolation process). This was incubated for 2 hours in $37^{\circ} \mathrm{C}$ to allow antigen-antibody binding. The plate was then emptied, and washed with $300 \mu \mathrm{l} 1 \mathrm{M} \mathrm{NaCl} 3$ times, and twice with 300 $\mu \mathrm{l}$ distilled water. Following the last wash, the plate was knocked vigorously against a bench covered in cell paper, to remove any remaining water. The plate was sealed with tape and refrigerated until trypsin digestion was started.

\section{Protein A and Protein G columns were used to isolate background total IgG:}

$1 \mathrm{ml}$ HiTrap protein A and $1 \mathrm{ml}$ HiTrap protein G columns from GE Healthcare were coupled together with protein A first, followed by the protein G column. By this procedure; IgG1, IgG2 and IgG4 should be bound to the protein A column, while IgG3 should be bound to the protein $\mathrm{G}$ column. ELISA 
quantitation was carried out to determine whether the isolation had been successful and only negligible traces of IgG3 were found in the eluates from the protein A column (data not shown).

$375 \mu$ l of serum mixed with $625 \mu$ l of PBS/azid were added to the columns and left in room temperature for 10 minutes. $1 \mathrm{ml}$ of PBS/azid were then injected and left for 10 minutes incubation in room temperature. $10 \mathrm{ml}$ of PBS/azid were then eluted through the columns to remove any unbound proteins.

The two columns were then separated and flushed with an additional $5 \mathrm{ml} \mathrm{PBS/azid} \mathrm{before} \mathrm{IgG3}$ elution with $0.1 \mathrm{M}$ glycin/ $\mathrm{HCl}(\mathrm{pH} 2.8)$ from the protein $\mathrm{G}$ column while IgG1, IgG2 and IgG4 were eluted from the protein A column with $0.2 \mathrm{M} \mathrm{NaAc}(\mathrm{pH} 4.0)$. In total, $5 \mathrm{ml}$ of elution buffer was used for each column, giving 5 vials of $1 \mathrm{ml}$ eluate. This was neutralized with $1.5 \mathrm{M}$ TRIS pH 8.5.

\section{Trypsin digestion before MS analysis}

The background IgG samples were digested with trypsin in Nanosep ${ }^{\circledR}$ Centrifugal Devices (10K, blue, OD010C33, Pall Corporation, NY, USA). Approximately $50 \mu \mathrm{g}$ of antibodies were transferred to Nanosep devices. The devices were centrifuged for 5 minutes at $13000 \times \mathrm{xg}$ at $4^{\circ} \mathrm{C}$, and the content at the bottom of the vial was discarded. $120 \mu \mathrm{l}$ Trypsin digestion buffer ( $50 \mathrm{mM}$ ammonium bicarbonate with $15 \%$ acetonitrile) was added to each well or Nanosep ${ }^{\circledR}$ device, incubated for 5 minutes at $80^{\circ} \mathrm{C}$ and sonicated in a water bath for 30 seconds. $600 \mathrm{ng}$ of trypsin was added to each well and $1 \mu \mathrm{g}$ of trypsin was added to each centrifugal device (Sequencing grade modified trypsin from Promega (V5111) or Roche (11418025001)) and sonicated for 30 seconds in a water bath, followed by an overnight incubation at $37^{\circ} \mathrm{C}$. The following day the centrifugal devices were centrifuged again at $13000 \mathrm{G}$ at $4^{\circ} \mathrm{C}$ for 5 minutes and the separation filters removed. The content of the wells were transferred to Eppendorf tubes (Rainin LiteTouch ${ }^{\mathrm{TM}} 1.7 \mathrm{ml}$ Microcentrifuge Tube LTT170_B(17011862)) and the extracts were dried in a Speedvac centrifuge (Maxi dry lyo F.D.1.0, HetoHolten, Allerød, Denmark) which took approximately 2 hours. $17 \mu$ l of $0.1 \%$ formic acid was added to each Eppendorf tube or centrifugal device, quickly centrifuged, sonicated for 30 seconds and lastly 
centrifuged at $16000 \mathrm{G}$ for 10 minutes at $4^{\circ} \mathrm{C} .15 \mu \mathrm{l}$ was then transferred to MS vials (VWR International microvials PP $0.3 \mathrm{ml}$ with short thread, Cat. No 548-0440 and VWR International Screw cap PP transparent, $9 \mathrm{~mm}$ silic.white/PTFE r, Cat.No. 548-0034), and the tubes were consequently stored at $-20^{\circ} \mathrm{C}$ until they were analyzed.

\section{Mass spectrometry analysis of trypsin digested IgG samples}

The samples were analyzed on a LC-ESI Orbitrap (apart from the samples from one vaccine from the pneumococcal vaccine group, details below). LC separation was carried out on Agilent 1200 series capillary high-performance liquid chromatography (HPLC).

$6 \mu \mathrm{l}$ digestion mixture was injected in to reverse phase $\left(C_{18}\right)$ nano online liquid chromatography coupled MS/MS analysis, length $150 \mathrm{~mm}$ and width $0.075 \mathrm{~mm}$, GlycproSIL $\mathrm{C}_{18}-80 \AA$, Glycpromass, Stove, Germany. The peptides were eluted in positive ion mode and HCD (higher energy collisional dissociation) and CID mode (collision-induced dissociation), where the spectra are isolated and detected in a linear ion trap, providing speed and sensitivity.

Mobile phases were A: water with $0.1 \%$ formic acid and B: acetonitrile with $0.1 \%$ formic acid. LC separationwas carried out with a gradient from 10 to $95 \%$ and a flow rate of $0.2 \mu \mathrm{l} / \mathrm{min}$.

LC system connected to nanoelectrospray source of Thermo Scientific LTQ Orbitrap XL mass spectrometer (Thermo Fisher Scientific, Bremen, Germany) operated by Xcalibur 2.0.

The samples were analysed with higher energy collisional dissociation, HCD, and collision induced dissociation, CID. For HCD fragmentation, Orbitrap survey scans were obtained the mass range $m / z$ 300-2000 and CID fragmentation performed with a target value of 5000 ions. When developing the method, samples were run in parallels of three, but as the method was established and reproducible results were seen, this was reduced to two parallels for each sample. The majority of the meningococcal vaccine response samples were run in parallels of three, while the rest of two. 
Nanospray ionization was carried out by applying $1.2 \mathrm{kV}$ between $8 \mu \mathrm{m}$ diameter emitter (PicoTip Emitter, New Objective, Woburn, MA). The capillary temperature was $200^{\circ} \mathrm{C}$ and capillary voltage was $30 \mathrm{~V}$.

One volunteer from the pneumococcal vaccine group was not run on the Orbitrap mentioned above, but on another Orbitrap. This was also a Thermo Scientific LTQ XL mass spectrometer (Thermo Fisher Scientific, Bremen, Germany) and the LC separation was carried out on Dionex UltiMate 3000 RCLC nano system. $6 \mu$ l digestion mixture was injected in to reverse phase $\left(C_{18}\right)$ nano online liquid chromatography coupled MS/MS analysis, length $150 \mathrm{~mm}$ and width 0,075 mm, Acclaim PepMap $\mathrm{C}_{18^{-}}$ $100 \AA ̊$ (Dionex, Thermo Scientific, Sunnyvale CA, USA) with a trap colum, (Acclaim PepMap 100 C18, 5 $\mu \mathrm{m}, 100 \AA$, $300 \mu \mathrm{m}$ i.d. $5 \mathrm{~mm}$ length with a flow of $10 \mu \mathrm{l} / \mathrm{min}$ ).

\section{Mass spectrometry data analysis}

Mass spectrometric data were analyzed using Thermo Scientific Xcalibur software version 2.0. Samples were made in duplicates and the variation measured was calculated. The mass tolerance of the parent ion was set at $5 \mathrm{ppm}$. The MS peaks from each glycopeptides were extracted as the maximum peak height within the same retention time window based on parent ion mass, and the MS/MS spectra were manually searched by Qual Browser version 2.0.7. To compare different integration methods both the area of the peaks and the average height were tried, but as these gave the same results (data not shown), the two methods can be used interchangeably and the average height was used in this report. Statistical analysis was carried out using the Friedman test to evaluate differences between the visits and the Wilcoxon test to evaluate differences between specific lgG and total background IgG, both with a $p$-value of $<0.05$ considered statistically significant. 


\section{Results}

4 different types of vaccines were tested, meningococcal (7 vaccinees), pneumococcal (4 vaccinees), pandemic influenza 2009-2010 (5 vaccinees) and seasonal influenza 2009-2010 (one vaccinee), 20102011 (two vaccinees) and 2011-2012 (three vaccinees). For the pneumococcal and both types of influenza vaccines, three general time points were chosen for blood collection, day 0 , right before the first vaccine, and day 30 and day 90 after vaccination. Deviations from this did occur to accommodate the schedules of the vaccinees. Subclass quantitation confirmed that IgG2 was the main subclass response for the pneumococcal vaccine and IgG1 and IgG3 for the others (See Supp. Table 1 for meningococcal results, data for the others not shown). It was not possible to obtain serum from day 100 from two of the pneumococcal vaccinees, hence day 0 , day 14 and day 26 were analysed in this case. There was however not much differences between day 14, day 26 and day 112 and for ease of presentation, the time points for those two vaccinees are still labelled day 30 and day 90. Additional time points for some vaccinees were collected. For the 5 vaccinees in the pandemic influenza group, three were in the age group 26-30 (vaccinees \# 005, \# 006 and \# 007) and two in the age group 65+ (vaccinees \# 008 and \# 009). These two age groups are not large enough to determine statistically significant differences, but can provide indications of trends regarding age differences.

For the meningococcal vaccinees, the scheme varied somewhat, as these vaccinees had received several doses of the vaccine. Plasma samples from seven vaccinees were analysed and the three time points used were 1-2 weeks after the third vaccine dose (visit 4), 10-12 months after the third dose (visit 6) and finally 1-2 weeks after the fourth dose (visit 7). For vaccinee \# 020, serum from three earlier time points were also analysed; Day 0 before the first vaccine dose (visit 1), 6-8 weeks after the first vaccine dose (visit 2) and 6-8 weeks after the second dose (visit 3). In addition, 8 samples from volunteer \# 022 were analysed, including the six mentioned, as well as 6-8 weeks after the third vaccine dose (visit 5) and 4-6 weeks after the fourth dose (visit 8). The samples taken at all other time points than visit 4, 6 and 7 were serum samples, not plasma. 
The samples studied in this report were all analyzed using LC-ESI Orbitrap, searching for 20 different glycoforms $(45,63)$. These include glycoforms with and without fucose, galactose and sialic acid, as well as bisecting $\mathrm{N}$-acetylglucosamine (See Fig.1). The glycoforms can be in different charge states depending on the number of protons they have, charge state $2(\mathrm{M}+2 \mathrm{H})^{2+}$, when two protons are added, and charge state $3(\mathrm{M}+3 \mathrm{H})^{3+}$, when three protons are added. Even higher charge states are available, but in the experiments reported here, those were the ones found, giving two options for each IgG1 or IgG3 glycoform (See Table 1).The peaks were integrated and the values for each glycoform in charge state 2 and 3 were combined, and the values for all glycoforms added together, and from this the percentage distribution of each glycoform was calculated. $\mathrm{MS}^{2}$ was carried out to confirm that the mass belonged to the correct glycoform (See Fig.2). Glycoforms that represented less than $1 \%$ of the total distribution were excluded from the graphs. The background IgG was also analysed to compare any changes seen in glycosylation. When analysing IgG2 and IgG3 in mass spectrometry a differentiation between the two is not possible as the mass of the trypsin generated peptides will be the same in both cases. The vaccine serum was separated in to an IgG1/IgG2/IgG4 fraction by elution from the protein A column, and an IgG3 fraction eluted from the protein $G$ column.

\section{Galactosylation:}

The main responding subclass: All vaccines induced an increase in galactose from day 0 to day 30 after vaccination (See Fig.3 A, D, G and J). At 3 months, galactose levels varied between different vaccines and for individual vaccinees. Reactive pneumococcal IgG2 galactose levels increased from day 0 to day 30 and then stayed the same or slightly decreased while the galactose levels for pandemic IgG1 increased from day 0 to day 30 , with a further increase (3 vaccinees) or a decrease (2 vaccinees) from day 30 to day 100 . For the extra pandemic influenza samples, an increase was seen at day 290 (vaccinee \# 005) and day 559 (vaccinee \# 006), both from the younger group, while for one vaccinee in the 65+ group, a decrease was seen on day 201. Galactose levels in seasonal 
influenza IgG1 increased from day 0 to day 30, and kept stabile or decreased from day 30 to day 100. Meningococcal IgG1 increased after vaccination (visit 7) and showed diverse level between vaccinees after time. Statistical analysis showed statistical significant increases was seen for three of the vaccines (See Supp. Table 2 ), the meningococcal vaccine ( $p$-value 0.005$)$, the seasonal influenza vaccine ( $p$-value 0.016$)$ and the pneumococcal vaccine ( $p$-value 0.018$)$.

The minor responding subclass: Pneumococcal IgG1 and seasonal influenza IgG3 had stable levels of galactose (See Table 2). Pandemic IgG3 showed an increase in galactose for most vaccinees at day 30 , followed by either stabile levels or a further increase at day 100 . The same trend regarding the late sampling days for IgG1 was seen for IgG3, an increase at day 290 (vaccinee \# 005) and day 559 (vaccinee \# 006) and a decrease at day 201 (vaccine \# 009). Galactose levels for meningococcal IgG3 increased after vaccination and decreased with time. No statistical differences were seen for galactosylation (See Supp Table 3).

\section{Fucosylation:}

The main responding subclass: Fucose levels increased for the seasonal influenza from day 0 to day 30, and remained stable or decreased slightly for other vaccines, but fucose levels were overall close to or at $100 \%$ fucosylation (See Fig. 3 B, E, H and K). All glycoforms were close to or at $100 \%$ fucosylation. No statistical differences were seen for fucosylation (See Supp. Table 2).

The minor responding subclass: Fucose levels of IgG1 from the pneumooccal vaccine also stay stable throughout (See Table 2). Fucose levels in IgG3 for the other 3 vaccines differed between the vaccines, with seasonal influenza staying stable, pandemic influenza decreasing and meningococcal vaccine increasing. Pneumococcal IgG1 were completely fucosylated while seasonal influenza IgG3 had one vaccine with stable levels, all the others were non-fucosylated. Pandemic IgG3 fucosylation decreased from day 0 to day 30 for almost all vaccinees, and either stayed the same or decreased at 
day 100. OMV IgG3 decreased at visit 6 , followed by an increase at visit 7 . Statistical analysis showed no significant differences for fucosylation (See Supp. Table 3).

\section{Sialylation:}

The main responding subclass: Sialic acid levels increased from day 0 to day 30 after vaccination for all vaccines, and at three months they decreased again for most vaccines (See Fig.3 C, F, I and L). Pneumococcal IgG2 sialylation increased from day 0 to day 30, and then stayed stabile. Pandemic IgG1 sialylation was more varied, as amongst the $65+$ group there was either no sialic acid or a decrease on day 30 , followed by an increase on day 100 . The younger group showed either low amounts and a steady decrease throughout, or an increase at day 30 and then a decrease at the next time points. For seasonal and meningococcal vaccinees, IgG1 sialylation levels increased after vaccination and decreased with time. For the meningococcal vaccinee with 8 visits analysed, the amount of sialic acid increased after each vaccination. Statistical analysis showed significant increases for three of the vaccines (See Supp. Table 2), the meningococcal vaccine ( $p$-value 0.034 ), the seasonal influenza vaccine ( $p$-value 0.002$)$ and the pneumococcal vaccine ( $p$-value 0.039 ).

The minor responding subclass: Pneumococcal IgG1 sialylation stayed stable at $15-20 \%$, while pandemic IgG3 had no sialic acid levels (3 vaccinees) or continuous increases with time (2 vaccinees) (See Table 2). Sialylation for seasonal IgG3 stayed stable, while an increase was seen after vaccination for meningococcal lgG3, followed by a decrease with time. Sialic acid levels for pneumococcal IgG1 did not change very much throughout. IgG3 sialylation levels for the other vaccines differed between vaccines, with no change in the seasonal influenza vaccine, increases or stable levels at day 30 for the other two, and decreasing or stable levels at day 90 . Only the meningococcal vaccine showed a statistical significant differences ( $p$-value 0.028) (See Supp. Table 3).

\section{Vaccine formulation affects glycosylation of the minor, but not the major responding subclass}


The pneumococcal vaccine is a carbohydrate vaccine, producing mainly an IgG2 response. The main response was rather similar, irrespective of subclass, but the IgG1 minor response from the pneumococcal vaccine differed significantly from the $\lg G 1$ response from the other vaccines, as levels stayed stable for pneumococcal IgG1, but increased in levels for all three carbohydrates (See Table 2).

\section{The adjuvant squalene leads to less complex glycoforms}

Two different types of influenza vaccine were analysed, a seasonal influenza vaccine without adjuvant and a pandemic influenza vaccine with the adjuvant squalene. The pandemic influenza vaccine induced fewer different glycoforms (4-10 vs 11-13) and these were of a less complex type, compared to the adjuvant-free seasonal influenza vaccine (See Fig.4). The meningococcal vaccine had another adjuvant, $\mathrm{Al}(\mathrm{OH})_{3}$, but this did not affect the glycoforms in the same way that squalene did for the pandemic influenza vaccine.

\section{Repeated annual vaccination results in similar glycosylation pattern}

For the seasonal influenza, 3 individuals participated, but two volunteers received the vaccine in two or three consecutive years. Hence season 2009-2010 (vaccinee \# 010), 2010-2011 (vaccinee \# 011) and season 2011-2012 (vaccinee \# 012) is all the same individual. Season 2010-2011 (vaccinee \# 013) and 2011-2012 (vaccinee \# 014) is the same individual. For the last volunteer, only one season was analysed, 2011-2012, from vaccinee \# 015. We found that being given the same vaccination for consecutive years, the same glycosylation pattern was observed (See Fig.3 G, H and I).

\section{Differences in glycosylation between individuals}

Variation in glycoforms from one individual to another occurred, but one vaccinee was fairly unique compared to the other vaccinees. For meningococcal vaccinee \# 022, 8 time points were analyzed, and the IgG3 response differed substantially compared to the other meningococcal vaccinees (See Fig.5). The IgG3 response was mainly un-fucosylated, but this was apparently specific for that 
individual, as the total background IgG3 also were mainly non-fucosylated, unlike all the other vaccinees, regardless of type of vaccine.

For seasonal influenza IgG3, all but one vaccinee only had glycoforms with galactose. The same vaccinee also portrayed a stabile level with $90 \%$ fucosylated glycoforms, while all other vaccinees had no fucosylated glycoforms (See Table 2). This was quite unique compared to the other vaccines, as there was no distinct difference between fucosylation of $\lg G 1$ and $\lg G 3$. For this vaccine, no $\lg G 3$ with sialic acid was observed.

\section{Glycosylation of background IgG}

The total background IgG did not change significantly from an early time point to a late time point after immunization and little difference was seen between IgG1 and IgG3 (vaccinee \# 022 being the exception), perhaps most surprisingly regarding fucosylation (data not shown). Changes seen in the glycosylation pattern for specific IgG were therefore caused by the immunization. When combining total background IgG for all four vaccines, total background IgG1 eluted from protein A represented 54-86 \% galactose, 82-99 \% fucose and 1-16 \% sialic acid. IgG3 eluted from protein G displayed 56-99 \% galactose (excluding pneumococcal vaccinees that had 39-76\%), 77-97 \% fucose (except two meningococcal vaccinees, \# 019 and \# 022, that portrayed 24-47 \% and 2-15\%, respectively) and 0$31 \%$ sialic acid. Vaccine \# 022 showed a large difference in fucosylation between IgG1 and IgG3 (See Fig.5). Total background IgG2 from the pneumococcal vaccinees were eluted for protein A; displaying 46-73 \% galactose, $67-96 \%$ fucose and 4-8 \% sialic acid. The pandemic influenza vaccine had 2 vaccinees at $65+$ and 3 younger, and the levels of galactose in the $65+$ group were $55-58 \%$ for $\operatorname{lgG} 1$ and IgG3, which was distinctly lower than the corresponding values in the younger group; $69-75 \%$. Statistical analysis using the Wilcoxon test with a $p$-value $<0.05$ considered significant, the main responding subclass were compared to the background IgG at day 0 and day 90 for the pneumococcal and the two influenza vaccines, and visit 4 and 6 for the meningococcal vaccine. 
Statistically significant differences were seen for most of the vaccines (See Supp. Table 4). The pandemic influenza showed random changes in sialylation following vaccination which was reflected in the Wilcoxon test with a $p$-value of 0.5 , and hence not significant. The pneumococcal vaccine showed no statistically significant p-values for any types of glycosylation, possibly because the second time point was very far apart from the first. 


\section{Discussion}

The structure of the carbohydrates attached to asparagine 297 in the Fc portion of an IgG molecule has direct influence on its effector functions and immune protective capacity. The aim of this pilot study was to analyze antibody response after immunization with four different types of vaccines to determine the glycosylation pattern. These vaccines were chosen in order to show influence on IgG glycosylation by varying the vaccine components by using split, hemagglutinin based influenza vaccines, more complex meningococcal outer membrane vesicles ( $88 \%$ protein, $5 \%$ LPS and $7 \%$ phospholipids) with $\mathrm{Al}(\mathrm{OH})_{3}$ as adjuvant and pure pneumococcal capsule polysaccharide. The main differences between the pandemic and seasonal influenza vaccines were the dose (3.75 $\mu \mathrm{g} \mathrm{HA}$ for the pandemic and $15 \mu \mathrm{g} \mathrm{HA}$ for the seasonal) and adjuvant for the pandemic vaccine only. Furthermore, we wanted to investigate variation in IgG glycosylation over time since experiments in mice have indicated that especially sialic acid is increasing very late in the immune response, compatible with the notion that IgG act anti-inflammatory when the acute risk phase during infection is over. Here, mice were pre-sensitized with sheep IgG and challenged with a nephrotoxic serum, NTS, giving a mouse IgG response where the level of sialylation for total IgG was reduced by $40 \%$ and for specific anti-sheep IgG by $50-60 \%(16)$. It has been suggested that IgG immune response has two phases, one pro-inflammatory shown in the acute phase during infection and possibly also right after a primary vaccination. A hallmark of such pro-inflammatory IgG activity could be lack of core-fucose, favoring ADCC activity and phagocytosis $(34,35,46)$. However, this hypothesis is to a large extent based on experiments in mice and not in humans, such as mice being immunized with bovine serum albumin (BSA), resulting in anti-BSA titres with reduced levels of galactosylation, while increased fucosylation were seen after each ovalbumin immunizations $(11,21)$. Thus results from human immunizations are much needed to clarify if a two-phase biological activity could be observed in a vaccination situation in humans. Our present report is a pilot study and the number of subjects limited; however, we did observe many striking features which warrant further larger studies. 
First of all, we did not observe a prominent lack of IgG core-fucose right after vaccination for any of the vaccines applied compared to blood samples taken from the same person at later time points. Secondly, we did not observe the hallmark for anti-inflammatory IgG; a noticeable increase in terminal sialic acid late in the response (up to one year after the primary vaccination) for any of the vaccines used. IgG1 responses after influenza and tetanus vaccination have recently been reported, displaying the same lack of non-fucose in the beginning and increased sialic acid at later stages following vaccination, and instead showed increased galactose and sialic acid shortly after vaccination. In that study, two doses of a pandemic influenza vaccine was administered, and serum collected 3-5 weeks after each dose showed steady sialic acid levels with time(44). In the present report we extend this to $\lg G 3$ and $\lg G 2$ responses and also include a pure carbohydrate vaccine and a complex OMV protein vaccine. We see the same increase in sialic acid shortly after vaccination, but at later time points, the values varies from stable (pneumococcal $\lg G 2$ ), a decrease to pre-vaccination levels (seasonal influenza IgG1) or increases with booster doses (meningococcal IgG1). We do not dispute the presence of two-phase IgG, a pro-inflammatory and an anti-inflammatory, but the basis of inducing and balancing these pronounced opposite IgGs seems elusive at least for humans. The dependence of these $\lg G$ variants upon the glycosylation patterns might also be more complex than previously suggested. The anti-inflammatory activity of sialic acid rich human IgG seems well documented, although controversial, and a resent paper showed that immune complexes with galactose-rich mouse IgG1 asserted anti-inflammatory properties by supporting the association of FcyRIIB with dectin-1 $(17,19)$. This complexity has been shown in mice infected with the yeast Cryptococcus neoformans, as administration of monoclonal antibodies lead to acute lethal toxicity and cardiovascular collapse when IgG1 was administered due to an increase in platelet activating factor, PAF, caused by a complex between $C$. neoformans glucuronoxylomannan and IgG. The same occurrence was not seen with IgG3(23). On the other hand, when mice received IgG1 before a $C$. neoformans infection, pro-inflammatory responses were diminished and granulocyte production increased to clear the fungal infection(10). Insufficient amount of antibodies may not cause the 
desired response, but excessive amounts may be counterproductive, as studies on $C$. neoformans showed interference with oxidative killing when the concentrations of antibodies on the capsule surface was too high(53). The same antibody may exhibit both pro- and anti-inflammatory properties depending upon the state of infection, type of microbe and the amount of antibody. All these factors contribute to a more complex picture than just glycosylation being the foundation of the two-phase $\lg (7)$.

Thirdly, a clear difference was seen between the pro-inflammatory IgG1 and IgG3 subclasses following seasonal influenza vaccination as the $\lg G 1$ immune response exhibited glycoforms that were mainly fucosylated, while the IgG3 glycoforms were mainly non-fucosylated. The total background IgG did not portray this pattern and it was therefore a result of the immunization, but was seen for this vaccine only. This is the first report on the lgG3 glycoforms after vaccination. We have previously studied recombinant chimeric mouse-human IgG3, which we found to be mainly non-fucosylated (Vestrheim et al in press). Interestingly, IgG3 antibodies in general appears superior to IgG1 regarding capacity for both ADCC and opsonophagocytic activity $(2,29)$. As ADCC is mainly activated through FcyRIIla, and removal of fucose caused a 50-fold increase in receptor-binding, the non-fucosylated IgG3 induced after seasonal influenza vaccination are likely to possess a strong capability for $A D C C(47)$. There are several potential explanations for the glycoform differences between $\lg G 1$ and $\lg G 3$, with noteworthy differences in the hinge region structure between $\lg G 1$ and IgG3 being one of them $(15,30)$. However, no significant glycosylation differences were seen between recombinant wild type $\lg G 3$ and a hinge truncate mutant of this $\lg G 3$, hence the differences seem not to be caused by the long hinge region of IgG3 (62 amino acids) relative to the IgG1 hinge region (15 amino acids)(31) and Vestrheim et al in press).

Fourthly, we observed more simple glycoforms by the low antigen dose with squalene adjuvant compared to similar high dose, non-adjuvanted seasonal influenza vaccine, but importantly without the dominance of non-fucose and non-sialic acid seen in IgG3 from the seasonal influenza (See Fig.4). 
The seasonal influenza vaccine also caused more diverse glycoforms compared to the pandemic vaccine, with 11-13 glycoforms compared to 4-10 glycoforms. Perhaps the low vaccine dose or more probably the use of the strongly stimulating squalene adjuvant is having a direct influence on IgG glycosylation, as adjuvants are used to enhance the specific immune response against the antigens it is inoculated with $(20,22,37,38)$. Possibly this strong immune-stimulation induced by squalene enhances the kinetics of the immune response resulting in a less matured IgG glycosylation. Squalene has been shown to influence glycosylation, as inhibiting squalene production can improve $\mathrm{N}$ glycosylation in Congenital disorders of glycosylation $(12,58)$. Interestingly, the meningococcal OMV vaccination also included an adjuvant $\left(\mathrm{Al}(\mathrm{OH})_{3}\right)$, but without the same lack of matured glycoforms as for the pandemic influenza vaccination; $\mathrm{Al}(\mathrm{OH})_{3}$ adjuvant being less potent than squalene might be a plausible explanation. When the adjuvant MF59, a squalene emulsion, was used in a previous vaccine study with the pandemic influenza vaccine, no differences regarding variety and complexity of glycoforms compared to influenza vaccination without adjuvant were noted $(36,44)$.

Fifthly, there was a considerable variation in glycoforms from one individual to another, indicating that glycosylation is a flexible process harboring several parameters which varies among individuals. One vaccinee differed strongly from the rest, as meningococcal vaccinee \# 022 unlike the others, displayed non-fucosylated antigen-specific IgG3 antibodies following vaccination, but as this was also reflected in the same individual's total IgG3, this was a characteristic of the individual, not of the vaccine (See Fig.5).

The IgG subclass dominating the response induced by a polysaccharide vaccine is $\lg G 2(26,40)$, and the IgG2 glycosylation pattern from the pneumococcal vaccine did not differ too much compared to the IgG1 dominating the immune response from the other vaccines. The antibody response towards polysaccharides differ compared to that against proteins as polysaccharides are generally T-cell independent and thus the polysaccharide responding B-cells need less help from T-cells in their development towards antibody producing plasma cells. Apparently, such T-cell help towards B-cells 
has minor influence on the glycosylation pattern of downstream production of IgG from the resulting plasma cells. Furthermore, the minor IgG1 subclass response from the pneumococcal vaccine did stand out compared to the IgG1 response from the others, as the glycoforms were all fucosylated, while galactose and sialic acid levels stayed the same (See Fig.3 and Table 2).

As glycosylation seems time dependent, the time of an antigenic challenge can therefore be crucial to the type of protection offered. Quantifiable IgG titres have been measured between 2 and 4 weeks after immunization for pneumococcal polysaccharide vaccines, seasonal influenza and $\operatorname{MenBVac}{ }^{\circledast}(24,25,32,49,61)$. As a measurable antibody response occurs at relatively the same time for these vaccines, certain antigens taking longer to trigger an immune response than others are therefore not likely to be the reason for glycosylation differences.

The antibodies produced following an immunization may kill or otherwise neutralize the pathogens by a number of ways such as phagocytosis and serum bactericidal activity $(\mathrm{SBA})(1,52)$, and glycosylation can be involved in regulating antibody function $(9,41,47,56)$. Serum bactericidal activity (SBA) and opsonic activity have previously been published for the vaccinees receiving the meningococcal vaccine, where reciprocal antibody titres were used to measure the activity(43). For SBA, no trends were seen in the glycosylation pattern, but for opsonic activity, three vaccinees displayed changes in opsonic activity that could be compared to the glycosylation pattern from these two visits(43). Vaccinees \# 017 and \# 020 showed a large increase in opsonic activity from visit 6 to visit 7 with a parallel increase in galactosylation and sialylation for $\lg G 1$ and $\lg G 3$ antibodies for the same visits, (See Table 3), as well as an increase in fucose for IgG3 antibodies. Vaccine \# 018 showed some increase in opsonophagocytic activity with an increase in sialic acid for both IgG1 and IgG3 (See Table 3). While the specific antibody concentration did not change much between these two visits for vaccine \# 018, a clear increase was seen for both IgG1 and IgG3 in vaccinee \# 017 and \# 020 (See Supp. Table 1). 
In conclusion, we have analysed serum or plasma from volunteers after immunization with four different vaccines and determined that the majority of vaccinees showed distinct increases in IgG galactosylation and sialylation following immunization. Changes in IgG fucosylation following immunization seemed vaccine dependent and several vaccines resulted in fully fucosylated IgG, while seasonal influenza vaccine was the only vaccine resulting in non-fucosylated IgG3. Differences were seen in complexity and variability of glycoforms between influenza vaccines with and without adjuvant. Glycosylation patterns therefore seem to be affected by both type and intervals of immunization, and with further knowledge from larger studies combined with biological data; these findings can possibly be used to optimize vaccine formulation and vaccination schedules. 
1. Aase, A., G. Bjune, E. A. Hoiby, E. Rosenqvist, A. K. Pedersen, and T. E. Michaelsen. 1995. Comparison among opsonic activity, antimeningococcal immunoglobulin $\mathrm{G}$ response, and serum bactericidal activity against meningococci in sera from vaccinees after immunization with a serogroup B outer membrane vesicle vaccine. Infect.Immun. 63:3531-3536.

2. Aase, A. and T. E. Michaelsen. 1994. Opsonophagocytic activity induced by chimeric antibodies of the four human IgG subclasses with or without help from complement. Scand.J.Immunol. 39:581-587.

3. Anthony, R. M., F. Nimmerjahn, D. J. Ashline, V. N. Reinhold, J. C. Paulson, and J. V. Ravetch. 2008. Recapitulation of IVIG anti-inflammatory activity with a recombinant IgG Fc. Science 320:373-376.

4. Arnold, J. N., M. R. Wormald, R. B. Sim, P. M. Rudd, and R. A. Dwek. 2007. The impact of glycosylation on the biological function and structure of human immunoglobulins. Annu.Rev Immunol 25:21-50. doi:10.1146/annurev.immunol.25.022106.141702 [doi].

5. Bautista, E., T. Chotpitayasunondh, Z. Gao, S. A. Harper, M. Shaw, T. M. Uyeki, S. R. Zaki, F. G. Hayden, D. S. Hui, J. D. Kettner, A. Kumar, M. Lim, N. Shindo, C. Penn, and K. G. Nicholson. 2010. Clinical aspects of pandemic 2009 influenza A (H1N1) virus infection. N Engl J Med 362:1708-1719. doi:362/18/1708 [pii];10.1056/NEJMra1000449 [doi].

6. Bjune, G., E. A. Hoiby, J. K. Gronnesby, O. Arnesen, J. H. Fredriksen, A. Halstensen, E. Holten, A. K. Lindbak, H. Nokleby, E. Rosenqvist, and . 1991. Effect of outer membrane vesicle vaccine against group B meningococcal disease in Norway. Lancet 338:1093-1096.

7. Casadevall, A. and L. A. Pirofski. 2012. A new synthesis for antibody-mediated immunity. Nat.Immunol. 13:21-28. doi:ni.2184 [pii];10.1038/ni.2184 [doi].

8. Danzig, L. 2004. Meningococcal vaccines. Pediatr Infect Dis J 23:S285-S292. doi:00006454200412001-00004 [pii].

9. Davies, J., L. Jiang, L. Z. Pan, M. J. LaBarre, D. Anderson, and M. Reff. 2001. Expression of $\mathrm{GnTIII}$ in a recombinant anti-CD20 CHO production cell line: Expression of antibodies with altered glycoforms leads to an increase in ADCC through higher affinity for FC gamma RIII. Biotechnol.Bioeng. 74:288-294. doi:10.1002/bit.1119 [pii].

10. Feldmesser, M., A. Mednick, and A. Casadevall. 2002. Antibody-mediated protection in murine Cryptococcus neoformans infection is associated with pleotrophic effects on cytokine and leukocyte responses. Infect.Immun. 70:1571-1580.

11. Guo, N., Y. Liu, Y. Masuda, M. Kawagoe, Y. Ueno, T. Kameda, and T. Sugiyama. 2005. Repeated immunization induces the increase in fucose content on antigen-specific IgG Nlinked oligosaccharides. Clin.Biochem. 38:149-153. doi:S0009-9120(04)00285-1 [pii];10.1016/j.clinbiochem.2004.10.002 [doi].

12. Haeuptle, M. A., M. Welti, H. Troxler, A. J. Hulsmeier, T. Imbach, and T. Hennet. 2011. Improvement of dolichol-linked oligosaccharide biosynthesis by the squalene synthase 
inhibitor zaragozic acid. J.Biol.Chem. 286:6085-6091. doi:M110.165795

[pii];10.1074/jbc.M110.165795 [doi].

13. Hall, M. A., M. S. Edwards, and C. J. Baker. 1992. Complement and antibody participation in opsonophagocytosis of type IV and V group B streptococci. Infect.Immun. 60:5030-5035.

14. Hoiby, E. A., G. Bjune, L. O. Froholm, J. Eng, A. Halstensen, E. Rosenqvist, E. Ronnild, and E. Wedege. 1991. The Norwegian meningococcal serogroup B outer membrane vesicle vaccine protection trials: case tracing, meningococcal antigen detection and serological diagnosis. NIPH Ann 14:107-121.

15. Huck, S., P. Fort, D. H. Crawford, M. P. Lefranc, and G. Lefranc. 1986. Sequence of a human immunoglobulin gamma 3 heavy chain constant region gene: comparison with the other human C gamma genes. Nucleic Acids Res 14:1779-1789.

16. Kaneko, Y., F. Nimmerjahn, and J. V. Ravetch. 2006. Anti-inflammatory activity of immunoglobulin G resulting from Fc sialylation. Science 313:670-673.

17. Karsten, C. M., M. K. Pandey, J. Figge, R. Kilchenstein, P. R. Taylor, M. Rosas, J. U. McDonald, S. J. Orr, M. Berger, D. Petzold, V. Blanchard, A. Winkler, C. Hess, D. M. Reid, I. V. Majoul, R.

T. Strait, N. L. Harris, G. Kohl, E. Wex, R. Ludwig, D. Zillikens, F. Nimmerjahn, F. D. Finkelman, G. D. Brown, M. Ehlers, and J. Kohl. 2012. Anti-inflammatory activity of IgG1 mediated by FC galactosylation and association of FcgammaRIIB and dectin-1. Nat.Med. 18:1401-1406. doi:nm.2862 [pii];10.1038/nm.2862 [doi].

18. Kaur, K., M. Sullivan, and P. C. Wilson. 2011. Targeting B cell responses in universal influenza vaccine design. Trends in Immunology 32:524-531. doi:doi: 10.1016/j.it.2011.08.007.

19. Kazatchkine, M. D. and S. V. Kaveri. 2001. Immunomodulation of autoimmune and inflammatory diseases with intravenous immune globulin. N.Engl.J.Med. 345:747-755. doi:10.1056/NEJMra993360 [doi].

20. Lai, R. P., M. S. Seaman, P. Tonks, F. Wegmann, D. J. Seilly, S. D. Frost, C. C. LaBranche, D. C. Montefiori, A. K. Dey, I. K. Srivastava, Q. Sattentau, S. W. Barnett, and J. L. Heeney. 2012. Mixed adjuvant formulations reveal a new combination that elicit antibody response comparable to Freund's adjuvants. PLoS One 7:e35083. doi:10.1371/journal.pone.0035083 [doi];PONE-D-11-24343 [pii].

21. Lastra, G. C., S. J. Thompson, A. S. Lemonidis, and C. J. Elson. 1998. Changes in the galactose content of IgG during humoral immune responses. Autoimmunity 28:25-30.

22. Launay, O., C. Desaint, C. Durier, P. Loulergue, X. Duval, C. Jacomet, G. Pialoux, J. Ghosn, F. Raffi, D. Rey, F. Ajana, d. Colin, V, J. Reynes, V. Foubert, F. Roman, J. M. Devaster, J. F. Delfraissy, and J. P. Aboulker. 2011. Safety and immunogenicity of a monovalent 2009 influenza A/H1N1v vaccine adjuvanted with AS03A or unadjuvanted in HIV-infected adults: a randomized, controlled trial. J.Infect.Dis. 204:124-134. doi:jir211 [pii];10.1093/infdis/jir211 [doi].

23. Lendvai, N., X. W. Qu, W. Hsueh, and A. Casadevall. 2000. Mechanism for the isotype dependence of antibody-mediated toxicity in Cryptococcus neoformans-infected mice. J.Immunol. 164:4367-4374. doi:ji_v164n8p4367 [pii]. 
24. Lortan, J. E., A. Vellodi, E. S. Jurges, and K. Hugh-Jones. 1992. Class- and subclass-specific pneumococcal antibody levels and response to immunization after bone marrow transplantation. Clin.Exp.Immunol. 88:512-519.

25. Lue, C., A. Tarkowski, and J. Mestecky. 1988. Systemic immunization with pneumococcal polysaccharide vaccine induces a predominant IgA2 response of peripheral blood lymphocytes and increases of both serum and secretory anti-pneumococcal antibodies. J.Immunol. 140:3793-3800.

26. Mackell, S. M. 2003. Vaccinations for the Pediatric Traveler. Clinical Infectious Diseases 37:1508-1516.

27. Mashburn-Warren, L., R. J. McLean, and M. Whiteley. 2008. Gram-negative outer membrane vesicles: beyond the cell surface. Geobiology. 6:214-219. doi:GBI157 [pii];10.1111/j.14724669.2008.00157.x [doi].

28. Matsumoto, A., K. Shikata, F. Takeuchi, N. Kojima, and T. Mizuochi. 2000. Autoantibody activity of IgG rheumatoid factor increases with decreasing levels of galactosylation and sialylation. J Biochem 128:621-628.

29. Michaelsen, T. E., A. Aase, L. Norderhaug, and I. Sandlie. 1992. Antibody dependent cellmediated cytotoxicity induced by chimeric mouse-human IgG subclasses and IgG3 antibodies with altered hinge region. Mol.Immunol. 29:319-326.

30. Michaelsen, T. E., B. Frangione, and E. C. Franklin. 1977. Primary structure of the "hinge" region of human IgG3. Probable quadruplication of a 15-amino acid residue basic unit. J Biol Chem 252:883-889.

31. Michaelsen, T. E., I. Sandlie, D. B. Bratlie, R. H. Sandin, and O. Ihle. 2009. Structural difference in the complement activation site of human IgG1 and IgG3. Scand J Immunol 70:553-564. doi:SJI2338 [pii];10.1111/j.1365-3083.2009.02338.x [doi].

32. Naess, L. M., T. Aarvak, A. Aase, F. Oftung, E. A. Hoiby, R. Sandin, and T. E. Michaelsen. 1999. Human IgG subclass responses in relation to serum bactericidal and opsonic activities after immunization with three doses of the Norwegian serogroup B meningococcal outer membrane vesicle vaccine. Vaccine 17:754-764.

33. Naess, L. M., E. Rosenqvist, E. A. Hoiby, and T. E. Michaelsen. 1996. Quantitation of IgG subclass antibody responses after immunization with a group $B$ meningococcal outer membrane vesicle vaccine, using monoclonal mouse-human chimeric antibodies as standards. J Immunol Methods 196:41-49. doi:0022175996001081 [pii].

34. Nimmerjahn, F. and J. V. Ravetch. 2007. The antiinflammatory activity of IgG: the intravenous IgG paradox. J Exp.Med 204:11-15.

35. Nimmerjahn, F. and J. V. Ravetch. 2008. Anti-inflammatory actions of intravenous immunoglobulin. Annu. Rev Immunol. 26:513-533.

36. O'Hagan, D. T., G. S. Ott, G. V. Nest, R. Rappuoli, and G. D. Giudice. 2013. The history of MF59((R)) adjuvant: a phoenix that arose from the ashes. Expert.Rev.Vaccines. 12:13-30. doi:10.1586/erv.12.140 [doi]. 
37. Pellegrini, M., U. Nicolay, K. Lindert, N. Groth, and C. G. Della. 2009. MF59-adjuvanted versus non-adjuvanted influenza vaccines: integrated analysis from a large safety database. Vaccine 27:6959-6965. doi:S0264-410X(09)01310-3 [pii];10.1016/j.vaccine.2009.08.101 [doi].

38. Petrovsky, N. and J. C. Aguilar. 2004. Vaccine adjuvants: current state and future trends. Immunol.Cell Biol. 82:488-496. doi:ICB1272 [pii];10.1111/j.0818-9641.2004.01272.x [doi].

39. Pitsiou, G. G. and I. P. Kioumis. 2011. Pneumococcal vaccination in adults: Does it really work? Respiratory Medicine 105:1776-1783. doi:doi: 10.1016/j.rmed.2011.07.008.

40. Pittet, L. F. and K. M. Posfay-Barbe. 2012. Pneumococcal vaccines for children: a global public health priority. Clin Microbiol Infect. doi:10.1111/j.1469-0691.2012.03938.x [doi].

41. Raju, T. S. 2008. Terminal sugars of Fc glycans influence antibody effector functions of IgGs. Curr Opin.Immunol 20:471-478. doi:S0952-7915(08)00112-X [pii];10.1016/j.coi.2008.06.007 [doi].

42. Rosenqvist, E., E. A. Hoiby, G. Bjune, K. Bryn, O. Closs, B. Feiring, A. Klem, H. Nokleby, and L. 0 . Frolm. 1991. Human antibody responses after vaccination with the Norwegian group $B$ meningococcal outer membrane vesicle vaccine: results from ELISA studies. NIPH Ann 14:169-179.

43. Sandbu, S., B. Feiring, P. Oster, O. S. Helland, H. S. Bakke, L. M. Naess, A. Aase, I. S. Aaberge, A. C. Kristoffersen, K. M. Rydland, S. Tilman, H. Nokleby, and E. Rosenqvist. 2007. Immunogenicity and safety of a combination of two serogroup B meningococcal outer membrane vesicle vaccines. Clin.Vaccine Immunol. 14:1062-1069. doi:CVI.00094-07 [pii];10.1128/CVI.00094-07 [doi].

44. Selman, M. H., S. E. de Jong, D. Soonawala, F. P. Kroon, A. A. Adegnika, A. M. Deelder, C. H. Hokke, M. Yazdanbakhsh, and M. Wuhrer. 2011. Changes in antigen-specific IgG1 Fc Nglycosylation upon influenza and tetanus vaccination. Mol Cell Proteomics. doi:M111.014563 [pii];10.1074/mcp.M111.014563 [doi].

45. Selman, M. H., R. J. Derks, A. Bondt, M. Palmblad, B. Schoenmaker, C. A. Koeleman, F. E. van de Geijn, R. J. Dolhain, A. M. Deelder, and M. Wuhrer. 2012. Fc specific IgG glycosylation profiling by robust nano-reverse phase HPLC-MS using a sheath-flow ESI sprayer interface. J Proteomics. 75:1318-1329. doi:S1874-3919(11)00554-9 [pii];10.1016/j.jprot.2011.11.003 [doi].

46. Shibata-Koyama, M., S. lida, H. Misaka, K. Mori, K. Yano, K. Shitara, and M. Satoh. 2009. Nonfucosylated rituximab potentiates human neutrophil phagocytosis through its high binding for FcgammaRIIIb and MHC class II expression on the phagocytotic neutrophils. Exp.Hematol. 37:309-321. doi:S0301-472X(08)00524-9 [pii];10.1016/j.exphem.2008.11.006 [doi].

47. Shields, R. L., J. Lai, R. Keck, L. Y. O'Connell, K. Hong, Y. G. Meng, S. H. Weikert, and L. G. Presta. 2002. Lack of fucose on human IgG1 N-linked oligosaccharide improves binding to human Fcgamma RIII and antibody-dependent cellular toxicity. J Biol Chem 277:26733-26740. doi:10.1074/jbc.M202069200 [doi];M202069200 [pii].

48. Shinkawa, T., K. Nakamura, N. Yamane, E. Shoji-Hosaka, Y. Kanda, M. Sakurada, K. Uchida, H. Anazawa, M. Satoh, M. Yamasaki, N. Hanai, and K. Shitara. 2003. The absence of fucose but not the presence of galactose or bisecting $\mathrm{N}$-acetylglucosamine of human IgG1 complex-type 
oligosaccharides shows the critical role of enhancing antibody-dependent cellular cytotoxicity. J Biol Chem 278:3466-3473. doi:10.1074/jbc.M210665200 [doi];M210665200 [pii].

49. Soonawala, D., G. F. Rimmelzwaan, L. B. Gelinck, L. G. Visser, and F. P. Kroon. 2011. Response to 2009 pandemic influenza $A$ (H1N1) vaccine in HIV-infected patients and the influence of prior seasonal influenza vaccination. PLoS.One. 6:e16496. doi:10.1371/journal.pone.0016496 [doi].

50. Stadlmann, J., M. Pabst, D. Kolarich, R. Kunert, and F. Altmann. 2008. Analysis of immunoglobulin glycosylation by LC-ESI-MS of glycopeptides and oligosaccharides. Proteomics. 8:2858-2871. doi:10.1002/pmic.200700968 [doi].

51. Stephens, D. S., B. Greenwood, and P. Brandtzaeg. Epidemic meningitis, meningococcaemia, and Neisseria meningitidis. The Lancet 369:2196-2210. doi:doi: 10.1016/S01406736(07)61016-2.

52. Swanson, J. and I. Goldschneider. 1969. The serum bactericidal system: ultrastructural changes in Neisseria meningitidis exposed to normal rat serum. J.Exp.Med. 129:51-79.

53. Taborda, C. P., J. Rivera, O. Zaragoza, and A. Casadevall. 2003. More is not necessarily better: prozone-like effects in passive immunization with IgG. J.Immunol. 170:3621-3630.

54. Treanor, J. J., H. K. Talbot, S. E. Ohmit, L. A. Coleman, M. G. Thompson, P. Y. Cheng, J. G. Petrie, G. Lofthus, J. K. Meece, J. V. Williams, L. Berman, H. C. Breese, A. S. Monto, M. R. Griffin, E. Belongia, and D. K. Shay. 2012. Effectiveness of Seasonal Influenza Vaccines in the United States During a Season With Circulation of All Three Vaccine Strains. Clin Infect Dis. doi:cis574 [pii];10.1093/cid/cis574 [doi].

55. Vila-C+ 'rcoles, A. 2007. Advances in Pneumococcal Vaccines: What are the Advantages for the Elderly? Drugs \& Aging 24.

56. Wang, J., C. I. Balog, K. Stavenhagen, C. A. Koeleman, H. U. Scherer, M. H. Selman, A. M. Deelder, T. W. Huizinga, R. E. Toes, and M. Wuhrer. 2011. Fc-glycosylation of IgG1 is modulated by B-cell stimuli. Mol.Cell Proteomics. 10:M110. doi:M110.004655 [pii];10.1074/mcp.M110.004655 [doi].

57. Wang, S. M., M. H. Tsai, H. Y. Lei, J. R. Wang, and C. C. Liu. 2012. The regulatory T cells in antiinfluenza antibody response post influenza vaccination. Hum Vaccin.Immunother. 8. doi:21117 [pii].

58. Welti, M. 2012. Regulation of dolichol-linked glycosylation. Glycoconj.J. doi:10.1007/s10719012-9417-y [doi].

59. Westerink, M. A., H. W. Schroeder, Jr., and M. H. Nahm. 2012. Immune Responses to pneumococcal vaccines in children and adults: Rationale for age-specific vaccination. Aging Dis 3:51-67.

60. World Health Organization. 2002. Weekly Epidemiological Record. World Health Organization http://www.who.int/immunization/wer7740meningococcal Oct02 position paper.pdf. 
61. World Health Organization. 2009. Recommended composition of influenza virus vaccines for use in the 2010 influenza season (southern hemisphere winter). Wkly Epidemiol Rec. 84:421431.

62. Wuhrer, M., L. Porcelijn, R. Kapur, C. A. Koeleman, A. Deelder, H. M. de, and G. Vidarsson. 2009. Regulated glycosylation patterns of IgG during alloimmune responses against human platelet antigens. J Proteome.Res. 8:450-456.

63. Wuhrer, M., J. C. Stam, F. E. van de Geijn, C. A. Koeleman, C. T. Verrips, R. J. Dolhain, C. H. Hokke, and A. M. Deelder. 2007. Glycosylation profiling of immunoglobulin G (IgG) subclasses from human serum. Proteomics. 7:4070-4081. doi:10.1002/pmic.200700289 [doi].

64. Young, F. and F. Marra. 2011. A systematic review of intradermal influenza vaccines. Vaccine 29:8788-8801. doi:doi: 10.1016/j.vaccine.2011.09.077. 


\section{Figures}

\section{FIGURE 1}

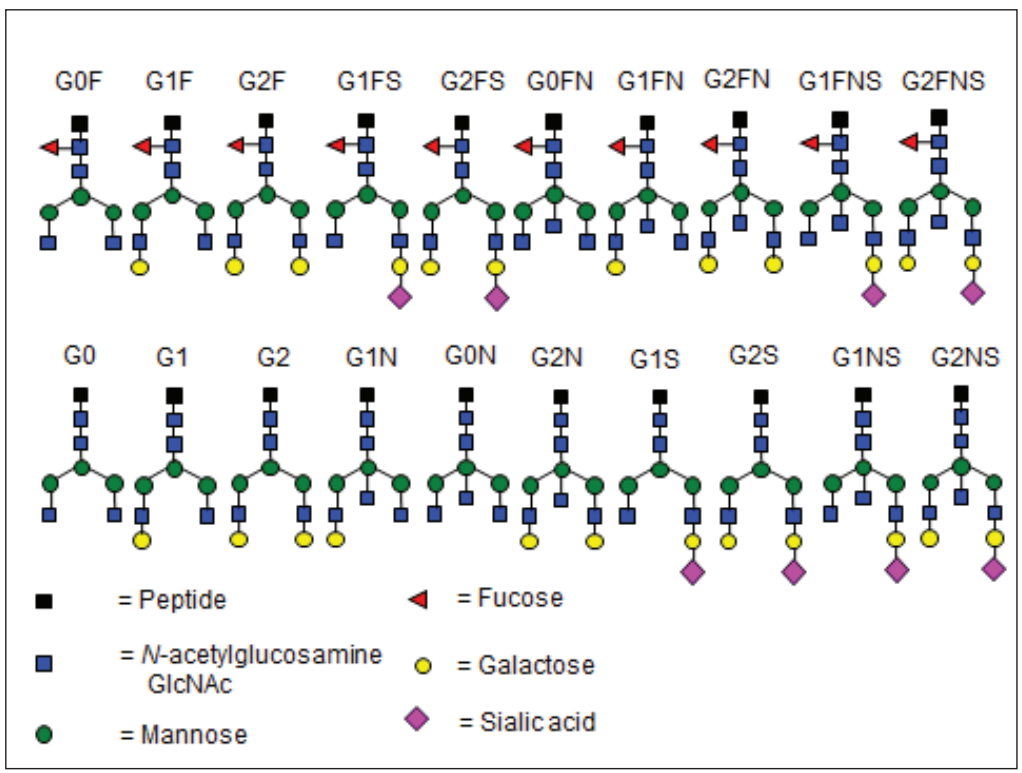

Figure 1: The 20 different glycoforms studied in this report. Black square $=$ peptide, blue square $=\mathrm{N}$ acetylglucosamine, green (dark grey) circle $=$ mannose, red triangle $=$ fucose, yellow (light grey) circle $=$ galactose and pink diamond $=$ sialic acid. 
FIGURE 2

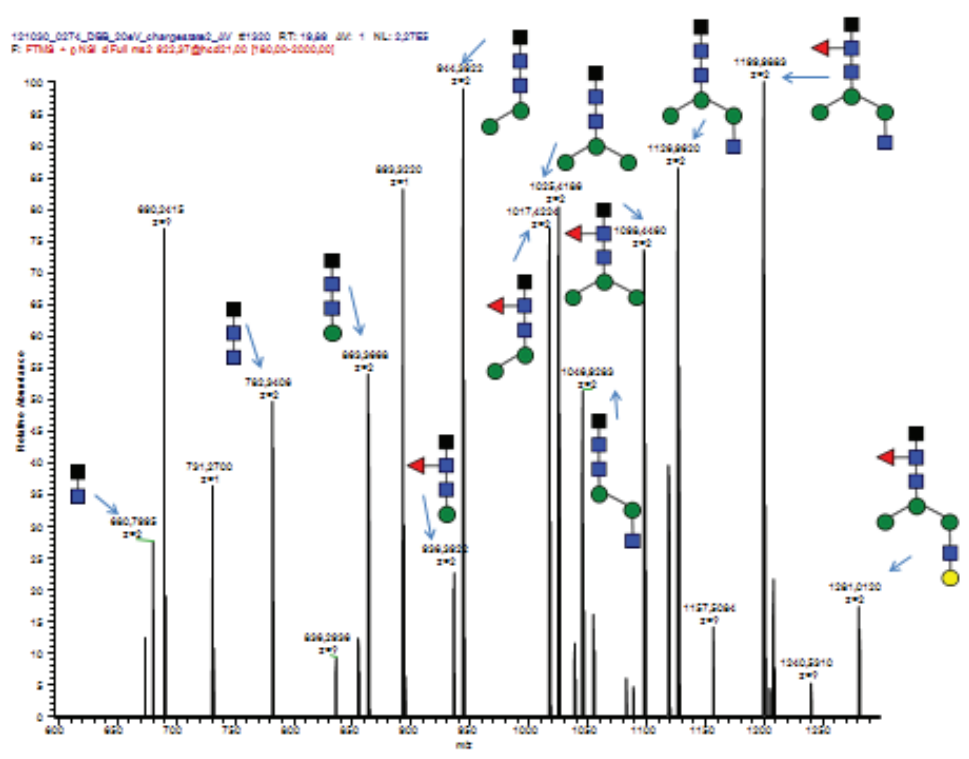

Figure 2: MS2 glycanspecter of an IgG3 molecule, where the peaks for the different carbohydrate compositions are shown. Black square $=$ peptide, blue square $=$ GlcNAc, green (dark grey) circle $=$ mannose, yellow (light grey) circle $=$ galactose and red triangle $=$ fucose . 

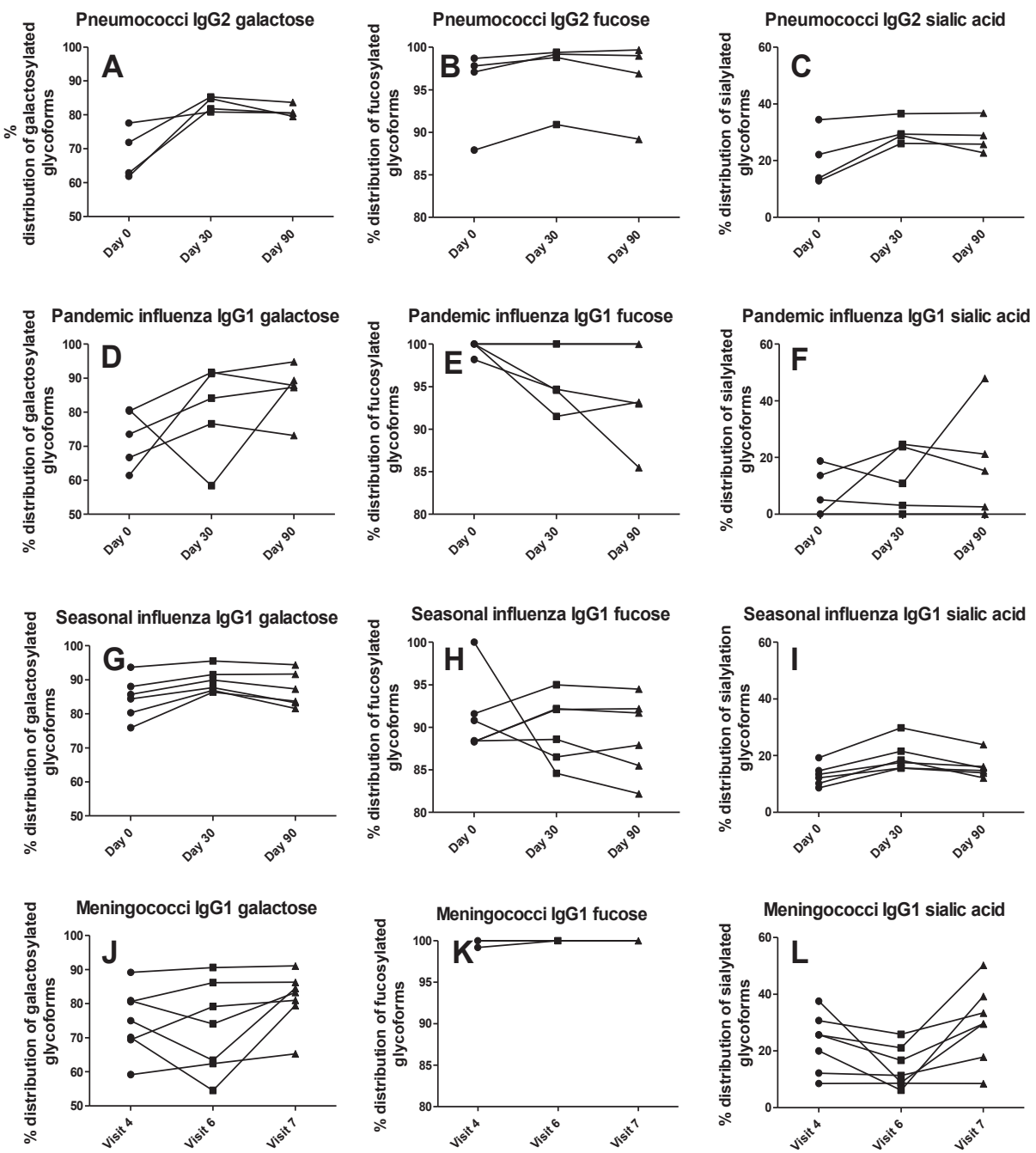

Figure 3: The three main time points for all 4 vaccines presented as percentage distribution of galactosylation, fucosylation and sialylation. $A, B$ and $C$ are showing pneumococcal IgG2 while D, E and $F$ are showing pandemic influenza IgG1. G, $\mathrm{H}$ and $\mathrm{I}$ are showing seasonal influenza $\operatorname{IgG} 1$ and $\mathrm{J}, \mathrm{K}$ and $L$ are showing meningococcal lgG1. The time points for the meningococcal vaccine were visit 4 (1-2 weeks after $3^{\text {rd }}$ dose), visit 6 (10-12 months after $3^{\text {rd }}$ dose) and visit 7 (1-2 weeks after $4^{\text {th }}$ dose). 


\section{FIGURE 4}
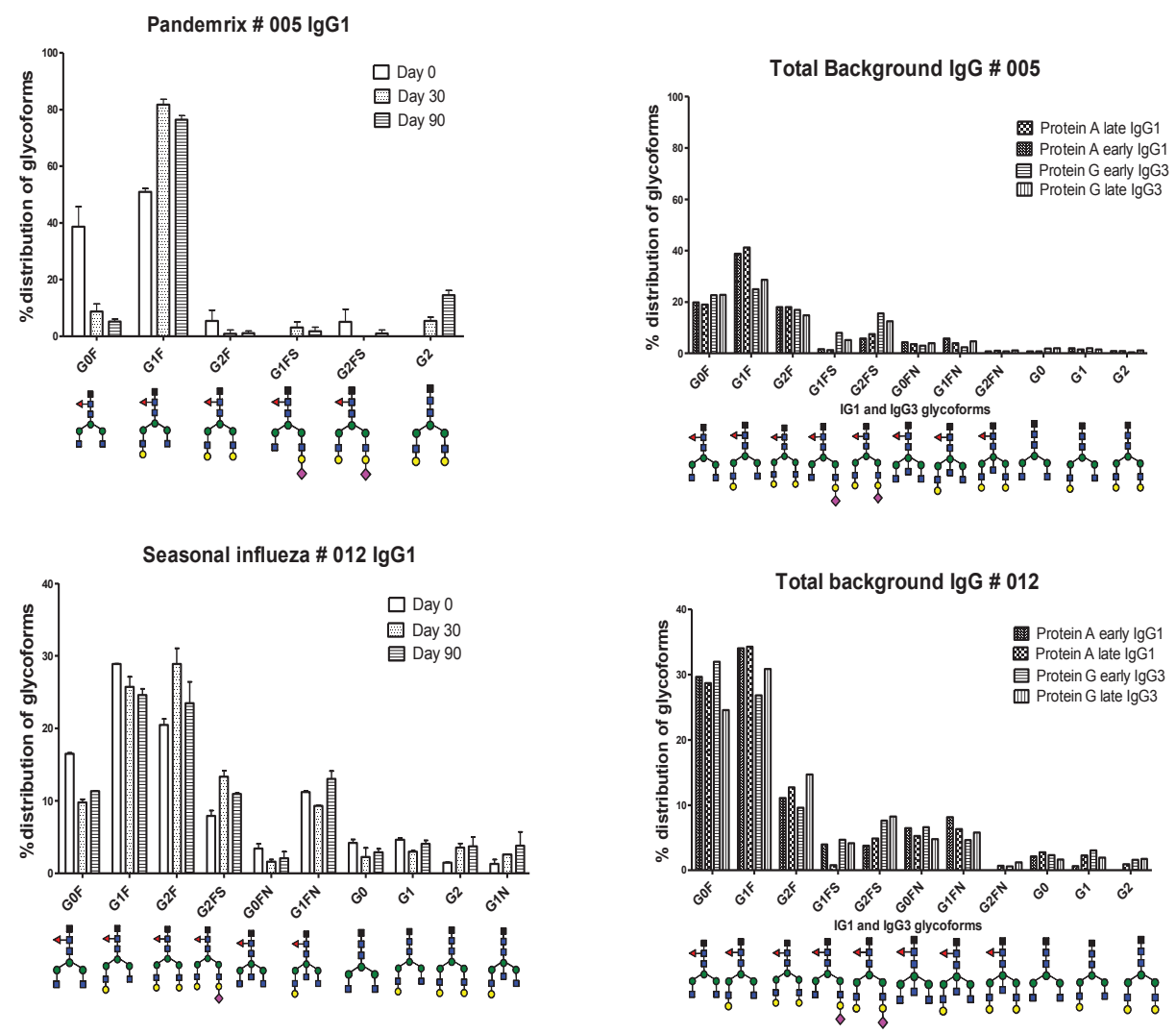

Figure 4: Glyform distribution of specific IgG1 (3 time points) and total background IgG (2 time points) for one vaccinee receiving the pandemic influenza vaccine and one vaccinee receiving the seasonal influenza vaccine. Glycoforms present at less than $1 \%$ were not included. 


\section{FIGURE 5}
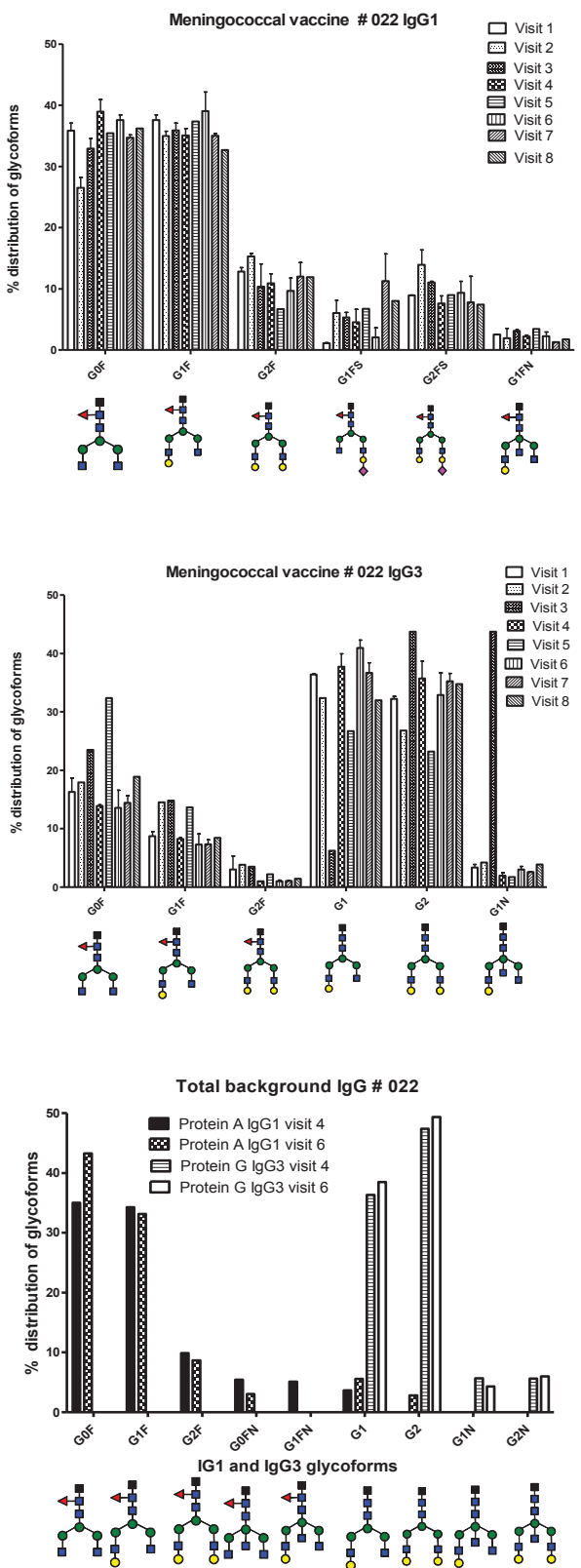

Figure 5: Glycoform distribution of IgG1, IgG3 (both 8 time points) and total background IgG (2 time points for one vaccine after 4 doses of the meningococcal vaccine. Glycoforms present at less than 1 $\%$ were not included. Visit 1 (Day $0-1$.dose), visit 2 (6-8 weeks after the $1^{\text {st }}$ dose), visit 3 (6-8 weeks after $2^{\text {nd }}$ dose), visit 4 (1-2 weeks after $3^{\text {rd }}$ dose), visit 5 (6-8 weeks after $3^{\text {rd }}$ dose), visit 6 (10-12 
months after $3^{\text {rd }}$ dose), visit 7 (1-2 weeks after $4^{\text {th }}$ dose) and visit 8 (4-6 weeks after $4^{\text {th }}$ dose). Doses were given at visit 1 ( $1^{\text {st }}$ dose $)$, visit 2 ( $2^{\text {nd }}$ dose $)$, visit 4 ( $3^{\text {rd }}$ dose $)$ and visit 6 ( $4^{\text {th }}$ dose). 


\section{Tables}

\begin{tabular}{|c|c|c|c|c|}
\hline & \multicolumn{2}{|c|}{ IgG1 } & \multicolumn{2}{|c|}{ IgG3 } \\
\hline & Chargestate 2 & Chargestate 3 & Chargestate 2 & Chargestate 3 \\
\hline & \multicolumn{2}{|c|}{ IgG1 EEQYNSTYR } & \multicolumn{2}{|c|}{ IgG3 EEQFNSTFR } \\
\hline GOF & 1317.5270 & 878.6891 & 1301.5320 & 868.0235 \\
\hline G1F & 1398.5530 & 932.7044 & 1382.5581 & 922.0411 \\
\hline G2F & 1479.5794 & 986.7220 & 1463.5848 & 976.0587 \\
\hline G1FS & 1544.1007 & 1029.7362 & 1528.1058 & 1019.0729 \\
\hline G2FS & 1625.1271 & 1083.7538 & 1609.1322 & 1073.0905 \\
\hline GOFN & 1419.0663 & 946.3799 & 1403.0714 & 935.7166 \\
\hline G1FN & 1500.0927 & 1000.3975 & 1584.0978 & 989.7342 \\
\hline G2FN & 1581.1191 & 1054.4151 & 1565.1242 & 1043.7518 \\
\hline G1FNS & 1645.6404 & 1097.4293 & 1629.6455 & 1086.7660 \\
\hline G2FNS & 1726.6668 & 1151.4469 & 1710.6719 & 1140.7836 \\
\hline G0 & 1244.4976 & 830.0008 & 1228.5027 & 819.3375 \\
\hline G1 & 1325.5240 & 884.0184 & 1309.5291 & 873.3551 \\
\hline G2 & 1406.5504 & 938.0360 & 1390.5555 & 927.3727 \\
\hline G1N & 1427.0637 & 951.7115 & 1411.0688 & 941.0483 \\
\hline GON & 1346.0373 & 897.6939 & 1330.0420 & 887.0307 \\
\hline G2N & 1508.0901 & 1005.7291 & 1492.0952 & 1381.2423 \\
\hline G1S & 1471.0717 & 981.0502 & 1455.0768 & 1356.5634 \\
\hline G2S & 1552.0981 & 1035.0678 & 1536.1032 & 1410.5810 \\
\hline G1NS & 1572.6114 & 1048.7433 & 1556.6165 & 1424.2570 \\
\hline
\end{tabular}




\begin{tabular}{|l|l|l|l|l|}
\hline G2NS & 1653.6378 & 1102.7609 & 1637.6430 & 1478.2740 \\
\hline
\end{tabular}

Table 2: The minor responding subclass from the different vaccines, displayed as increase $(\uparrow)$, decrease $(\downarrow)$ or no change $(\leftrightarrow)$ in sugar composition observed at day $\mathbf{3 0}$ and day 90 after immunization, compared to the sample taken before immunization.

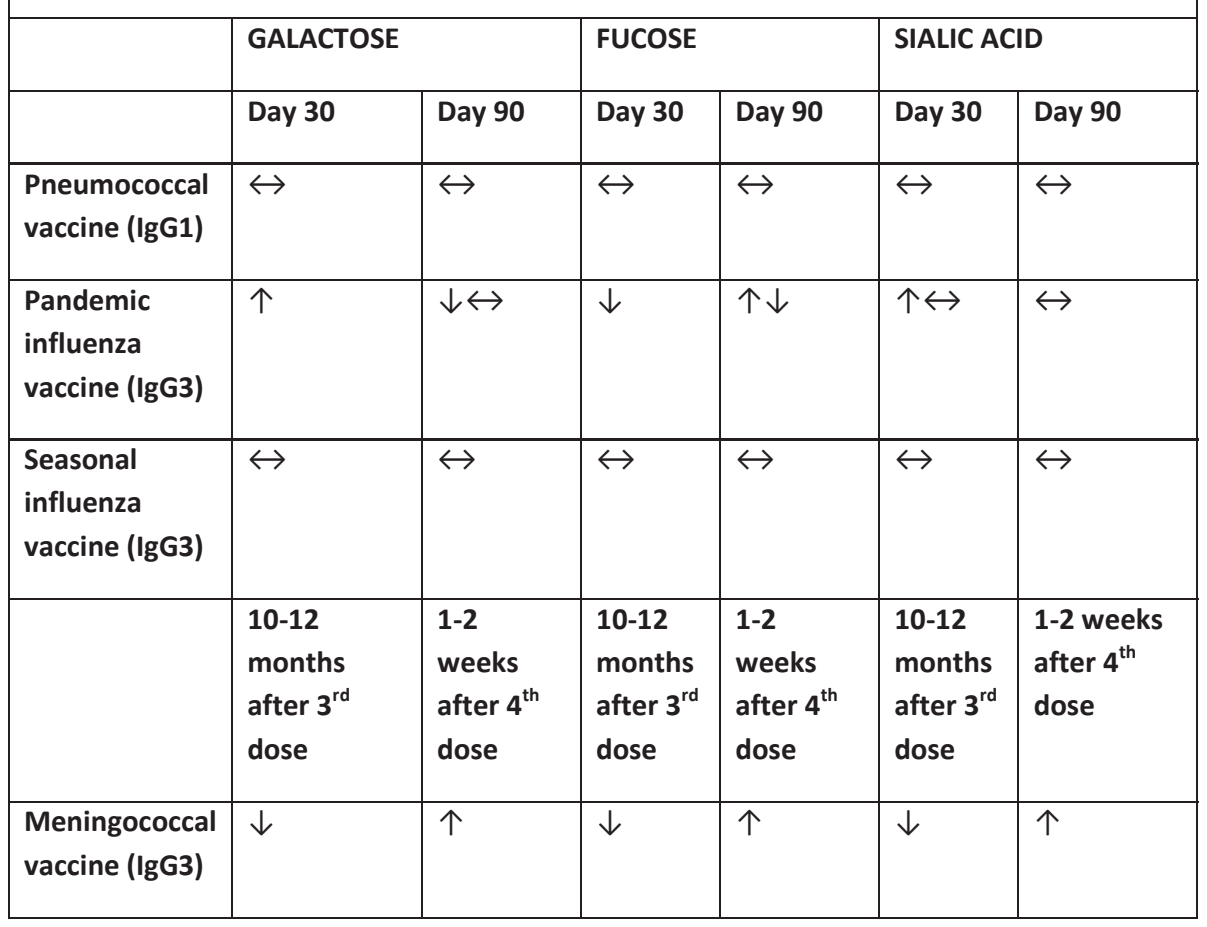


Table 3: The 7 meningococcal vaccinees were previously tested for serum bactericidal activity and opsonaphagocytic activity. Results are shown as reciprocal titres, published previously(43).

\begin{tabular}{|l|l|l|l|l|} 
& \multicolumn{2}{|l}{$\begin{array}{l}\text { Serum bactericidal } \\
\text { activity }\end{array}$} & \multicolumn{2}{l}{ Opsonophagocytic activity } \\
& Visit 6 & Visit 7 & Visit 6 & Visit 7 \\
\hline Vaccinee \# 016 & 128 & 128 & 128 & 128 \\
\hline Vaccinee \# 017 & $<2$ & 8 & 8 & 64 \\
\hline Vaccinee \# 018 & 8 & 8 & 32 & 64 \\
\hline Vaccinee \# 019 & $<2$ & $<2$ & $<2$ & 8 \\
\hline Vaccinee \# 020 & 2 & 4 & 32 & 64 \\
\hline Vaccinee \# 021 & 8 & 2 & 16 & 16 \\
\hline Vaccinee \# 022 & 16 & 16 & 16 & 32 \\
\hline
\end{tabular}




\section{Supplementary material}

SUPPLEMENTARY TABLE 1

\begin{tabular}{|c|c|c|c|c|c|c|}
\hline & $\begin{array}{l}\text { IgG1 } \\
\text { visit } 4\end{array}$ & $\begin{array}{l}\text { IgG1 } \\
\text { visit } 6\end{array}$ & $\begin{array}{l}\text { IgG1 } \\
\text { visit } 7\end{array}$ & $\begin{array}{l}\text { IgG3 } \\
\text { visit } 4\end{array}$ & $\begin{array}{l}\text { IgG3 } \\
\text { visit } 6\end{array}$ & $\begin{array}{l}\text { IgG3 } \\
\text { visit 7 }\end{array}$ \\
\hline \# 016 & 15 & 7.5 & 6.6 & 2.3 & 0 & 2.0 \\
\hline \# 017 & 11.3 & 0.9 & 3.8 & 3.4 & 0 & 5.2 \\
\hline \# 018 & 26.3 & 5.6 & 6.3 & 5.2 & 0 & 0.9 \\
\hline \# 019 & 2.6 & 1.3 & 1.6 & 0.8 & 0.2 & 0.4 \\
\hline \# 020 & 21.3 & 5.6 & 9.8 & 7.8 & 0 & 4.7 \\
\hline \# 021 & 22.5 & 5.6 & 7.0 & 3.8 & 0 & 7.5 \\
\hline \# 022 & 15 & 5.6 & 6.5 & 1.1 & 0 & 5.6 \\
\hline
\end{tabular}




\begin{tabular}{|c|c|c|c|c|c|c|c|}
\hline \multirow[b]{3}{*}{$\begin{array}{l}\text { Meningococcal } \\
\text { vaccine }\end{array}$} & \multicolumn{5}{|c|}{ MEDIAN } & \multicolumn{2}{|c|}{ P-value } \\
\hline & \multicolumn{3}{|c|}{ SPECIFIC IgG1 response } & \multicolumn{2}{|c|}{$\begin{array}{l}\text { TOTAL IgG1 } \\
\text { Prot A }\end{array}$} & \multirow[t]{2}{*}{ Specific } & \multirow[t]{2}{*}{ Total Prot A } \\
\hline & Visit 4 & Visit 6 & Visit 7 & Visit 4 & Visit 6 & & \\
\hline Galactosylation & 75 & 84.1 & 83.3 & 74.3 & 71.2 & 0.005 & 0.059 \\
\hline Fucosylation & 100 & 100 & 100 & 93.4 & 95.8 & 0.368 & 0.705 \\
\hline \multirow[t]{3}{*}{ Sialic acid } & 25.6 & 11.4 & 29.6 & 3.7 & 3.5 & 0.034 & 0.705 \\
\hline & \multicolumn{5}{|c|}{ MEDIAN } & \multicolumn{2}{|c|}{ P-value } \\
\hline & \multicolumn{3}{|c|}{ SPECIFIC response } & \multicolumn{2}{|c|}{$\begin{array}{l}\text { TOTAL IgG Prot } \\
\text { A }\end{array}$} & Specific & Total Prot A \\
\hline $\begin{array}{l}\text { Pandemic flu } \\
\text { vaccination(IgG1) }\end{array}$ & Day 0 & Day 30 & Day 90 & Day 0 & Day 90 & & \\
\hline Galactosylation & 73.5 & 84.1 & 87.9 & 69 & 68.6 & 0.074 & 1 \\
\hline Fucosylation & 100 & 94.7 & 93.2 & 92.7 & 89.4 & 0.097 & 0.655 \\
\hline Sialic acid & 5 & 10.8 & 15.3 & 8.6 & 7.8 & 0.779 & 0.655 \\
\hline \multicolumn{8}{|l|}{$\begin{array}{l}\text { Seasonal flu } \\
\text { vaccine (IgG1) }\end{array}$} \\
\hline Galactosylation & 85.05 & 88.8 & 85.5 & 61.85 & 64.24 & 0.016 & 0.014 \\
\hline Fucosylation & 89.6 & 90.35 & 89.8 & 94.39 & 93.9 & 0.607 & 0.102 \\
\hline Sialic Acid & 12.75 & 17.95 & 15.15 & 6.05 & 6.9 & 0.002 & 1 \\
\hline \multicolumn{8}{|l|}{$\begin{array}{l}\text { Pneumococcal } \\
\text { vaccine (IgG2) }\end{array}$} \\
\hline Galactosylation & 67.4 & 83.3 & 80.55 & 62.2 & 64.85 & 0.018 & 1 \\
\hline Fucosylation & 97.45 & 99.0 & 97.95 & 92.75 & 92.1 & 0.105 & 0.317 \\
\hline Sialylation & 17.95 & 29.1 & 27.35 & 5.85 & 7.85 & 0.039 & 0.317 \\
\hline
\end{tabular}




\begin{tabular}{|c|c|c|c|c|c|c|c|}
\hline & \multicolumn{5}{|c|}{ MEDIAN } & \multicolumn{2}{|l|}{ P-value } \\
\hline & \multicolumn{3}{|c|}{ SPECIFIC IgG3 response } & \multicolumn{2}{|c|}{$\begin{array}{c}\text { TOTAL IgG3 } \\
\text { Prot G }\end{array}$} & \multirow[t]{2}{*}{ Specific } & \multirow[t]{2}{*}{ Total Prot G } \\
\hline Meningococcal vaccine & Visit 4 & Visit 6 & Visit 7 & Visit 4 & Visit 6 & & \\
\hline Galactosylation & 77.8 & 71.1 & 85 & 76.3 & 79.9 & 0.565 & 0.257 \\
\hline Fucosylation & 190.6 & 74.4 & 85.9 & 84.4 & 86.5 & 0.18 & 0.705 \\
\hline \multirow[t]{3}{*}{ Sialic acid } & 23.6 & 4 & 23.4 & 15.9 & 17.8 & 0.028 & 0.705 \\
\hline & \multicolumn{5}{|c|}{ MEDIAN } & \multicolumn{2}{|l|}{ P-value } \\
\hline & \multicolumn{3}{|c|}{ SPECIFIC response } & \multicolumn{2}{|c|}{$\begin{array}{c}\text { TOTAL } \\
\text { IgGProtein G }\end{array}$} & Specific & Total Prot A \\
\hline $\begin{array}{l}\text { Pandemic flu } \\
\text { vaccination(IgG3) }\end{array}$ & Day 0 & Day 30 & Day 90 & Day 0 & Day 90 & & \\
\hline Galactosylation & 66.3 & 66.7 & 57.4 & 67.1 & 67.5 & 0.368 & 0.655 \\
\hline Fucosylation & 96.5 & 54.7 & 76 & 85.9 & 87.5 & 0.05 & 0.18 \\
\hline Sialic acid & 0 & 0 & 0 & 17.4 & 17.8 & 0.905 & 0.655 \\
\hline \multicolumn{8}{|l|}{$\begin{array}{l}\text { Seasonal flu vaccine } \\
\text { (IgG3) }\end{array}$} \\
\hline Galactosylation & 100 & 100 & 100 & 63.75 & 67.3 & 0.368 & 1 \\
\hline Fucosylation & 0 & 0 & 0 & 93 & 93.65 & 0.368 & 0.414 \\
\hline Sialic Acid & 0 & 0 & 0 & 17.65 & 16.2 & $\mathrm{X}$ & 1 \\
\hline $\begin{array}{l}\text { Pneumococcal vaccine } \\
\text { (IgG1) }\end{array}$ & & & & \multicolumn{2}{|c|}{$\begin{array}{l}\text { TOTAL IgG1 } \\
\text { Protein A }\end{array}$} & & \\
\hline Galactosylation & 85 & 88.5 & 87.65 & 70.05 & 61.15 & 0.627 & 0.317 \\
\hline Fucosylation & 100 & 9100 & 100 & 93.8 & 96.45 & 0.368 & 0.317 \\
\hline Sialylation & 14.45 & 15.15 & 16.9 & 10.1 & 9 & 0.717 & 0.317 \\
\hline
\end{tabular}


SUPPLEMENTARY TABLE 4

Table 4: Statistical analysis of specific IgG versus total background Wilcoxon. P-values of $<0.05$ were considered significant and are marked in bold.

\begin{tabular}{|l|l|l|l|l|l|l|l|l|}
\hline Wilcoxon test & \multicolumn{2}{|l|}{ Pneumo - Prot A } & \multicolumn{2}{l|}{ Pandemic - prot A } & \multicolumn{2}{l|}{ Seasonal - prot A } & \multicolumn{2}{l|}{ Meningo - prot A } \\
\hline & Day 0 & Day 90 & Day 0 & Day 90 & Day 0 & Day 90 & Visit 4 & Visit 6 \\
\hline Galactosylation & 0.465 & 0.068 & 0.5 & $\mathbf{0 . 0 4 3}$ & $\mathbf{0 . 0 2 8}$ & $\mathbf{0 . 0 2 8}$ & 0.499 & $\mathbf{0 . 0 1 8}$ \\
\hline Fucosylation & 0.465 & 0.465 & $\mathbf{0 . 0 4 3}$ & $\mathbf{0 . 0 4 3}$ & 0.173 & $\mathbf{0 . 0 2 8}$ & $\mathbf{0 . 0 1 8}$ & $\mathbf{0 . 0 1 8}$ \\
\hline Sialylation & 0.068 & 0.068 & 0.684 & 0.5 & $\mathbf{0 . 0 2 8}$ & $\mathbf{0 . 0 4 6}$ & $\mathbf{0 . 0 1 8}$ & $\mathbf{0 . 0 1 8}$ \\
\hline
\end{tabular}





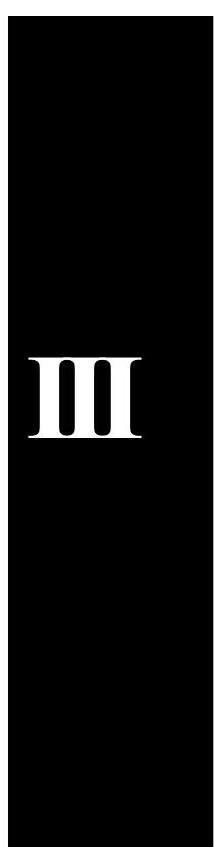


